UNIVERSIDADE DE SÃo PAULO

Faculdade de Economia, Administração e Contabilidade

Departamento de Administração

\title{
O MARKETING DO LUGARZINHO: \\ Uma Aplicação EXPLORATÓRIA da TÉCNICA de ÍNDICE DE PREÇOS \\ HEDÔNICOS A JoVENS CoNSUMIDORES DE RESTAURANTES \\ NA Cidade de São PaUlo
}

Carlos de Brito Pereira

Orientador: Prof. Dr. Celso Cláudio de Hildebrand e Grisi

Tese de doutorado apresentada ao Departamento de Administração da Faculdade de Economia, Administração e Contabilidade da Universidade de São Paulo como requisito parcial para a obtenção do título de Doutor em Administração. 


\section{Reitor da Universidade de São Paulo \\ Prof. Dr. Adolpho José Melfi}

Diretor da Faculdade de Economia, Administração e Contabilidade

Profa. Dra. Maria Tereza Leme Fleury

Chefe do Departamento de Administração

Prof. Dr. Eduardo Pinheiro Gondim de Vasconcellos

Pereira, Carlos de Brito

O marketing do lugarzinho: uma aplicação exploratória da técnica de índice de preços hedônicos a estudantes universitários consumidores de restaurantes da cidade de São Paulo / Carlos de Brito Pereira. São Paulo: FEA/USP, 2004.

pp.

Tese - Doutorado

Bibliografia.

1. Comportamento do Consumidor 2.Marketing 3. Microeconomia

4. Restaurante I. Faculdade de Economia, Administração e Contabilidade da USP. 
Para Mariana 
O lugarzinho tem que ser, antes de mais nada, desconhecido, ou só conhecido por uma minoria privilegiada, ou - para ser um lugarzinho ainda mais lugarzinho - só conhecido por uma minoria do lugar. Seu charme não pode ser intencional. Isto é, o lugarzinho não pode saber que tem charme, senão não é mais lugarzinho. [...] os lugarzinhos só são descobertos pouco antes de deixarem de ser, pois a própria descoberta determina a perda das credenciais de lugarzinho. Se alguém o recomendou a você, e você, claro, não vai perder a oportunidade de também poder dizer "Eu conheço UM lugarzinho..." a outros, não demorará muito antes que o lugar passe a ser freqüentado só por pessoas atrás de lugarzinhos.

Luis Fernando Veríssimo, crônica “O Lugarzinho”, em A Mesa Voadora (p. 142). 


\section{SUMÁRIO}

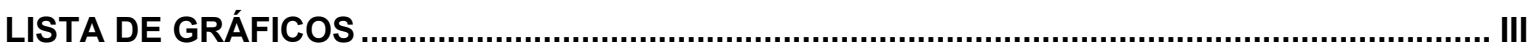

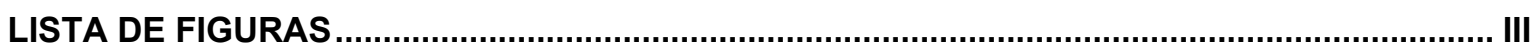

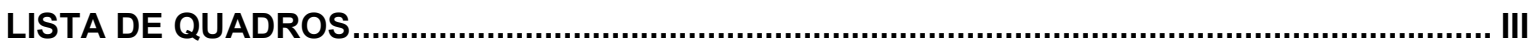

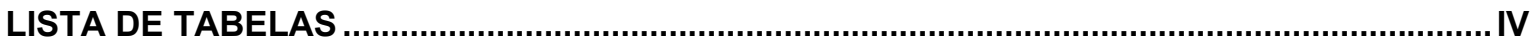

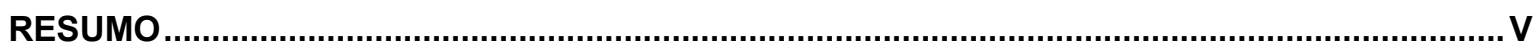

ABSTRACT

AGRADECIMENTOS

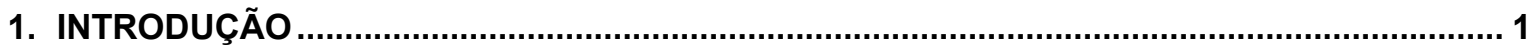

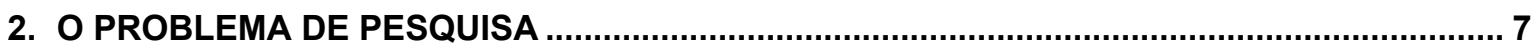

2.1. INTRODUÇÃO: TEORIA DE MARKETING E A QUESTÃO DO VALOR............................................ 7

2.2. FormulaÇÃo da SituaÇÃo PROBlema: FenÔMENOS Não EXPLICAdos PELAS TEORIAS

EXISTENTES ................................................................................................ 15

2.3. O PROBLEMA DE PESQUISA: APLICANDO o ÍNDICE DE PREÇOS HEDÔNICOS AOS CONSUMIDORES

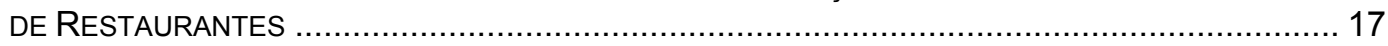

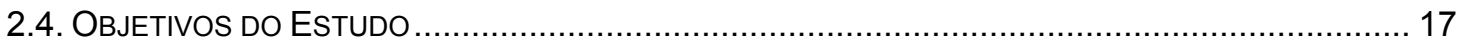

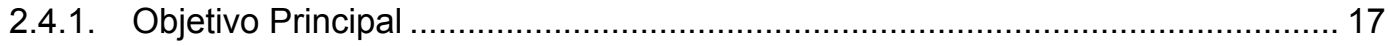

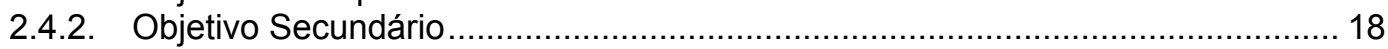

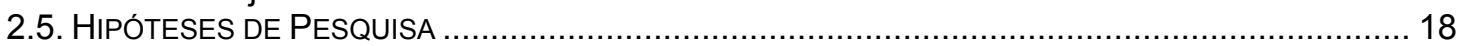

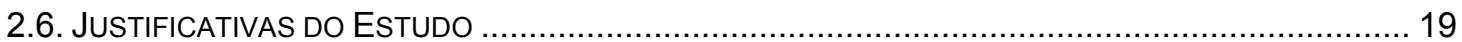

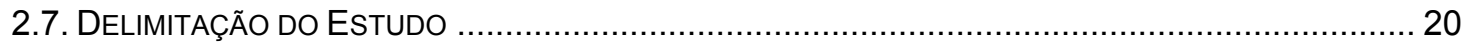

3. FUNDAMENTAÇÃO TEÓRICA: ATRIBUTOS E COMPORTAMENTO DO CONSUMIDOR ... 22

3.1. OS MODELOS DE ATRIBUTOS NOS MANUAIS DO COMPORTAMENTO DO CONSUMIDOR............... 23

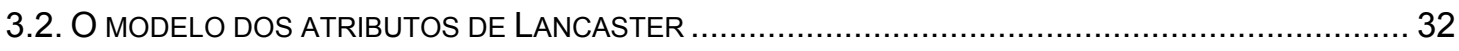

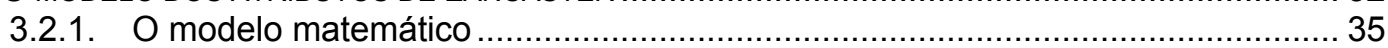

3.2.2. Uma classificação dos bens com base no modelo de Lancaster ...................... 42

3.2.3. Principais pontos da análise lancasteriana (e suas implicações para uma análise

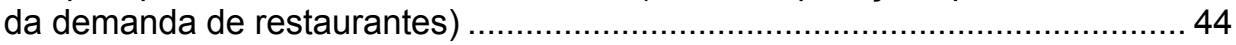

3.3. A CURVA DA DEMANDA COM FORMATO EM "s" DE GARY BECKER ................................. 45

3.2.1. A importância do público que freqüenta o restaurante .................................. 52

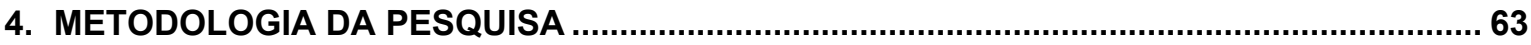

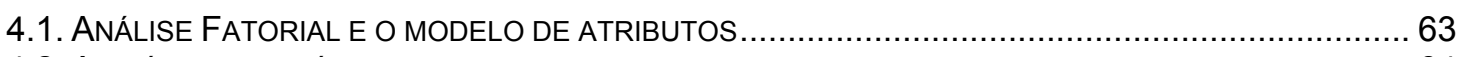

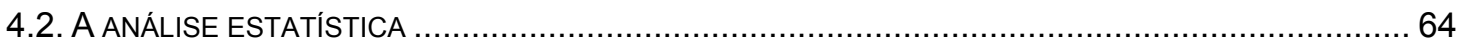

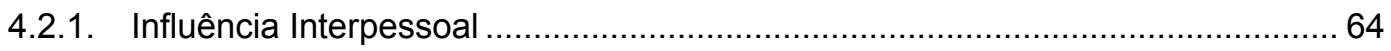

4.2.2. Identificação dos Tipos de Consumidores. ............................................ 65

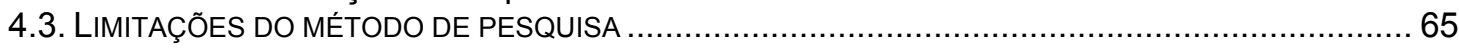

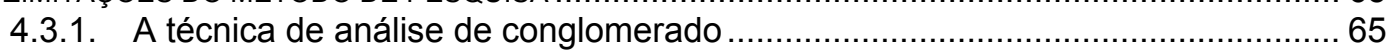

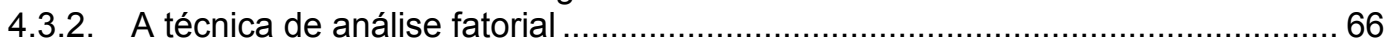

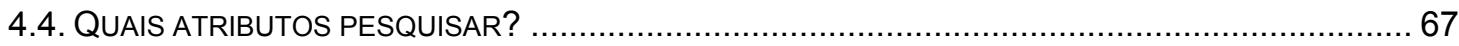

4.4.1. Atributos existentes nos guias de restaurantes ...................................... 67

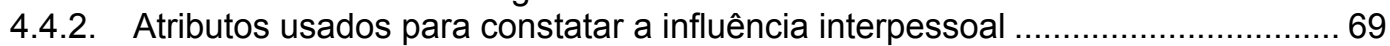

4.4.3. A construção do índice de preços hedônicos ........................................ 72

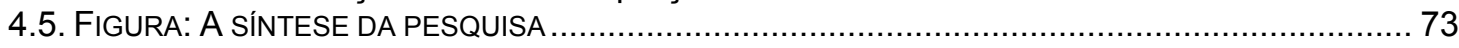

5. ANÁLISE DOS DADOS: A CONSTRUÇÃO DE UM ÍNDICE DE PREÇOS HEDÔNICOS PARA

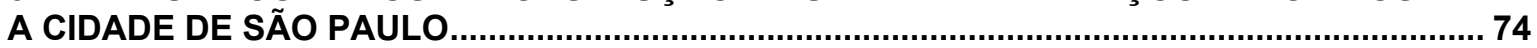




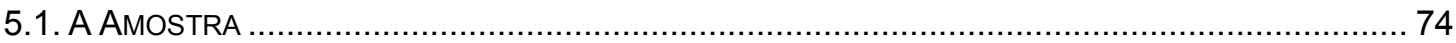

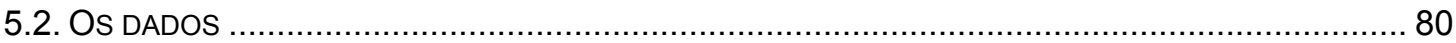

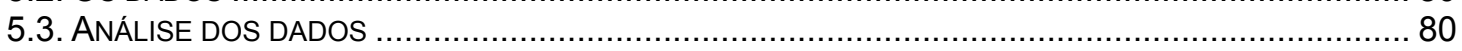

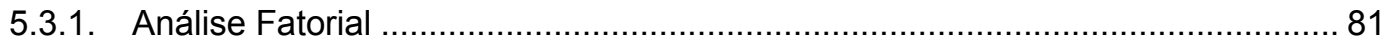

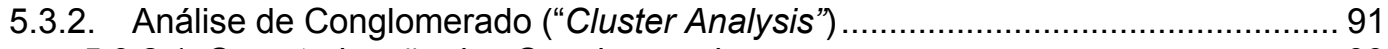

5.3.2.1. Caracterização dos Conglomerados ............................................... 99

5.3.2.2. Análise discrimante dos conglomerados encontrados .......................... 105

5.3.2.3. Análise discriminante passo a passo ("stepwise") dos conglomerados

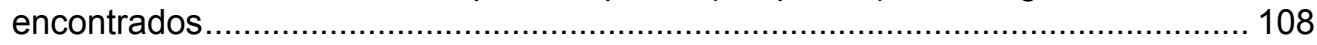

5.4. O ÍNDICE DE PREÇOS HEDÔNICOS ................................................................... 113

5.4.1. O índice hedônico calculado com base no coeficientes das funções

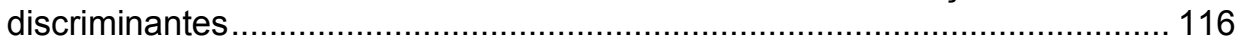

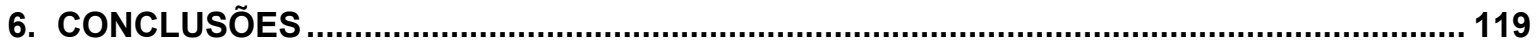

6.1. CONCLUSÕES FEITAS A PARTIR DAS HIPÓTESES UTILIZADAS......................................... 119

6.1.1. A mensuração da demanda de restaurantes utilizando o público como um

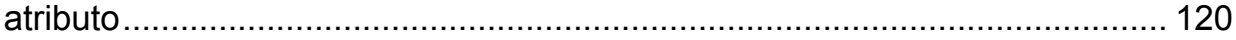

6.1.2. A contribuição da abordagem de Lancaster para a teoria de marketing .......... 123

6.2. SUGESTÕES PARA FUTURAS PESQUISAS EMPÍRICAS ............................................... 126

6.2.1. Análise Conjunta (Conjoint Analysis) e o modelo de atributos ....................... 126

6.2.2. A análise conjunta como uma técnica para a aplicação do modelo de Lancaster em restaurantes

6.3. INDICAÇÕES PARA POSSIVIEIS AVANÇOS TEÓRICOS: ESTILO DE VIDA, PAPEL SOCIAL E ATRIBUTOS

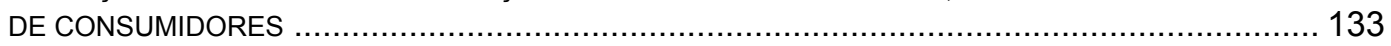

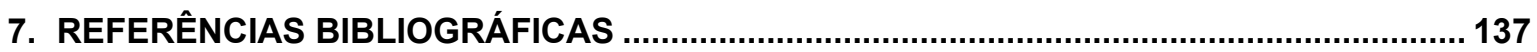

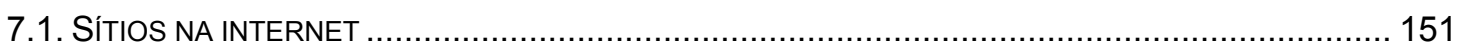

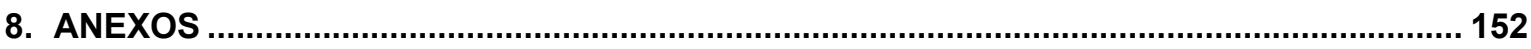

8.1. QUESTIONÁRIO UTILIZADO NA PESQUISA ......................................................... 152

8.2. REFERÊNCIAS BIBLIOGRÁFICAS PARA O ESTUDO DO CONCEITO DE EXTERNALIDADE NA TEORIA

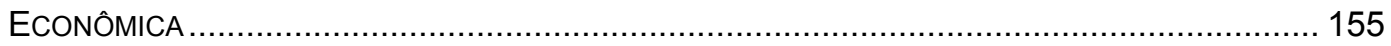

8.3. OS CRITÉRIOS UTILIZADOS PARA A AVALIAÇÃO DOS RESTAURANTES NOS GUIAS PESQUISADOS

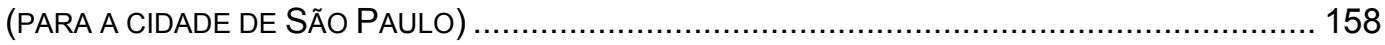

8.3.1. Jornal Gazeta Mercantil (coluna "Restaurantes") ........................................ 158

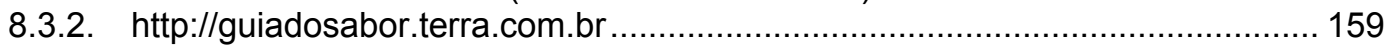

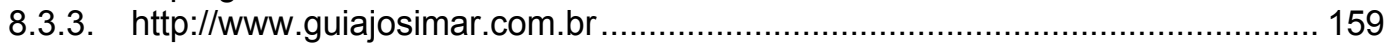

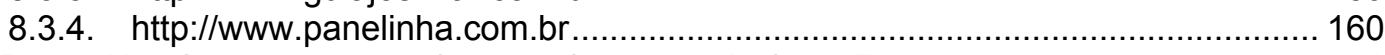

8.4. BREVE HISTÓRICO SOBRE O INÍCIO DA TÉCNICA DE ANÁLISE FATORIAL............................. 161

8.5. REFERÊNCIAS BIBLIOGRÁFICAS SOBRE RESTAURANTES ......................................... 162 


\section{LISTA DE GRÁFICOS}

GRÁFICO 1:COMPOSIÇÃO DA AMOSTRA POR SEXO

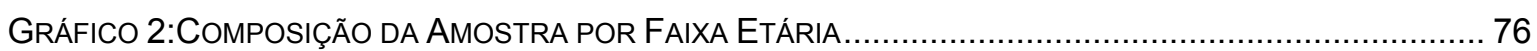

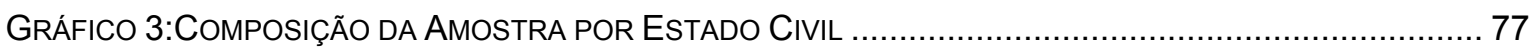

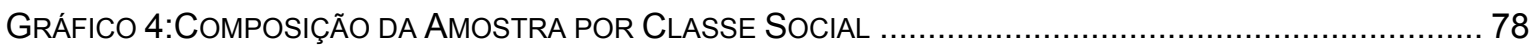

GRÁFICO 5: DISTRIBUIÇÃO DAS MULHERES PELOS CONGLOMERADOS ................................................ 100

GRÁFICO 6: DISTRIBUIÇÃO PELOS CONGLOMERADOS DAS PESSOAS ENTRE 18 A 20 ANOS .................... 101

GRÁFICO 7: DISTRIBUIÇÃO PELO CONGLOMERADOS DAS PESSOAS COM 26 ANOS OU MAIS...................... 101

GRÁFICO 8: DISTRIBUIÇÃo DE CLASSES (SIMPLIFICADAS) NO CONGLOMERADO EMULADORES .............. 103

\section{LISTA DE FIGURAS}

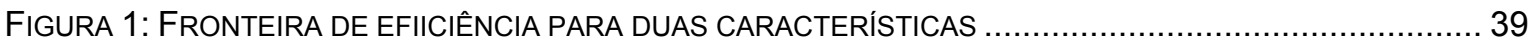

FIGURA 2: FRONTEIRA DE EFICIÊNCIA PARA DOIS ATRIBUTOS E QUATRO ATIVIDADES DE CONSUMO ........... 41

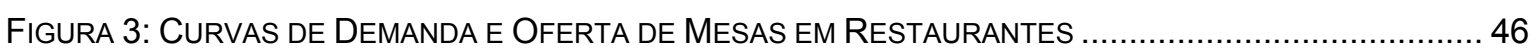

FIGURA 4: CURVA DE DEMANDA EM “S” PROPOSTA POR BECKER (1991) ............................................ 48

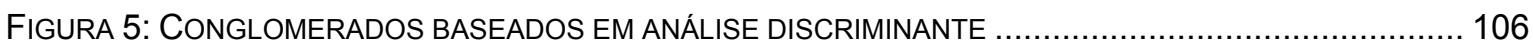

FIGURA 6: CONGLOMERADOS BASEADOS EM ANÁLISE DISCRIMINANTE PASSO A PASSO …....................... 112

\section{LISTA DE QUADROS}

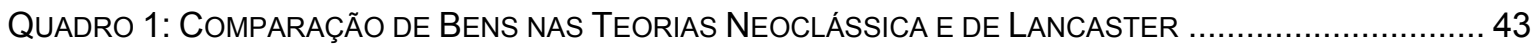

QUADRO 2: PROBABILIDADE DE CONSUMIDORES SE ENCONTRAREM EM UM BAR ..................................... 56

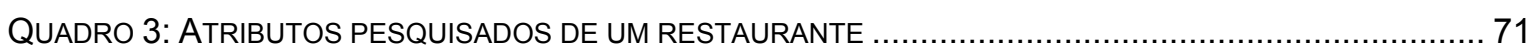

QUADRO 4: TÉCNICAS DESENVOLVIDAS NA PESQUISA DE MARKETING ............................................ 127 


\section{LISTA DE TABELAS}

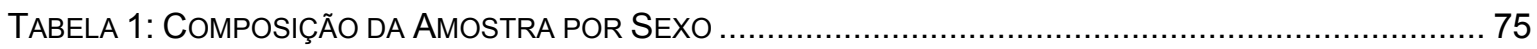

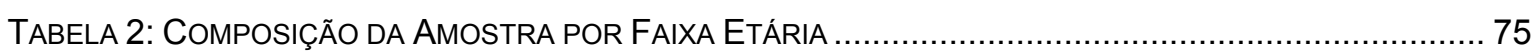

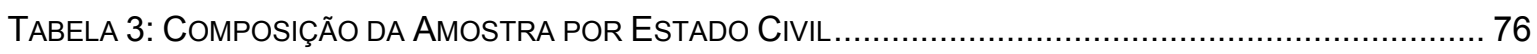

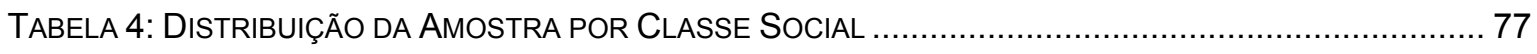

TABELA 5: CoMPosIÇÃo dA AMOSTRA POR CLASE SOCIAL (SIMPLIFICADA) E SEXO ................................. 78

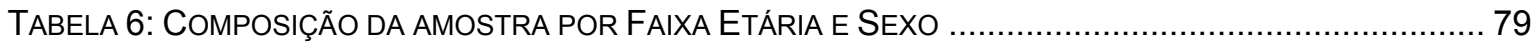

TABELA 7: COMPOSIÇÃO DA AMOSTRA POR FAIXA ETÁRIA E CLASSE SOCIAL (SIMPLIFICADA) ….............. 79

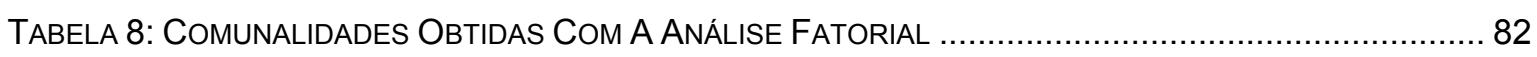

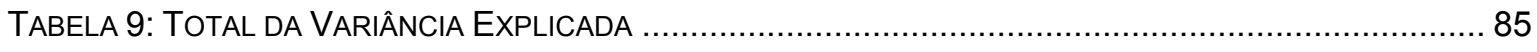

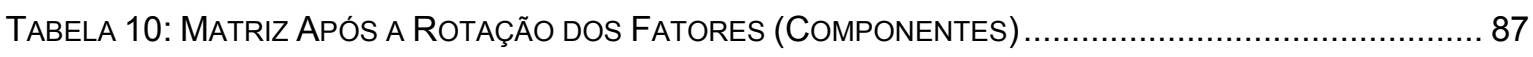

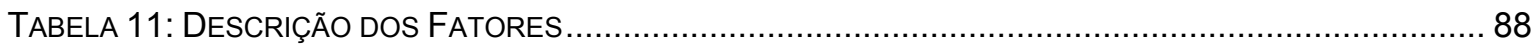

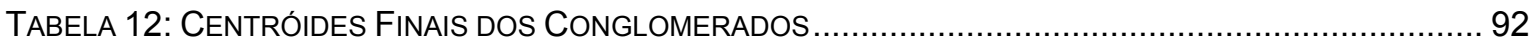

TABELA 13: FATORES IMPORTANTES PARA O CONGLOMERAdo 1 (EMULAdORES PECUNIÁRIOS) .............. 93

TABELA 14: FATORES IMPORTANTES PARA O CONGLOMERADO 2 (OS BONS GOURMETS) ....................... 94

TABELA 15: FATORES IMPORTANTES PARA O CONGLOMERADO 3 (“ARISTOCRATAS") ............................... 96

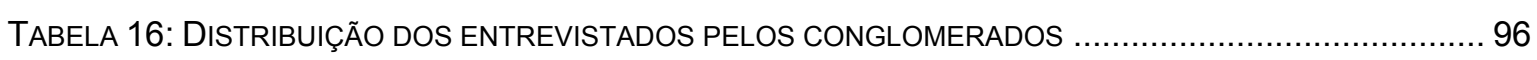

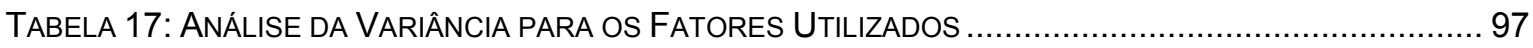

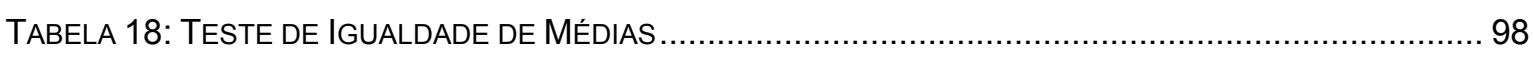

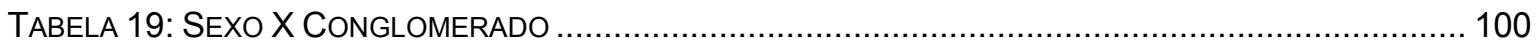

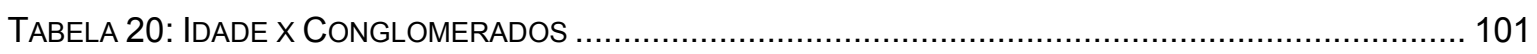

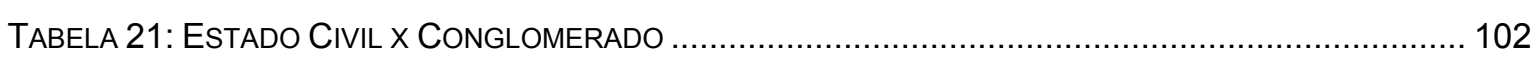

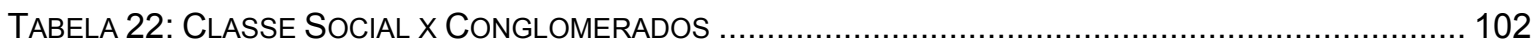

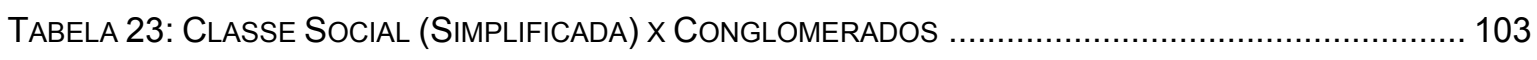

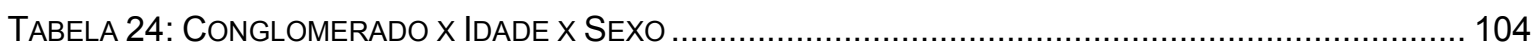

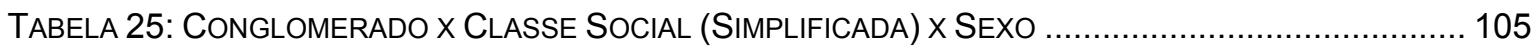

TABELA 26: RESULTADOS DAS FUNÇÕES CANÔNICAS VERSUS CONGLOMERADOS "REAIS" ........................ 106

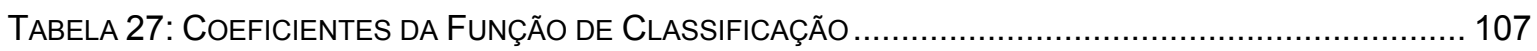

TABELA 28: VARIÁVEIS INCLUÍDAS E REMOVIDAS NA ANÁLISE DISCRIMINANTE PASSO A PASSO ............. 108

TABELA 29: ORdEM de INCLUSÃo dAS VARIÁVEIS NA ANÁlISE DISCRIMINANTE PASSO A PASSO ........... 110

TABELA 30: RESULTADOS DAS FUNÇÕES CANÔNICAS VERSUS CONGLOMERADOS "REAIS" (PASSO A PASSO)

Tabela 31: Coeficientes da Função de ClassificaÇão (ANÁlise Passo a Passo)........................ 112 


\title{
RESUMO
}

Esta tese é uma aplicação do índice de preço hedônico, desenvolvido por Kelvin Lancaster, no mercado de restaurantes de São Paulo. A amostra entrevistada é composta de jovens universitários. O objetivo do trabalho é demonstrar a importância desse método para a teoria de marketing. A inovação consiste em utilizar o público que consome o restaurante como um atributo do restaurante. O sucesso do modelo permite que no futuro seja utilizado como base para uma teoria de marketing da moda.

\begin{abstract}
This doctoral thesis is an application of the hedonic price index, developed by Kelvin Lancaster, for the restaurant market of São Paulo. The sample interviewed is formed by university students. The main objective of the research was to demonstrate the relevance of the method developed by Lancaster for the marketing theory. The key finding of the thesis is that the clients of the restaurants are an attribute of the restaurant itself. The success of this model allows it to be used in the future as the basis for a marketing theory of fashion.
\end{abstract}




\section{AGRADECIMENTOS}

A parte mais difícil de um trabalho é a mais prazerosa: escrever os agradecimentos. É difícil decidir quais pessoas citar, mas é uma alegria perceber quantos amigos fiz nestes anos e quantas pessoas me ajudaram, sem esperar ou desejar nada em troca. Esse auxílio descompromissado é a característica mais bonita da vida acadêmica.

Outra dificuldade ao se escrever agradecimentos é a ausência de uma regra ou guia universalmente aceito, talvez porque esta seja a seção mais pessoal de um trabalho acadêmico. Os manuais tão pródigos em conselhos sobre como fazer uma tese costumam calar ou pecar pela economia quando se trata dos agradecimentos: "seja breve, mas não lacônico" é o conselho básico.

Mas como ser breve ou lacônico diante de tanto auxílio, de tantas pessoas atenciosas que encontrei nesta Faculdade? A sensação de injustiça é enorme, porque sei que deixarei alguém de fora - mesmo ignorando a regra de ser breve mas não lacônico, há que evitar ser prolixo. O exagero diminui o elogio. - Desde já me desculpo por eventuais esquecimentos.

Assim, decidi fixar uma regra para estes agradecimentos: as pessoas citadas tiveram participação direta no trabalho que se segue. A ordem dos agradecimentos segue a da execução do trabalho e não indica a importância que 
porventura tenham para esta tese. Como é praxe, devo ressaltar que divido os méritos com todos os abaixo citados, mas assumo exclusivamente os erros e omissões existentes nesta tese. Finalmente, um último lembrete ao leitor destas linhas: Tucídides, em sua "História da Guerra do Peloponeso" cita o discurso de Péricles em homenagem aos mortos no primeiro ano dessa guerra. ${ }^{1} \mathrm{O}$ líder grego afirma que não se deve elogiar demais os mortos, porque toda pessoa toma-se como medida da humanidade. Se os vivos julgarem-se incapazes de igualar os feitos atribuídos aos mortos, dirão que o elogio é uma mentira. Segui a regra de Péricles e tentei ser o mais preciso possível ao expor os motivos para cada pessoa constar nestes agradecimentos. Tenho muitos defeitos, mas não sou mentiroso.

A idéia original para esta tese e o primeiro rascunho do projeto surgiu no curso de Microeconomia ministrado pelo Prof. Dr. José Augusto G. Silveira e pelo Prof. Dr. Claudio Felisoni De Angelo. O pronto apoio desses Professores na minha idéia de transformar o trabalho final da disciplina na minha tese de doutorado foi fundamental para a execução deste trabalho. Ademais, o Prof. Silveira sempre me atendeu ao longo de todo o trabalho e ainda fez parte da minha banca de qualificação - seu vasto conhecimento em tantos assuntos foi sempre um exemplo que tentei seguir e uma lembrança permanente de que o mundo não se resume a marketing e microeconomia.

Fiz todos os cursos oferecidos no doutorado pelo Prof. Dr. Geraldo Luciano Toledo. Li sua tese de doutorado. Escrevemos em parceria alguns artigos. E ainda não encontrei nenhum livro importante de teoria de marketing que

\footnotetext{
1 Tucídides: História da Guerra do Peloponeso. Brasília: Editora da UnB/ Hucitec, 1986 (2ª. Edição), capítulos 35 a 46. Esse texto inacabado é o único livro conhecido de Tucídides, que morreu cerca de 400 a.C.
} 
o Prof. Geraldo não conheça! A inveja intelectual pode ser um poderoso estímulo... Suas indicações de leitura, conselhos sobre a vida acadêmica, sugestões para esta tese e seu bom-humor sempre que lho procurei para conversar foram muito importantes para a feitura deste trabalho.

O Prof. Dr. Dílson Gabriel dos Santos foi o meu primeiro orientador nesta Casa (à época de meu ingresso no programa de Mestrado, em 1997, havia a figura do "orientador provisório" designado pelo Departamento). Desde cedo me ajudou e indicou literatura para meus trabalhos. No doutorado, cursei a disciplina "Comportamento do Consumidor" ministrada pelo Prof. Dílson e o trabalho final desta disciplina tornou-se o embrião de um capítulo desta tese, com seu apoio e incentivo.

Uma disciplina importante para este trabalho foi "Metodologia de Pesquisa Aplicada à Administração-II", ministrada pelo Prof. Dr. José de Oliveira Siqueira. As técnicas estatísticas utilizadas neste trabalho foram discutidas nesse curso. Um ponto importante sempre frisado pelo Prof. Siqueira é que deve haver motivo para o uso de cada técnica estatística. Se é possível apresentar um tema qualquer utilizando apenas uma tabela de freqüência, este deve ser o caminho do pesquisador. O Prof. Siqueira ensinou-me a importância da Navalha de Occam.

Durante um ano (dois semestres) fui monitor da disciplina "Pesquisa de Marketing" lecionada pelo Prof. Dr. José Afonso Mazzon no curso de graduação. Aprendi muito sobre pesquisa com o Prof. Mazzon. Mas, sobretudo, aprendi com seu exemplo de dedicação e obsessão pelo trabalho bem-feito e seu interesse em ajudar os outros. Mesmo não sendo formalmente meu professor ou orientador, o Prof. Mazzon sempre se interessou pelo avanço do meu trabalho fazendo perguntas, dando sugestões e demonstrando preocupação quanto ao 
prazo.

O Prof. Dr. Edson Crescitelli foi meu colega de doutorado e o primeiro amigo que fiz nessa etapa da minha vida. Cursamos juntos todas as disciplinas oferecidas pelo Prof. Geraldo Toledo, escrevemos alguns trabalhos em parceria e nos tornamos amigos. Depois, já Professor desta Universidade, o Prof. Crescitelli ajudou-me na parte prática desta tese, uma ajuda que foi muito além do que se espera de um mestre ou de um amigo. Que este trabalho esteja a altura de tanto estímulo é o que posso desejar.

Há vários matemáticos neste mundo, mas Prof. Canton só existe um. $\mathrm{O}$ Prof. Dr. Adolpho Walter P. Canton ajudou-me muitas vezes ao longo deste trabalho. Sua incrível capacidade de resolver problemas complexos, de apresentar sugestões as mais pertinentes, de manter o bom-humor quando tudo parecia dar errado (na expressão de Hemingway: "grace under pressure") são algumas das melhores lembranças que terei desta época da minha vida. Isto sem falar das inúmeras conversas e cafés sobre história da matemática, sobre ópera e tantos outros assuntos que parecem interessar o Prof. Canton e que foram momentos de rara alegria na labuta diária de se fazer uma tese.

Que é possível dizer sobre um professor que se tornou orientador, que depois se tornou amigo, numa dessas amizades que a passagem do tempo só faz aumentar? Durante todos esses anos de convivência próxima e intensa, aprendi a respeitar e admirar meu orientador, o Prof. Dr. Celso Cláudio de Hildebrand e Grisi. Sua amizade, compreensão e tudo o mais que excede em muito as funções de orientador foram e são importantes para mim. No doutorado descobri ainda outra virtude do Prof. Celso: sua capacidade de reconhecer valor nas outras pessoas. O Prof. Celso não apenas aceitou, mas estimulou que eu conversasse 
sobre a minha tese com os outros professores citados acima. Poucos orientadores, num mundo tão cioso das aparências como é o ambiente acadêmico de uma grande Universidade, teriam esse desprendimento. A tese encerra um capítulo das nossas vidas: a relação formal de orientado-orientador. Mas nossa amizade, estou certo, prosseguirá.

As funcionárias da biblioteca e da secretaria de pós-graduação (no prédio Fea-5) sempre gentis e prestativas, economizaram tempo que poderia ser perdido em burocracia ou busca de livros. E tempo é a variável mais preciosa para um ser humano, como percebemos quando ao envelhecer.

Fiz muitos amigos entre os colegas de Pós-Graduação. Marcelo Abib Finotti foi o amigo de todas as horas, todas mesmo. Ademais, seu espírito prático impediu-me de me perder em divagações teóricas que nada acrescentariam ao tema desta tese ("não há nada mais prático do que uma boa teoria", disse Kurt Lewin. É verdade. Pena que pesquisadores teóricos não costumem ser pessoas práticas - e isso Lewin não disse). Claudia Szafir-Goldstein é minha amiga dos tempos de mestrado. Conversar com ela sobre as agruras da pós-graduação foi um alívio; sua companhia em disciplinas, congressos e seminários foi sempre um prazer; e sua dedicação à pós, um exemplo. Sidney Maçazzo Caigawa foi fundamental na coleta de dados. Sem a sua ajuda resoluta este trabalho não teria sido possível (uma vez mais: os erros são todos meus). Sidney: muito obrigado mesmo! Marcelo Miyazaki também auxiliou-me bastante na aplicação dos questionários, sempre com bom-humor, dedicação e camaradagem.

Meus queridos amigos Rudi R. Laps e sua esposa Luciana de Bem Pacheco são o paradoxo da amizade: moram em outro Estado, mas estiveram presentes durante os créditos, as monitorias, a pesquisa teórica e o trabalho de campo. Jamais me deixaram esmorecer, sempre me deram os abraços e sorrisos 
(muitos telefônicos) dos verdadeiros amigos.

Renata M. River Serra, seu marido Roberto R. Allodi e seus filhos Marco e Giulia me receberam de braços abertos em sua casa, com um calor humano que nem sei como descrever. Foi bom saber que havia um lugar para esquecer da tese e curtir os prazeres das boas amizades.

Marcos Estellita, Marcelo Miele e Douglas Cláudio Mônaco: sua amizade, auxílio e companhia foram valiosas enquanto eu escrevia esta tese. 0 Prof. Dr. Thales Haddad N. Andrade, não apenas foi o amigo de sempre (nossa, já somos amigos há quase um quarto de século!), como também colaborou com indicações de leitura na área de sociologia. Isabel Estellita ajudou-me com o teste do questionário e sua calma inabalável e certeza de que tudo daria certo foram fundamentais num momento delicado.

Meus pais Lourdes Britto Pereira e o Prof. Dr. José Carlos de Medeiros Pereira sempre me apoiaram em todas as minhas decisões na vida profissional, estivessem corretas ou não (a experiência é uma lanterna na popa, diz o ditado). Ajudaram-me de todas as formas possíveis e são os principais responsáveis pelas eventuais virtudes que esta tese contenha. Em especial, agradeço ao meu pai, um acadêmico por escolha e personalidade, pelas várias sugestões e pelo seu exemplo de jamais aceitar argumentos de autoridade (e tampouco utilizá-los ao discutir comigo). Se argumentos de autoridade fossem aceitos como verdade absoluta, não haveria avanço científico.

Finalmente (“já não era sem tempo", dirá o leitor), este trabalho é dedicado a Mariana Sofia Cifuentes Montoya. Conhecemo-nos num momento muitíssimo conturbado da minha vida pessoal e sua amizade, apoio e carinho transformaram o pesadelo num sonho maravilhoso. Nossa amizade tornou bela a minha vida de doutorando e dedicar-lhe esta tese é apenas uma pequena expressão de todo o carinho que sinto por você, Mariana. 


\title{
1. INTRODUÇÃO
}

\begin{abstract}
"Bar é um objeto que se gasta como camisa, isto é, depois de certo tempo de uso é sempre necessário comprar uma camisa nova e mudar de bar. É preciso escolher bem o nosso bar, pois tão desagradável quanto tomar um bonde errado é tomar um bar errado. O homem que toma o bar errado pode gerar aborrecimentos ou ser a vítima deles."
\end{abstract}

Paulo Mendes Campos

(crônica Por que bebemos tanto assim?)

O objetivo desta tese é desenvolver uma aplicação do método do "índice preço hedônico" (hedonic price index) desenvolvido por Lancaster (1966a; 1966b; 1969; 1971 e 1991) e modificado para explicar a preferência dos consumidores por determinados restaurantes na cidade de São Paulo. Suscintamente, esse índice é análogo a um índice de inflação: é uma ponderação dos atributos de um dado produto considerados por um consumidor ao decidir a compra.

A principal diferença da teoria microeconômica formulada por 
Lancaster (1966a; 1966b; 1969; 1971 e 1991) em relação à microeconomia tradicional é a divisão de um bem em atributos. Na microenomia tradicional um bem é indivisível, sendo a unidade básica sujeita a transações em um dado mercado. Mal comparando, esse bem é como o átomo de Aristóteles para a Física: uno e indivisível. Para Lancaster (idem) um bem é um conjunto de atributos e os consumidores comparam atributos ao escolher ou não um determinado bem e preterir os outros bens existentes no mercado. Novamente recorrendo à comparação com a Física, os atributos lancasterianos podem ser considerados as partículas subatômicas da Física. ${ }^{3}$

Embora esta idéia não integre o corpo principal (mainstream) da teoria econômica, como atestam os manuais de microeconomia, dado que estes tratam

\footnotetext{
${ }^{2}$ Segundo a Associação Brasileira de Normas Técnicas (ABNT), quando se utiliza o sistema autor-data de referência, a data apresentada deve ser a da edição consultada - mesmo que seja a data de uma tradução (Pescuna \& Castilho, 2003; Universidade Federal do Paraná, 2002). Assim, Ferguson (1976) deveria ser apresentado como Ferguson (1984) e Pindyck e Rubenfeld (1991) deveria ser Pindyck e Rubenfeld (1994). Outra forma também apresentada em manuais de referências é sugerida pela American Psychological Association: quando se tratar de livro "clássico", deve-se apresentar entre parênteses a data da edição empregada e a data original de publicação; por exemplo: Ferguson (1976/1984) (American Pscychological Association, 1994). Nesta tese optou-se por não seguir nenhuma dessas normas. A regra aqui empregada é a de indicar a data do trabalho original, sempre que for possível sua identificação. O motivo disto é facilitar a compreensão do leitor quanto à evolução histórica da teoria empregada, bem como dos conceitos ora utilizados. Assim, obras clássicas são situadas corretamente no tempo, como, por exemplo, Marx (1857), ao invés de "Marx (1982)". Entre a norma burocrática e a clareza da exposição, nesta tese optou-se pelo segundo critério.

${ }^{3}$ Frise-se que na gênese da teoria econômica neoclássica está a aspiração de tornar a ciência econômica uma equivalente da Física nas ciências sociais (Lorino, 1989: cap.1). Jevons (1871: 4), por exemplo, afirma que

a teoria econômica, tratada dessa forma, sugere uma estreita analogia com a ciência da Mecânica Estática.

Curioso é que a teoria econômica, em sua vertente neoclássica, conservou-se nas analogias da Física newtoniana e suas certezas, sem atentar para o desenvolvimento da Física Quântica e da Matemática do Caos, que lidam com probabilidades e incertezas (sobre Física, ver Abdalla, 2002; Bodanis, 2000; Brennan, 1997; Feynman, 1965; Gleick, 1992; e Rosenfeld, 2003; sobre Matemática, ver Gleick, 1987; Prigogine, 1993 e Stewart, 1989). Parafraseando Marx (1852: 21), uma idéia científica se desenvolve duas vezes: a primeira como avanço teórico, a segunda como dogma (Para uma discussão detalhada sobre as analogias da Física aplicadas à Economia, ver Ganley, 1995, e também os principais trabalhos escritos por Philip Mirowski, em especial seu livro More Heat than Light, bem como uma coletânea de artigos que discutem a obra de Mirowski: de Marchi, 1993).
} 
principalmente de escolhas entre bens (Ferguson, 1976; Pindyck \& Rubinfeld, 1991), em marketing esta idéia já é aceita, sobretudo em manuais que versam sobre o comportamento do consumidor (Engel, Blackwell \& Miniard, 1995; Solomon, 2002). Nos manuais de comportamento do consumidor há até mesmo discussões sobre como os consumidores comparam os atributos: é discutido se a comparação é feita entre atributos dos bens existentes ou se o consumidor tem uma idéia de "bem ideal" e compara os atributos desse bem com os dos bens reais existentes no mercado. Finalmente, há um tipo de literatura intermediária entre os manuais de comportamento do consumidor e os manuais de microeconomia: os livros de microeconomia voltados para os cursos de Administração de Empresas, os chamados "Managerial Economics". Há pelo menos um manual desse tipo que explora as implicações da obra de Lancaster: Douglas, 1992 (em especial pp.87-9).

Destarte, a questão tratada nesta tese é dupla:

1) Em economia, trata-se de demonstrar a existência dos atributos nos moldes propostos por Lancaster (1966a; 1966b; 1969; 1971 e 1991).

2) Em marketing, trata-se de: (i) como operacionalizar esse conceito; e (ii) justificar teoricamente o uso desse conceito.

A modificação realizada no método desenvolvido por Lancaster (1966a; 1966b; 1969; 1971 e 1991) é a inclusão do público freqüentador do ambiente como um atributo específico de cada restaurante. Em outros termos, tratou-se de incluir a influência inter-pessoal na análise. Este passo introduz o que parece ser uma ampliação do campo de aplicação da teoria microeconômica, pois nessa teoria supõe-se que o consumidor forma seus gostos e toma suas decisões de 
forma isolada. ${ }^{4}$ Quanto à teoria de marketing, trata-se de buscar evidências empíricas da existência da influência inter-pessoal descrita nos manuais da disciplina (Churchill \& Peter, 1998; Kotler, 1994 e 2000; Kotler \& Armstrong, 1991) Para tanto, foi estudado um mercado específico: o dos restaurantes da cidade de São Paulo.

Assim, esta tese é uma tentativa de ampliar o modelo desenvolvido por Kelvin Lancaster, tentando incorporar o público (ou a audiência) como um dos atributos do serviço que influenciam a escolha do consumidor. Note-se que a influência interpessoal no consumo é um fenômeno reconhecido por autores de marketing. ${ }^{5}$ Nas palavras de Brown (1997), este fenômeno pode ser chamado de "demanda socialmente construída". 6 Todavia, esse fenômeno aparentemente segue inexplorado em teoria econômica. Pereira (2000) tentou gerar uma teoria de marketing aplicada aos bens de luxo partindo do relaxamento de hipóteses da teoria microeconômica neoclássica, suprindo as lacunas teóricas expostas comumente nos textos de marketing sobre comportamento do consumidor. Como ressaltado naquele trabalho, era uma tentativa de enfrentar o desafio proposto em Alderson (1965): gerar uma teoria de marketing que não seja um sincretismo de teorias criadas nas várias ciências sociais: economia, sociologia, psicologia, antropologia etc. Esta tese é, pois, a continuação lógica de Pereira (2000).

Frise-se, porém, que esta não é uma busca teórica solitária, pois está

\footnotetext{
${ }^{4}$ Para maiores detalhes dos axiomas da teoria microeconômica, ver Pereira (2000: cap.3).

${ }^{5}$ Ver, por exemplo, Engel, Blackwell e Miniard, 1995 ou Kotler e Armstrong, 1991.

${ }^{6}$ Brown (1997) utiliza essa expressão para contrapor os estudos de oferta e de demanda em economia. Para Brown (1997), ao enfatizarem o papel da concorrência nos estudos de oferta, os economistas estão reconhecendo a importância da interação entre as empresas e mostrando como a oferta é "socialmente construída". Porém, nos estudos de demanda, os economistas trabalham como o consumidor que não se influencia por nenhum outro, o chamado modelo "Robinson Crusoe". Assim, ao incorporar a influência dos outros consumidores no comportamento de cada consumidor específico, para Brown (1997) o que se está fazendo é assumir que também a demanda é socialmente construída. Pereira (2000: 35-8) discute em detalhes o trabalho de Brown (1997).
} 
integrado no que se poderia chamar de um "programa de pesquisa" (no sentido proposto por Lakatos — apud Blaug, 1980: 72-9) desenvolvido no âmbito do Departamento de Administração da Faculdade de Economia, Administração e Contabilidade da Universidade de São Paulo. Isto porque o tema abordado combina uma série de temas já estudados por pesquisadores desta instituição: segmentação e comportamento do consumidor (Grisi, 1986; Siqueira, 1995; Toledo, 1972), análise conjunta aplicada ao comportamento do consumidor (Siqueira, 1997), ${ }^{7}$ marketing de serviços (Santos, 1988; Toledo, 1972), teoria econômica aplicada ao marketing (Pereira, 2000), o uso e o cálculo de índices hedônicos (Sartoris Neto, 1996) e a questão do valor na teoria econômica neoclássica (Feijó, 1999). ${ }^{8}$

A tese está organizada na forma que se segue: no capítulo 2 "O PROBLEMA DE PESQUISA" é apresentado como a questão do valor é fundamental para o marketing. Dessa breve discussão sobre o valor em Economia e marketing deriva-se o problema de pesquisa em si: a influência interpessoal na decisão de consumo. Mostra-se que se o valor for socialmente construído será necessária uma revisão dos conceitos da teoria do valor subjetivo em Economia para uma posterior aplicação na questão do valor aplicada ao marketing. A partir disso são apresentados os objetivos e hipóteses da pesquisa.

No capítulo 3 "FUNDAMENTAÇÃO TEÓRICA", são apresentados os vários métodos de identificação e mensuração dos atributos utilizados por consumidores que estão catalogados nos manuais de comportamento do consumidor. Nas seções seguintes desse capítulo o modelo formulado por Kelvin Lancaster do índice de preço hedônico é apresentado (Lancaster, 1966a e 1966b

\footnotetext{
${ }^{7}$ Frise-se que Siqueira (1995) e Siqueira (1997) não são a mesma pessoa.

${ }^{8}$ Estes dois últimos trabalhos foram desenvolvidos no Departamento de Economia.
} 
e alguns de seus aperfeiçoamentos: Lancaster, 1969, 1971 e 1991). É discutido ainda o pioneiro trabalho de Gary Becker (1991) sobre o formato da curva de demanda por um restaurante. O capítulo se encerra com uma discussão sobre a dinâmica do modismo na demanda por um restaurante, usando por base os trabalhos de Corneo e Jeanne (1994a; 1994b; 1997a; 1997b e 1999).

No capítulo 4 é mostrado como foi realizada a pesquisa. O capítulo 5 é dedicado à análise dos dados, à demonstração da influência interpessoal no consumo de restaurante e à construção do índice de preço hedônico.

Finalmente, no capítulo 6 são apresentadas as conclusões. Esse capítulo está dividido em três seções: na primeira (6.1), são discutidas as hipóteses de pesquisa, comparando-as com a análise feita no Capítulo 5. Nas seção 6.2, é discutido como a técnica estatística de Análise Conjunta (Conjoint Analysis) pode ser utilizada para a mensuração dos atributos preferidos por um consumidor para um dado produto, sendo apresentados alguns estudos de comportamento do consumidor discutindo essa técnica. Finalmente, na seção 6.3 é apresentado um esboço de futuros aperfeiçoamentos teóricos do modelo desenvolvido nesta tese. 


\title{
2. O PROBLEMA DE PESQUISA
}

\author{
"Por si só, a observação não orientada é \\ insuficiente, a ciência precisa também de hipóteses \\ (...) e elas brotam da imaginação do cientista e não \\ apenas do mundo à sua volta."
}

Nicholas Fearn

\subsection{Introdução: Teoria de Marketing e a Questão do Valor}

Em Economia, "valor" é uma palavra com sentido preciso: é a medida absoluta de riqueza. ${ }^{9}$ Para a maioria dos economistas, há apenas dois tipos de valor: o valor de uso e o valor de troca. O primeiro refere-se ao valor que uma pessoa dá a um determinado bem. Daí ser chamado também de "valor subjetivo", pois a valoração depende, em última instância, de cada indivíduo. O valor de troca é o valor de mercado de um bem qualquer. Quando há coincidência entre o valor de uso e o valor de troca, o consumidor compra o bem em questão. 0

${ }^{9}$ Prosseguindo na analogia com a Física, seria possível dizer que "valor" está para os economistas como "energia" é para os físicos. Ao menos até o momento, nenhum economista aventurou-se a afirmar que o valor pode ser divido em "pacotes" ou "quantas". Assim, ainda não existe algo como "economia quântica". 
primeiro autor a apresentar formalmente essa divisão entre valor de uso e valor de troca é Smith (1776).

Um ponto importante nas teorias econômicas do valor é discutir o que cria o valor em uma economia capitalista. Lorino (1989), em uma visão radical, afirma que os economistas neoclássicos assumem que a quantidade de valor existente em uma economia é dada - numa analogia com a lei de conservação da matéria formulada por Lavoisier (1743-1794): "na natureza nada se cria, nada se perde: tudo se transforma".

Até a revolução marginalista (cerca de 1871), os economistas realizavam seus estudos de uma perspectiva que hodiernamente seria chamada de "macroeconômica". Ricardo e Marx sobretudo abordaram a questão do valor para entender como uma economia gera riqueza e como esta é distribuída entre as pessoas. Seguindo Smith (1776), Ricardo (1823) enfatizou a questão do trabalho como fonte de valor e Marx (1857; 1867) radicalizou essa visão, afirmando que somente o trabalho cria valor. Como o trabalho é uma mercadoria especial, seu valor de troca é inferior ao seu valor de uso. ${ }^{10}$ A diferença entre os dois valores é a chamada "mais-valia" que, em uma economia capitalista, é apropriada pelo dono do capital. ${ }^{11,12}$ Marx (1867) realiza então uma diferenciação entre dois tipos de mais-valia: absoluta e relativa. A primeira é a mais-valia obtida com o aumento das horas de trabalho. É a mais-valia do início do Capitalismo,

\footnotetext{
${ }^{10}$ Note-se que Marx não é o pioneiro nessa proposição: Hodgskin já a havia feito (ver Hodgskin, 1825). O pioneirismo de Marx está no uso dessa proposição (Sandroni, 1983).

${ }^{11}$ Embora não seja o tema desta pesquisa, é mister enfatizar que Marx $(1857,1867)$ mostra que o capitalista não poderia pagar mais pelo trabalho, pois isto seria economicamente irracional. O trabalho é uma mercadoria especial, mas seu valor de troca é dado no mercado. Portanto, formulações ideológicas como "a propriedade é um roubo" feita por Proudhon, que supostamente seriam derivadas análise marxista são, para usar uma expressão geralmente empregada na retórica de Marx, "bobagens". Ver Marx (1875) para uma crítica devastadora desse tipo de esquerdismo (a "doença infantil do comunismo", na formulação de Lênin).

12 Pereira e Grisi (2000) desenvolveram uma aplicação dessa teoria para explicar a globalização econômica nos moldes comumente utilizados nos trabalhos de Administração.
} 
durante a Revolução Industrial, em que a diária de trabalho poderia chegar a mais de 16 horas. Porém, o aumento da mais-valia absoluta é limitado pela quantidade de horas existentes em um dia de trabalho. Num segundo momento, há o surgimento de outra forma de mais-valia: a relativa. Esta se dá pelo incremento da produtividade do trabalho: a relação produto/horas trabalhadas. A possibilidade de incremento da mais-valia relativa é infinito, dependendo apenas do progresso técnico. $^{13}$

Com a formulação da mais-valia relativa, Marx (1867) realiza uma distinção fundamental entre sua teoria e as formuladas por outros autores, nãomarxistas: a inclusão do progresso técnico e, por conseguinte, o abandono da premissa de "tecnologia constante". O mais famoso autor não marxista a incluir o progresso técnico em seu modelo de funcionamento de uma economia é Schumpeter (1911).

Com o surgimento de trabalhos como os de Jevons (1871) e de Menger (1871) inicia-se o que convencionou-se chamar de "revolução marginalista". ${ }^{14} \mathrm{O}$ valor de um bem depende do consumidor: nessa abordagem

\footnotetext{
${ }^{13}$ Um ponto interessante é ausência, na análise marxista do valor, do conceito de "menosvalia": o trabalho improdutivo. Essa menos-valia seria o trabalho de uma burocracia disfuncional, por exemplo. Assim, seria possível explicar a terceirização de algumas tarefas em nas empresas. Um Estado que não cumpre suas funções também seria exemplo de "menos-valia", que diminuiria a riqueza de uma nação pela apropriação do valor gerado pelo trabalho produtivo via impostos e taxas. Assim, anarquistas e outros que julgam a "propriedade" como um roubo estariam em palpos de aranha, pois o Estado, se disfuncional, também seria "um roubo" (a idéia original de "menosvalia" é do Prof. Dr. José Carlos de Medeiros Pereira, que obviamente está isento das considerações sobre o conceito feitas neste trabalho).

O conceito de "menos-valia" também serve para explicar porque as empresas apresentam determinado tamanho, ao contrário da formulação quase tautológica de Coase (1937 e 1987) e Williamson (1985 e 1993) de que tudo seria um problema de "custos de transação". Coase e Williamson, como autores neoclássicos, assumem que o valor de uso é sempre idêntico ao valor de troca, daí os problemas com suas análises, como descrito em detalhes em Pereira (2001a). Note-se que aos poucos Williamson sofistica seu modelo e torna-se menos neoclássico (Williamson, 1998 e Pereira, 2001b).

14 Pereira (2000) cita vários autores, em especial Feijó (1999) e Schumpeter (1954), que discutem o pioneirismo de Jevons, Menger e Walras e até que ponto esses autores podem ser agrupados como formuladores do mesmo tipo de teoria.
} 
considera-se apenas o valor de uso. Menger (1871: 268-81) discute a questão do trabalho como fonte única de riqueza e a divergência entre o valor de troca e o valor de uso (em especial, ver as notas de rodapé \# 6 e 7). Concluiu Menger que o valor de uso é o mais importante para a análise econômica e que o valortrabalho não é a explicação correta para a origem do valor: a principal fonte do valor seria a raridade de um bem. Daí a formulação de que a Economia é a ciência da escassez. Para Menger (1871), um bem econômico é aquele para o qual a demanda é superior à oferta. Bens que não se incluam neste caso não seriam objeto da análise econômica, o que elimina da discussão muitos dos bens atualmente produzidos em uma economia capitalista moderna. ${ }^{15}$ Confrontando essa proposição mengeriana com a formulação de Alderson (1965) de que o principal problema de marketing é saber quanta informação é o bastante para que a empresa case (match) a sua oferta com a demanda e constatar-se-á que os problemas de marketing são semelhantes porém não idênticos aos da economia neoclássica. Pois a partir de Alderson (1965) é possível constatar que o problema de marketing surge quando oferta e demanda não são iguais, mas não apenas quando a procura é superior à oferta. Portanto, o escopo do marketing está além daquele da economia mengeriana.

O ponto importante é que ao afimar o valor subjetivo, Menger (1871) e os outros economistas neoclássicos (Jevons, Marshall, Pareto, Walras etc.) permitem o surgimento da análise econômica moderna, que hoje permeia a maioria, senão todos, os manuais de microeconomia. A premissa fundamental dessa teoria do valor é que a decisão de consumo é, em última instância,

\footnotetext{
${ }^{15}$ Pereira (2000: 106-9) apresenta o debate entre Galbraith e Hayek sobre se a produção determina o consumo (posição de Galbraith) ou se é o inverso (Hayek). A questão de fundo desse debate é ausência ou não de escassez - em última instância, se os bens são econômicos ou não no sentido mengeriano.
} 
individual. ${ }^{16}$ Outra premissa importante, por suas conseqüências lógicas, é a de "tecnologia constante". Com isso, assume-se que a única forma de aumentar a quantidade de bens ofertados em uma economia é o investimento em ampliação da capacidade produtiva, ou seja, a construção de novas fábricas.

O modelo neoclássico, em suas várias vertentes (Menger, Walras, Jevons etc.), implica em uma visão teórica que julga a sociedade como a mera soma dos comportamentos individuais. Ademais, ao tornar a escassez o ponto central na definição do domínio da análise neoclássica, isto permite que essa teoria seja aplicada a qualquer sociedade, em qualquer momento, sem levar em conta as especificidades sócio-culturais de cada civilização.

Se tal proposição for verdadeira, a Sociologia não poderia existir como ciência, posto que a Psicologia bastaria para explicar a sociedade humana. E de fato, autores como Gary Becker utilizam o individualismo metodológico e o ahistoricismo dessa teoria para estudar o casamento, a discriminação racial, a família etc. ${ }^{17}$ Porém, desde Durkheim, é reconhecido que a sociedade pode e deve ser considerada como algo diferente da soma das personalidades individuais (Durkheim, 1895 e 1897). Mesmo Freud (1921) realizou a distinção entre comportamento individual e comportamento de grupo. ${ }^{18}$ Portanto, pode-se assumir que a influência interpessoal nas ações de um único indivíduo é fato. Com isto, fica prejudicada a generalização da teoria neoclássica para qualquer fenômeno econômico, em especial aqueles não-ligados aos problemas da escassez.

\footnotetext{
${ }^{16}$ Pereira (2000) explorou em detalhe essa questão do "individualismo metodológico" e das outras pressuposições do modelo teórico neoclássico (em especial, ver Pereira, 2000: 68-88).

${ }^{17}$ Ver, por exemplo, The Economics of Discrimination (1957; Chicago: University of Chicago Press) ou The Economic Approach to Human Behaviour (1971, Chicago: University Press).

${ }^{18}$ Este ponto foi apresentado ao doutorando pelo Dr. Carlos R. Briganti, que obviamente não é responsável pelas conclusões aqui apresentadas.
} 
Neste ponto cabe indagar: o que a teoria de marketing tem a ver com isto? A teoria de marketing, como mostrada em Bartels (1976), Grisi, Grisi e Santos (1983) e Pereira (2000), ${ }^{19}$ surge das limitações da teoria econômica neoclássica. Os pioneiros teóricos de marketing, voltados que estavam para questões eminentemente práticas no âmbito da empresa individual, aos poucos foram abandonando os pressupostos da teoria neoclássica. Pereira (2000) propõe que a teoria de marketing avança com a incorporação de economistas nãoneoclássicos, notadamente os institucionalistas das cepas vebleniana e "commonsiana"20, aos departamentos/faculdades de Administração nas Universidades Norte-americanas. Esse fenômeno histórico tem como conseqüência o abandono progressivo de muitas das pressuposições teóricas da teoria neoclássica, embora sem que isto signifique o abandono puro e simples de toda teoria econômica. Daí Pereira (2000: viii) parafrasear Clausewitz e afirmar que o marketing "é a continuação da economia por outros meios."

Sobretudo na área do comportamento do consumidor inicia-se uma busca de modelos mais complexos do que o "homem econômico" racional e individualista da teoria neoclássica. O principal veio teórico explorado é da Psicologia: Mason (1995; 1998 e 1999) é o autor que estudou mais detidamente esse avanço da teoria de marketing em direção à psicologia. Também Sheth (1979) explora esse ponto, embora com um enfoque mais crítico do que o apresentado por Mason. Porém esse "sincretismo teórico" de economia neoclássica, psicologia, economia institucional e empirismo (a solução prática

\footnotetext{
${ }^{19}$ Para outros autores que estudaram a história do marketing, ver Pereira (2000: seção 2.1 "Breve Histórico: A Ciência Econômica e o Marketing').

${ }^{20}$ Uma alusão a dois fundadores da escola institucionalista: Thorstein B. Veblen e John R. Commons. Note-se que Veblen jamais utilizou o termo "institucionalista", embora tenha cunhado a expressão "neoclássico" em Economia (Astropomourgos, 1986).
} 
sem a explicação teórica) ${ }^{21}$ não gerou um todo uno, como mostra a crítica de Alderson (1965) de que se deveria formular uma teoria pura de marketing e não um derivativo da economia ou da psicologia. Daí todo o esforço metodológico da obra de Hunt (sintetizado em seu trabalho de 1991) para realizar uma exegese da teoria de marketing, o que permitiria estabelecer os fundamentos (os axiomas) dessa teoria.

Todavia, a exegese de Hunt (1991) é incompleta, se não for enfrentado em marketing a questão fundamental do que é valor. Uma breve consulta a alguns dicionários de marketing e será percebida a questão: Bennett $(1995)^{22}$ apresenta oito definições de valor; Imber e Toffler (2000) não apresentam nenhuma definição; Ivanovic e Collin (1996) apresentam onze definições; Lewis e Littler (1999) conceituam apenas "valor agregado"23; Moreira, Pasquale e Dubner (1999) simplesmente ignoram o conceito.

A questão do valor em marketing espraia-se para outros temas correlatos, como qual é o âmbito da disciplina (outro ponto debatido em detalhe por Hunt, 1991): desde o acrimonioso debate entre Kotler e Levy (1969) versus Luck (1969) sobre o escopo do marketing, passando pelas contribuições ao debate feitas por Bagozzi (1975), Bartels (1974) e Dawson (1979), Enis (1973), Hirschman (1983), Hunt (1976) e Kotler (1975), entre outros autores, permanece a questão de se definir o que é e qual o escopo do marketing (Pereira, 2001c). ${ }^{24}$ Há um consenso sobre o fato do objeto do marketing ser a troca entre dois ou mais

\footnotetext{
${ }^{21} \mathrm{Ou}$, nas palavras de Wright Mills (1959): "empirismo abstrato".

${ }^{22}$ Bennett (1995) é o dicionário editado sob os auspícios da American Marketing Association (AMA). Apenas duas definições são apresentadas como "oficiais" por essa entidade: "marketing" e "pesquisa de marketing".

${ }^{23} \mathrm{O}$ que é uma tautologia, porque como definir "valor agregado" sem antes definir "valor"?

${ }^{24}$ Pereira (2001c) resume o debate e apresenta várias conceituações de "marketing".
} 
de dois agentes. Mas qual tipo de troca? Kotler e Levy (1969) e Kotler (1975) sugerem qualquer tipo de troca, Luck (1969) refere-se somente às trocas econômicas feitas em uma economia capitalista (no que aparentemente é seguido por Bartels, 1974). Os outros autores parecem posicionar-se entre esses dois pólos, discutindo se conceituar é importante, o que é ciência e se marketing é uma ciência (em especial Hunt, 1991), que parecem ser um subterfúgio para evitar a questão central do valor. Um economista teórico marxista consideraria essa discussão como carente de sentido. Se o Capitalismo destrói todos os outros modos de produção com os quais trava contato, e se no Capitalismo tudo tende a se tornar mercadoria - a sociedade capitalista é uma sociedade mercantilizada então quanto mais capitalista for a sociedade, maior será o conjunto de objetos passíveis de ações de marketing. Exemplificando esta questão: se a prática política torna-se mercadoria, então é possível usar ferramentas de marketing para influenciar a atividade política. Destarte percebe-se que tanto Kotler e Levy (1969) como Luck (1969) estão corretos: os primeiros porque a mercantilização da vida social amplia o escopo do marketing; o segundo porque essa mesma mercantilização possibilita que o marketing continue a ser aplicado apenas em trocas exclusivamente econômicas.

Uma troca acontece quando o valor do produto trocado é considerado justo para as partes envolvidas, quanto a isto não há discussão. Volta-se pois, às questões iniciais da teoria econômica: o que é valor? O que gera valor? Sem uma resposta adequada, conceituar marketing e seu escopo torna-se uma busca do Santo Graal teórico. 


\subsection{Formulação da Situação Problema: Fenômenos Não Explicados Pelas Teorias Existentes}

Os manuais de comportamento do consumidor reconhecem a importância da opinião alheia no consumo individual (Engel, Blackwell \& Miniard, 1991; Peter \& Olson, 1999; Schiffman \& Kanuk, 1994; Solomon, 2002). A questão é como essa influência é tratada teoricamente. Geralmente, e por causa da história do pensamento de marketing, são utilizados modelos advindos da psicologia, como já foi explicitado e discutido na seção anterior.

O problema com essa abordagem derivada da psicologia é duplo: 1) não permite a exploração de outro tipo de teoria do valor, o que gera as dificuldades teóricas expostas na seção anterior; 2) não considera que o comportamento de um grupo de pessoas pode ser diferente da soma dos comportamento individuais dessas mesmas pessoas.

Assim, esta tese pretende ser uma análise do comportamento do consumidor em termos de grupo social. Se o grupo influencia o consumo individual, de acordo com a noção de "valor subjetivo" ou valor de uso neoclássico, o valor econômico é socialmente construído. Portanto, é mister incorporar a opinião do grupo na análise do valor, o que poderia ser um avanço teórico tanto na microeconomia quanto no marketing.

Note-se que considerar o consumo como um fenômeno social é aceitável teoricamente pois, por analogia, se Durkheim (1897) considerou o suicídio um fenômeno social, o consumo sendo um fenômeno aparentemente mais simples e que envolve decisões menos essenciais (ou existenciais) também 
permite esse tratamento teórico. Como se diz em Direito: "quem pode o mais, pode o menos". Em teoria científica, o mesmo se aplica. Como mostrou Kuhn (1962), as novas teorias tornam as antigas "casos especiais", ou seja: uma nova teoria deve explicar novos fenômenos ainda inexplicados e também os fenômenos antigos, já explicados pelas teorias existentes. Daí Keynes (1936) chamar seu trabalho de "Teoria Geral", em contraponto à teoria neoclássica prevalecente à sua época, que seria então um caso específico da teoria keynesiana. Portanto, abordar o comportamento do consumidor sob a perspectiva do consumo como um fenômeno social não implica em considerar errado a abordagem individual. Antes, significa um passo além na explicação do fenômeno.

Com isso, seria possível ir além da segmentação como forma de descobrir grupos homogêneos de consumidores (Siqueira, 1997; Grisi, 1986; Weinstein, 1993): será possível explicar porque a segmentação funciona e quais as causas do fenômeno.

Uma outra implicação teórica seria a possibilidade de se fazer uma "teoria da moda", pois conhecendo os mecanismos de influência interpessoal e as explicações para esses mecanismos, abrir-se-ia a perspectiva de se criar uma teoria da moda que fosse além do empírico "ciclo de vida do produto" (quando modismos seriam unicamente definidos pelo tempo de duração). 


\subsection{O Problema de Pesquisa: Aplicando o Índice De preços hedônicos aos Consumidores de Restaurantes}

O problema de pesquisa é duplo: teórico e prático.

O problema prático é verificar se há a influência interpessoal no consumo de restaurantes e se é possível mensurá-lo. Se for possível mensurá-lo, se também é possível identificar os consumidores que são "líderes de opinião" e quais são os consumidores "seguidores de moda".

A importância teórica desse problema já foi discutida nas seções anteriores desta tese. Deve-se ressaltar a contribuição para a formulação de uma teoria do valor tipicamente de marketing, ainda que herdeira da teoria econômica neoclássica.

\subsection{Objetivos do Estudo}

\subsubsection{Objetivo Principal}

O principal objetivo da tese é mensurar a influência interpessoal entre os estudantes universitários consumidores de restaurantes na cidade de São Paulo, aplicando para tanto o método do índice de preço hedônico formulado por Lancaster (1966a; 1966b; 1969; 1971 e 1991). 


\subsubsection{Objetivo Secundário}

Contribuir para o desenvolvimento de uma teoria de marketing que explique como se dá a influência interpessoal entre consumidores.

\subsection{Hipóteses de Pesquisa}

Como esta tese é um trabalho exploratório, a palavra "hipótese" aqui está sendo utilizada no sentido metodológico do termo, mas não sentido estatístico. Não há testes de hipóteses neste trabalho. ${ }^{25}$

1. É possível mensurar a influência interpessoal entre jovens universitários consumidores de restaurante na cidade de São Paulo.

2. É possível ampliar a explicação teórica em marketing de como se dá a influência interpessoal utilizando a teoria proposta por Kelvin Lancaster.

\footnotetext{
${ }^{25}$ A expressão "metodologia" aparentemente tornou-se quase sinônimo de "estatística", a julgar pelos inúmeras disciplinas intituladas "Metodologia da Pesquisa" que nada mais são do que o ensino de técnicas estatísticas. Daí a necessidade de explicar qual o sentido da palavra "hipótese" empregado nesta seção. Porém, se esse critério de tomar a metodologia como mera técnica estatística for utilizado, trabalhos como os de Bacon (1620) ou de Durkheim (1895), verdadeiros clássicos de metodologia, não poderiam assim ser chamados. Há que se tomar cuidado para não incorrer, em ciência, no fetichismo da estatística.
} 


\subsection{Justificativas do Estudo}

Os motivos teóricos foram expostos nas seções anteriores. Cumpre agora discutir os motivos práticos para a escolha de restaurante como tema de pesquisa.

A razão da escolha do tema "restaurante" para a aplicação prática é a ausência de estudos empíricos nessa área. Uma busca no sítio WoPEc e no banco de dados Proquest foi realizada e não foram encontrados artigos sobre "índices hedônicos e análise conjunta aplicados a consumidores de restaurantes". ${ }^{26}$ Mesmo se restaurantes forem considerados varejos (e são), há poucos ou quase nenhum estudo sobre esse tema (considerando como amostra os estudos citados em McGoldrick, 1990): a utilização do índice de preço hedônico em restaurante. ${ }^{27}$

Um outro motivo, este no campo teórico, para a escolha do tema é o

\footnotetext{
${ }^{26} \mathrm{Na}$ pesquisa bibliográfica foram encontradas duas teses brasileiras sobre o tema restaurante: Iglesias Filho (1990) e Peters Filho (2003). O primeiro trabalho é uma dissertação de mestrado. Adota a suposição de que pessoas vão a um restaurante de luxo "porque tem fome" e considera a curva de demanda como sendo negativamente inclinada em relação ao preço. Há que se discordar dessa abordagem, pois Pereira (2000) mostrou que a demanda de bens de luxo pode ser positivamente inclinada em relação a preço. Já Peters Filho (2003), sendo uma tese de doutorado, adotou uma abordagem mais sofisticada baseada em extensivo levantamento bibliográfico sobre o tema, ao estudar sobretudo a questão da qualidade do valor percebido. Ainda que de forma indireta, Peters Filho (2003) demonstrou a importância do público que freqüenta o restaurante para o consumidor, ao classificar os restaurantes que pesquisou como "1) descontração; 2) ver e ser visto; 3) premium; e 4) clássico. Porém, seu estudo não faz referência ao modelo de atributos proposto por Lancaster e não mensurou especificamente o público como um atributo do restaurante.

${ }^{27}$ Há pelo menos um estudo empírico em larga escala sobre os consumidores de restaurante, contudo realizado sob a ótica estritamente sociológica: Warde e Martens (2000). Quanto ao estudo dos hábitos alimentares feitos por economistas, aparentemente o pioneiro foi Thorstein Veblen: quando ainda era aluno de graduação em Carleton, Veblen escreveu um texto chamado "A Plea for Cannibalism" para a disciplina de retórica e o apresentou num sábado, causando comoção na platéia de alunos e professores (Dorfman, 1947: 31). Infelizmente esse texto se perdeu. Há ainda uma tese de doutorado em Administração sobre os consumidores de restaurantes: Harris (2002). Como já foi explicado na nota anterior, no âmbito brasileiro, há uma dissertação e uma tese que tratam do tema, que são, respectivamente: Iglesias Filho (1990) e Peters Filho (2003).
} 
fato de que embora a utilização de atributos na escolha do bem proposta por Lancaster (1966a; 1966b; 1969; 1971 e 1991) seja um significativo avanço teórico em microeconomia, esse modelo lancasteriano do preço "hedônico" não tenta incorporar a influência interpessoal na escolha do produto. Talvez isso faça sentido para um conjunto de bens, mas não para todos - Pereira (2000) estudou em detalhe esse tema. - Em especial, na escolha do consumo de serviços como concertos musicais e espetáculos, nos quais a presença e o contato com estranhos é praticamente inevitável, as pessoas tendem a considerar o possível público como um dos atributos do serviço em si (DeSerpa \& Feith, 1996). ${ }^{28}$

\subsection{Delimitação do Estudo}

Como em Pereira (2000: 191), é mister apontar a especificidade de tempo e lugar: demonstrar a existência da influência interpessoal entre os consumidores de restaurantes da cidade de São Paulo nos moldes propostos não significa que estas conclusões possam ser expandidas para outros lugares, em outro momento e para outros produtos.

Novamente seguindo Pereira (2000: 191-2), demonstrar a existência da influência interpessoal talvez não signifique que esse modelo teórico possa ser aplicado a todos os produtos. Contudo, Pereira (2000: 236) aventou a

\footnotetext{
${ }^{28}$ A abordagem de DeSerpa e Feith (1996) é atípica. Veja-se, por exemplo, Heilbrun e Gray (1993, cap.4): esses autores utilizam a abordagem tradicional neoclássica, inclusive o "util", a medida de utilidade inventada por Jevons (1871) e praticamente ignoram a influência interpessoal na demanda por artes e espetáculos. No capítulo 11, Heilbrun e Gray (1993) discutem a influência da educação no consumo de artes. Porém, economistas habitualmente não consideram "educação" como influência interpessoal (ver Hayek, 1961, sobre essa questão).
} 
possibilidade de se tratar o valor como formado por vários planos, no sentido matemático-topológico da expressão. Assim, haveria o plano do valor subjetivo e existiria o plano do valor subjetivo com influência interpessoal. Pesquisas futuras poderiam demonstrar a existência de outros planos. A topologia matemática, pois, pode representar uma solução teórica para a questão do valor em Economia. Portanto, limita-se a explicação teórica a um hiperplano específico.

Cumpre finalmente enfatizar que toda solução teórica encontrada é provisória, até que sejam descobertos fatos que contradigam a teoria (Magee, 1973; Pereira, 2000 e Popper, 1959 e 1974). 


\section{FUNDAMENTAÇÃO TEÓRICA: Atributos e Comportamento do Consumidor}

Nesta seção são apresentados dois modelos econômicos para explicar o comportamento do consumidor: o primeiro é o formulado por Kelvin Lancaster em 1966, com as posteriores evoluções. O segundo é aquele criado por Gary Becker em 1991 para explicar o comportamento do consumidor de restaurante. Antes, porém, são descritos os modelos de atributos utilizados nos manuais de comportamento do consumidor. Assim, é possível compreender como as formulações de Lancaster (1966a; 1966b; 1969; 1971 e 1991) podem ser utilizadas em marketing e, mais especificamente, para contribuir teoricamente no estudo da influência interpessoal e na formulação de uma teoria do valor tipicamente de marketing.

A importância do modelo lancasteriano para esta pesquisa é fundamental, pois Lancaster (1966a) desenvolveu uma abordagem que permite subdividir um bem em seus atributos. Isto possibilita a inclusão do comportamento dos outros consumidores como um atributo - que é o ponto central desta tese algo até o presente momento inédito em teoria. Conquanto a aplicação prática do conceito de "índice de preço hedônico" seja anterior aos trabalhos de Lancaster 
(1966a), é este autor o pioneiro na explicação teórica de porque esse técnica econométrica funciona na prática, junto com o trabalho de Richard F. Muth $(1966)^{29,30}$ (Griliches, 1971).

O trabalho de Becker (1991) é apresentado para demonstrar que essa abordagem neoclássica utilizando a "racionalidade" como axioma é incapaz de explicar o fenômeno, sobretudo se se pretende utilizar essa teoria (a microeconomia neoclássica) e esse modelo como subsídios para ações de marketing. Porém, não se pode ignorar o esforço beckeriano, em especial porque é demonstrada a existência de uma curva de demanda com ao menos uma parte com inclinação positiva (preços e quantidades demandas aumentam simultaneamente), o que tem implicação para o marketing. ${ }^{31}$

\subsection{Os modelos de atributos nos manuais do comportamento do consumidor}

O estudo do comportamento do consumidor como disciplina independente é fenômeno recente, que remonta à década de 1960 (Bartels, 1976). Para muitos autores, o trabalho pioneiro nessa área é o livro de Francesco

${ }^{29}$ É mister não confundir este Richard F. Muth com John F. Muth, que se tornou mais conhecido como o "pai" das teoria das expectativas racionais da macroeconomia (sobre John F. Muth, ver Klamer, 1983). O sítio (site) do Prof. Richard Muth na internet fornece uma relação de seus trabalhos publicados (http://www.emory.edu/COLLEGE/ECON/Muth.htm, visitado em 13 de maio de 2003, 20h58).

${ }^{30}$ Note-se que o artigo de Muth (1966) não versa sobre as possibilidades de se subdividir um bem qualquer em um conjunto de atributos, como o faz Lancaster (1966a). Muth (1966) discute a possibilidade de um conjunto qualquer de mercadorias (commodities) ser considerado como insumo (input) para a produção de bens em uma unidade familiar (household).

${ }^{31}$ Para detalhes sobre este assunto, ver Pereira (2000). 
M. Nicosia, de 1966: Consumer Decision Process: Marketing and Advertising (Bartels, 1976; Lunn, 1974; Mason, 1984; Pereira, 2000). Já Walters (1980) aponta um livro do professor Paul F. Nystron, de 1929, Economics of Consumption, como sendo o primeiro livro de Marketing a tratar do comportamento do consumidor em termos modernos (Pereira, 2000). Obviamente, o estudo do comportamento do consumidor é anterior à década de 1960 e pode ser remontado ao final do século XIX, com o pioneiro trabalho de Veblen (1899)(Hamilton, 1987; Mason, 1984; Pereira, 2000) ou ainda antes, com os pioneiros autores da revolução marginalista na Economia Política do século XIX, como Jevons, Menger e Walras (Pereira, 2000).

Essa digressão sobre o pioneirismo da disciplina não é de relevância somente histórica. Pois serve para demonstrar que, dada a juventude dessa área de estudos, ainda hoje há a falta de uma teoria do comportamento do consumidor. O que há são modelos teóricos (Hunt, 1991; Kotler, 1969; Lunn, 1974; Sheth, 1979), o que pode caracterizar essa disciplina como pré-paradigmática, nos moldes preconizados por Kuhn (1969). Isto pode ser evidenciado em trabalhos como Engel, Blackwell e Miniard (1995), Peter e Olson (1999) ou Schiffman e Kanuk (1994), nos quais o ecletismo é evidenciado pela citação de estudos de várias ciências, tais como economia, psicologia e, em menor escala, antropologia e sociologia. Se o estudo do comportamento do consumidor pode ou não vir a se tornar uma ciência, é questão em aberto.

Assim, o ponto importante é que, dada a multiplicidade de modelos existentes (por exemplo: Frenzen, Hirsch \& Zerrillo, 1994 e Sheth, 1974, apresentam um extenso rol desses modelos), faz-se mister explorá-los teórica e empiricamente, na esperança de que alguns se mostrem viáveis como "programas de pesquisa" como proposto por Lakatos (apud Blaug, 1980:72-9): 
"aglomerados de teorias mais ou menos interconectados ou programas de pesquisa científica" (Blaug, 1980: 73-4).

Nesse sentido, um dos modelos mais promissores parece ser o formulado por Lancaster (1966a). Esse modelo será discutido em detalhes na próxima seção. Cumpre nesta parte do ensaio apresentar sua utilização nos trabalhos de marketing e, mais precisamente, nos manuais de Comportamento do Consumidor.

Lancaster (1996a) propôs uma idéia revolucionária (para a teoria econômica): ${ }^{32}$ um consumidor não compra um bem, mas um conjunto de atributos. Se houver no mercado um produto com a combinação desejada desses atributos, será esse bem o adquirido pelo consumidor. Caso não exista, o consumidor procurará o bem que mais se adequar ao seu "bem ideal". A questão, em termos práticos, seria descobrir qual seria essa combinação de atributos desejados pelo consumidor para um dado produto. $\mathrm{E}$ mais, se haveria um conjunto de atributos que seria comum a um conjunto de consumidores, o que permitiria realizar uma segmentação de mercado com base em atributos desejados (Grisi, 1986; Smith, 1956; Siqueira, 1997), seja por meio da Análise Conjunta ou pelo Escalonamento Multidimensional (Aaaker, Kumar \& Day, 1999; Hair Jr., Andersen, Tatham \& Black, 1998; Malhotra, 1999).

Os modelos apresentados nos manuais de Comportamento do Consumidor que destacam a importância da análise de atributos curiosamente não citam a obra de Kelvin Lancaster (Engel, Blackwell \& Miniard, 1995; Peter \& Olson, 1999; ou Schiffman \& Kanuk, 1994), porém a idéia apresentada é a

${ }^{32}$ Como demonstraram Boyer, Palda e Ratchford (1984), já em 1939 A.T. Court havia apresentado essa idéia, em um trabalho para a General Motors norte-americana (para maiores detalhes, ver Pereira, 2000: 34). 
mesma. Frise-se que, quanto aos antecedentes do modelo de multiatributos, Peter e Olson (1999) destacam a contribuição pioneira de Thurstone em 1931 sobre a conceituação de atitude. Para Peter e Olson (1999: 120), atitude é "avaliação geral de um conceito por uma pessoa". A partir desse conceito, é possível decompor a atitude de um consumidor em relação a um produto em vários atributos desse produto, ou seja, decompor essa "avaliação geral" em partes específicas e, assim, descobrir quais são os atributos de um produto que um consumidor mais preza (note-se a semelhança com a idéia proposta em Lancaster, 1966b).

Já Engell, Blackwell \& Miniard (1995: 362) definem "atitude" como uma avaliação geral sobre algo (produto, pessoa, lugar etc.). O conceito de atitude, neste sentido, possui algumas características: valência (o sentido da atitude: positivo ou negativo), resistência (ou grau de possibilidade de mudança), persistência (o quanto a passagem do tempo afeta a atitude) e confiança (a crença de que a atitude está correta).

Engell, Blackwell \& Miniard (1995) apresentam um modelo de relacionamento entre atitude (pp .364 e segs.): Crenças e sentimentos concorrem para formar atitudes, que levam à intenção de comportamento que pode (ou não) se materializar. As crenças referem-se ao componente cognitivo (em outros termos: uma análise mais "racional", no sentido da teoria econômica tradicional), os sentimentos referem-se ao componente afetivo (ou um comportamento nãoracional, novamente no sentido da teoria econômica). Como apontam Engel, Blackwell \& Miniard (1995), o comportamento do consumidor oscila entre os dois pontos (racional e não-racional), sendo os pontos extremos do modelo apenas 
referências teóricas ${ }^{33}$ - note-se que essa forma de modelar o comportamento do consumidor já é prática antiga em marketing. Veja-se, por exemplo, Maynard, Weidler e Beckman (1932). Ademais, Engel, Blackwell \& Miniard (1995: 366) enfatizam que crenças e sentimentos não são formados no vácuo, mas sim em um dado contexto — o ambiente no qual a pessoa vive. — Daí a importância das instituições sociais no estudo da economia e do marketing (eis o paradoxo: estudar o indivíduo não pode ser feito no vácuo: as instituições contam). ${ }^{34}$ Como frisam Engel, Blackwell \& Miniard (1995), há pelo menos dois modelos para entender as atitudes do consumidor: o modelo de Fishbein e o modelo do ponto ideal.

O modelo de Fishbein mede, ou tenta mensurar, as atitudes do consumidor em relação a um dado produto (Engel et al., 1995; Peter \& Olson, 1999; Shiffman \& Kanuk, 1999). Como já destacado, esse modelo parte do princípio semelhante ao proposto em Lancaster (1966), de que um consumidor não compra um produto, mas um conjunto de atributos. O modelo de Fishbein, pois, mensura a atitude do consumidor para cada atributo de um produto.

Matematicamente, esse modelo é apresentado como (Engel et al.: 369; Peter \& Olson, 1999: 129; Shiffman \& Kanuk: 246):

Onde:

$$
A_{0}=\sum_{i=1}^{n} c_{i} a_{i}
$$

$A_{0}$ é a atitude em relação ao produto;

\footnotetext{
${ }^{33}$ Pereira (2000: 57 e segs.) expôs essa questão de outra forma, discutindo o conceito de racionalidade na modelagem do comportamento do consumidor.

${ }^{34}$ Daí Hamilton (1980) apontar Thostein Veblen como o "primeiro professor de marketing", pois Veblen foi além da modelagem neoclássica e incluiu as instituições sociais e o comportamento do consumidor individual não-racional econômico em seu modelo.
} 
$c_{i}$ é força da crença de que o produto apresenta o atributo i;

$a_{i}$ é a avaliação do atributo i; e

n é o número de atributos salientes (percebidos) do produto.

Assim, quanto mais atributos considerados importantes o produto apresentar, maior será a probabilidade de o consumidor apresentar uma atitude positiva em relação a esse produto e, portanto, maior a probabilidade de compra desse produto pelo consumidor.

Peter \& Olson (1999) frisam que a importância desse modelo está em sua praticidade e que vários aperfeiçoamentos podem ser feitos a partir dessa fórmula básica. Já Engell, Blackwell \& Miniard (1995: cap. 11) discutem a validade do modelo de Fishbein, apontando que esse modelo não permite saber qual é o conjunto "ideal" de atributos desejado pelos consumidores. Isto seria obtido somente se for utilizado o "modelo do ponto ideal".

Segundo Engell, Blackwell \& Miniard (1995: 373), a forma matemática do modelo do ponto ideal seria a seguinte:

$$
A_{b}=\sum_{i=1}^{n} W_{i}\left|I_{i}-X_{i}\right|
$$

Onde:

$A_{b}$ é a atitude em relação à marca (ao produto);

$W_{i}$ é a importância do atributo i;

$\mathrm{I}_{\mathrm{i}}$ é a avaliação (performance) ideal do atributo i;

$X_{i}$ é a avaliação real feita pelo consumidor do atributo i e

n é o número de atributos salientes (percebidos) do produto.

Neste modelo do ponto ideal, que é um aperfeiçoamento do modelo de Martin Fishbein, quanto mais próximo um produto estiver do conjunto ideal de 
atributos idealizado pelo consumidor, maior sua probabilidade de ser adquirido por esse consumidor. Novamente, a similitude com a proposta de Lancaster (1966b) é acentuada.

Segundo Engel et al. (1995), esse acréscimo do "ponto ideal" ao modelo original de Fishbein permite às empresas: (1) mudar o produto, de acordo com o gosto dos consumidores e/ou (2) realizar campanhas promocionais para influenciar a atitude dos consumidores em relação aos atributos. Quando realizar cada uma das duas estratégias (ou uma combinada), depende da situação, do mercado e do tipo de produto (versus, sempre, uma análise de custos).

Aplicando esse modelo a restaurantes, seria possível avaliar o posicionamento de um estabelecimento qualquer com base nos mais variados atributos, tais como tipo de cozinha, aceitação de cartão de crédito, atendimento, carta de vinhos, faixa de preço etc. (embora Hair Jr. et al., 1998, enfatizem que preço é um atributo difícil de ser objetivamente mensurado).

Contudo, esses modelos de medição de preferência por atributos apresentam aparentemente duas falhas importantes e raramente citadas: (1) não permitem aferir a influência interpessoal dos consumidores; e (2) são modelos derivados da psicologia.

A primeira questão, o quanto o consumo de um produto por parte de um conjunto de consumidores afeta o consumo de outro conjunto de consumidores, é um ponto importante para o cálculo da demanda agregada. Como demonstrou Pereira (2000), se a influência interpessoal for considerada, o cálculo da demanda agregada deve ser outro que não a simples multiplicação do número de consumidores pelo consumo individual de cada produto (ponderado por renda e preço, naturalmente). 
Quanto ao segundo ponto, são modelos derivados da psicologia e, como tal, tributários de uma teoria que não a de marketing (aceitando-se que Alderson, 1965, estava correto em clamar por uma teoria genuinamente de marketing que explicasse o fenômeno da troca, o ponto focal da teoria de marketing segundo Bagozzi, 1975; Kotler, 1972; Kotler \& Levy, 1969). Embora a teoria de marketing seja uma espécie de sincretismo teórico entre economia e psicologia (Bartels, 1974; Mason, 1995), é mister enfatizar que uma sociedade não é a soma de seus indíviduos (Durkheim, 1895, Giddens, 1978). Como qualquer manual de sociologia ensina, indíviduos tendem a apresentar um comportamento distinto quando em grupo (Charon, 1996). Portanto, não há porque separar o comportamento de consumo do resto das atividades cotidianas: também este deve ser considerado socialmente.

Note-se que Peter e Olson (1999: 137-41) expandiram o modelo original de Fishbein de forma distinta daquela apresentada por Engel et al. (1995): Peter e Olson (1999) incluíram uma "norma subjetiva" que relaciona o comportamento do consumidor com o comportamento do conjunto de consumidores. Matematicamente, este modelo é o seguinte (Peter \& Olson, 1999: 137):

$$
B \sim B I=A_{a c t}\left(w_{1}\right)+S N\left(w_{2}\right)
$$

onde:

B é um comportamento específico (de compra)

BI é a intenção do consumidor em realizar tal comportamento

$A_{\text {act }}$ é a atitude do consumidor em praticar o comportamento

SN é uma norma subjetiva que significa o comportamento das outras pessoas em relação a quem pratica o comportamento 
$w_{1}$ e $w_{2}$ são pesos que refletem a influência relativa dos componentes $A_{a c t}$ e SN sobre BI.

O problema com esse modelo de Fishbein expandido, ou "modelo da ação razoável" (como é chamado por Peter \& Olson, 1999), é que cada consumidor não necessariamente reage da mesma forma à uma norma social ou à influência interpessoal. Williamson (1998), embora preocupado com outras questões teóricas, abordou a questão dupla da assimetria informacional e da capacidade cognitiva dos agentes, mostrando que pode haver um mercado no qual cada agente econômico tenha uma quantidade única de informação e uma capacidade também única de computar e usar essa informação. Assim, para Williamson (1998), um modelo que pretenda levar em conta como os agentes interagem entre si necessita incorporar as variâncias existentes do grau de assimetria informacional e da capacidade cognitiva dos agentes de processar as informações disponíveis (Pereira, 2001b). Já Pereira (2001a) discute a validade de se formalizar uma regra única de comportamento, sem levar em conta as várias formas e graus que essa regra pode tomar em uma sociedade complexa. Destarte, um modelo que apresente uma regra única (SN) e uma reação única $\left(w_{2}\right)$ provavelmente não abarca a complexidade da maioria dos mercados consumidores.

Assim, conquanto o "modelo da ação razoável” proposto por Peter e Olson (1999) represente um avanço em relação aos outros modelos que utilizem atributos propostos nos manuais de Comportamento do Consumidor (Engell et al., 1995; Peter \& Olson, 1999; Shiffman \& Kanuk, 1999), aparentemente também esse modelo apresenta deficiências metodológicas na apreensão do fenômeno da influência interpessoal no comportamento de compra (como exemplo de estudo 
empírico sobre esse tema, e que serve de prova da dificuldade em apreender o fenômeno, ver Quester \& Smart, 1998 e Rada, 1998).

\subsection{O modelo dos atributos de Lancaster}

Em 1966 Kelvin Lancaster escreveu dois artigos sobre o estudo do comportamento do consumidor em economia que se mostraram revolucionários (Lancaster, 1966a e 1966b). Nesses artigos, Lancaster mostrou como o consumidor não escolhe um bem especificamente, mas um conjunto de atributos que têm correspondência (exata ou aproximada) a um bem. $\mathrm{Na}$ visão lancasteriana um bem seria um conjunto de atributos.

O trabalho pioneiro de Lancaster (1966a) se inicia afirmando que na teoria neoclássica, as propriedades intrínsecas a um bem não são estudadas. 0 consumidor compara bens diferentes, mas não as propriedades desses mesmos bens. O exemplo dado em Lancaster (1966a: 132) é o seguinte: se um consumidor prefere diamante a pão, é racional. Se prefere pão a diamante, também o é. Porém, ceteris paribus, se prefere alternadamente pão e diamante, a teoria não aceita esse comportamento como racional. Nas palavras de Lancaster (1966a: 132): "a única propriedade sobre a qual a teoria pode ser fundada é a propriedade partilhada por todos os bens, a qual é simplesmente que estes são bens".

Porém, Lancaster (1966a) mostra que essa visão de bem econômico é contraditória com um exemplo clássico utilizado nos manuais de microeconomia: 
a substituição de manteiga por margarina. Essa substituição só faz sentido se o que estiver sendo comparado for os atributos de cada tipo de bem, e não o bem em si. São as propriedades de manteiga e margarina que as tornam bens substitutos. O mesmo vale para bens complementares, como automóvel e gasolina (Lancaster, 1966a: 132).

O ponto mais importante para uma nova abordagem da teoria do consumidor, talvez, seja a questão do lançamento de novos produtos e das mudanças de qualidade (Lancaster, 1966a: 133). Nesses casos, as propriedades dos novos produtos definirão as reações dos consumidores a esses produtos. $\mathrm{E}$ em economias complexas, como a norte-americana, essas questões são muito importantes (Lancaster, 1966b, discute a importância da tecnologia de consumo). ${ }^{35}$

A nova abordagem proposta por Lancaster (1966a) consiste basicamente em atribuir a utilidade não a um bem, mas a atributos desse bem. Assim, cada consumidor possui uma ordem de preferências de atributos e essa ordem é indiretamente aplicada aos bens existentes. No exemplo de Lancaster (1966a:133), uma refeição possui "características nutricionais" e "características estéticas" e "refeições distintas possuem essas características em diferentes proporções relativas". Some-se a isso o meio social (social setting) no qual essa refeição é consumida e pode-se ter vários conjuntos de atributos e de situações baseados nos quais uma refeição é consumida.

A novidade mais importante nessa abordagem é permitir que: se um bem possui mais de uma característica, então a atividade de consumir poderá ser

35 Em Lancaster (1966b), é mostrado como uma economia pode apresentar uma oferta tecnologicamente sofisticada mas o seu consumo pode ser simples (o exemplo dado é a hoje extinta União Soviética). A sofisticação do consumo se dá pelo número de atributos e usos de um bem. 
caracterizada como a "união de atributos" (joint outputs) (Lancaster, 1966a: 133134). Outra novidade nessa abordagem é que bens aparentemente diferentes em algumas características podem ser muito próximos em outras (idem, p.134).

Uma primeira assunção do modelo é que o consumidor é capaz de objetivamente constatar as características do bem. Dito de outra forma: dada a unidade de mensuração das características, se dois bens possuírem as mesmas quantidades de características, todos os consumidores serão capazes de perceber isto. Assim, a escolha será feita tendo por base o "gosto pessoal" do consumidor e não nenhuma outra característica intrínseca ao bem em questão (Lancaster, 1966a: 134). Isto significa que é possível assumir que se dois restaurantes apresentarem características físicas ("atributos") idênticas, será assumido que a escolha do consumidor será feita com base no público que freqüenta o local.

Lancaster (1966a: 134) resume as novidades da sua abordagem teórica aos seguintes pontos:

1. Um bem, por si mesmo, não tem utilidade para um consumidor. São as características do bem que possuem a utilidade.

2. A princípio, um bem possui mais de uma característica. Ao apresentar várias características, é possível assumir que algumas são comuns a vários bens.

3. A combinação de bens pode apresentar características diferentes daquelas "pertencentes a cada bem em separado" (Lancaster, 1966a: 134). 


\subsubsection{O modelo matemático}

O modelo formalizado proposto em Lancaster (1966a) é o seguinte: associa-se a atividade de consumo de um bem ou de um conjunto de bens a uma escala ("o nível de atividade" — the level of the activity — Lancaster, 1966a:135). Assim, k é o nível de atividade, y o número de bens consumidos e há uma relação linear entre essas variáveis. Destarte:

$$
x_{j}=\sum_{k} a_{j k} Y_{k}
$$

Onde $x_{j}$ é o j-ésimo bem consumido (Lancaster, 1966a: 135).

Assim, o vetor dos bens necessários para uma dada atividade de consumo é dado por (Lancaster, 1996a: 135):

$$
x=A y
$$

Como se assumiu que é possível objetivamente mensurar as qualidades do bens consumidos, as equações são válidas para todos os consumidores em um dado mercado (Lancaster, 1966a: 135). Note-se que para mercados distintos provavelmente há um conjunto de equações também diferentes. Ou seja: as relações de consumo válidas para um dado mercado não necessariamente o serão para outro (ver Lancaster, 1966b).

Assumindo que cada "atividade de consumo" apresenta um vetor fixo de características ("e novamente que a relação é linear"), é possível assumir que "zi é a quantidade da i-ésima característica" (Lancaster, 1966a: 135):

$$
z_{i}=\sum_{k} b_{i k} Y_{k} \text { ou } z=B Y
$$

Também se assume que cada consumidor possui uma função utilidade 
ordinal $U(z)$ e escolherá os bens de forma a maximizá-la. Essa função apresenta todas as características comumente associadas a uma função utilidade (convexidade, por exemplo) (Lancaster, 1966a, p.135). Daí:

$$
F_{k}(z, x)=0, k=1 \mathrm{~K} m
$$

Note-se que destarte há dois vetores: o vetor $\mathrm{X}$, de bens existentes, e o vetor $z$, das preferências dos consumidores. A relação entre um vetor e outro é mediada pelo vetor y, de atividade de consumo (Lancaster, 1966a: 136) - o fato da relação entre $X$ e $z$ ser mediada por y significa que não necessariamente há uma correspondência exata (um para um) entre as características desejadas pelos consumidores e o conjunto de bens disponíveis no mercado (Lancaster, 1996a: 136). - Assume-se que há uma relação linear entre os vetores e que a tecnologia de consumo é constante (em última instância: as relações de consumo não variam no período de tempo estudado).

Dadas as relações (3.2.1.2) e (3.2.1.3), suponha-se que há $r$ características (ou "atributos", como se diz em marketing), m atividades de consumo e $\mathrm{n}$ bens em um dado mercado (Lancaster (1966a: 136). Somente se $\mathrm{r}=$ $\mathrm{m}=\mathrm{n}$ haverá uma relação de um para um (um bem corresponderá exatamente a um desejo do consumidor) (idem, ibidem). Se houver diferença entre $r$, m e n, o consumidor não escolherá entre dois conjuntos de bens ( $\mathrm{x}_{1}$ e $\left.\mathrm{x}_{2}\right)$, mas entre dois conjuntos de características $\left(z_{1}\right.$ e $\left.z_{2}\right)$ (idem, ibidem).

Assim, para o consumidor, a questão será (Lancaster, 1966a: 136):

Maximizar U(z),

com restrição de $\quad \mathrm{px} \leq \mathrm{By}$

com $\quad z=B y$

$$
x=A y
$$


$x, y, z \geq 0$

Para simplificar o modelo (e sua solução), Lancaster (1966a: 136) sugere que a escolha do consumidor se dê da seguinte forma:

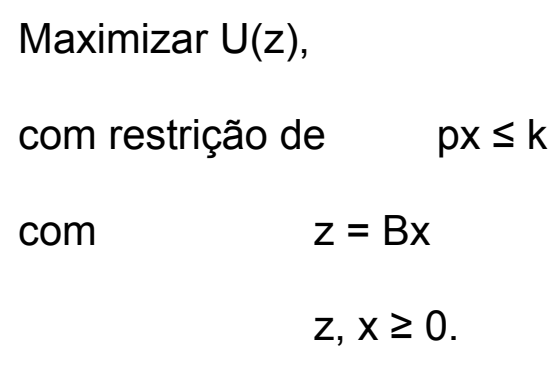

Para Lancaster (1966a), embora o modelo continue não-linear, neste último caso há apenas um "passo" (step) entre o conjunto de bens e o conjunto de características. A diferença principal desse modelo para a tradicional análise microeconômica é a seguinte: no modelo Lancasteriano, $U(z)$ é definido no Espaço-Característica (C-espaço), a restrição orçamentária ( $\mathrm{px} \leq \mathrm{k}$ ) está no Espaço-Bens (G-espaço) e a equação z = Bx é a transformação entre C-espaço e G-espaço (Lancaster (1966a: 136). Na análise tradicional, a restrição orçamentária e a função-utilidade estão no mesmo G-espaço. Assim, há duas possibilidades: transformar a função-utilidade para o G-espaço e relacioná-la diretamente à restrição orçamentária (idem: 137) ou transformar a restrição orçamentária para o C-espaço e relacioná-la diretamente à função-utilidade (idem, ibidem). Para Lancaster (1966a) qualquer uma dessas transformações depende de $z=B x$ e das qualidades da matriz $B$, que representa a tecnologia de consumo da economia (consumption technology of the economy).

Lancaster (1966a: 138) discute várias características da matriz B, sendo obviamente a mais importante a forma dessa matriz. Há três possibilidades:

(i) O número de características (atributos) é igual ao número de bens. 
Assim, $z=B x$ e $x=B-1 z$. Neste caso, o modelo torna-se idêntico ao modelo da microeconomia tradicional.

(ii) O número de características é maior do que o número de bens. Neste caso, $B x=z$ "contém mais equações do que variáveis $x_{i}$ " (idem, ibidem), Kelvin Lancaster considera este um caso especial de sua teoria.

(iii) Há mais bens do que características. Para Lancaster, este último caso assemelha-se com a situação da economia norte-americana à época em que o artigo foi escrito (meados da década de 1960).

Nesse último caso, no qual a quantidade de bens existentes supera a de atributos, há menos equações do que variáveis e para cada vetor de características há mais de um vetor para bens (Lancaster, 1966a: 139). Logo, para cada vetor-característica há mais de um vetor-bem: dado um vetor-preço, segundo Lancaster (idem, ibidem) a escolha do consumidor será uma escolha de eficiência: o consumidor escolherá "a mais eficiente combinação de bens para obter o conjunto de características, e o critério de eficiência será o menor custo" (idem, ibidem).

A escolha eficiente do vetor-caracterítica $z^{*}$, neste caso, será

Minimizar px,

com restrição de $\quad \mathrm{Bx}=\mathrm{z}^{*}$

$$
x \geq 0 .
$$

Como diz Lancaster (1966a: 139): “uma vez que este é um programa linear, uma vez que nós tenhamos a solução $x^{*}$ para algum $z^{*}$, nós podemos aplicar uma escala múltipla para estimar a solução para qualquer orçamento k e vetor-característica $\left(\mathrm{k} / \mathrm{k}^{*}\right) \mathrm{z}^{*}$."

Seguindo a argumentação de Lancaster (1996a: 139), é possível 
perceber que variando $\mathrm{z}^{*}$, dada a restrição orçamentária $\mathrm{px}=\mathrm{k}$, é possível determinar uma "fronteira de características" para todo z. Assim, dada a existência de duas características e quatro bens, é possivel estimar uma fronteira de eficiência como a reta $A B C D$, mostrada na Figura 1 abaixo(note-se que a distância entre o ponto e a origem é o preço do bem. Assim, AO é o preço do bem 1, OB é o preço do bem 2 etc.):

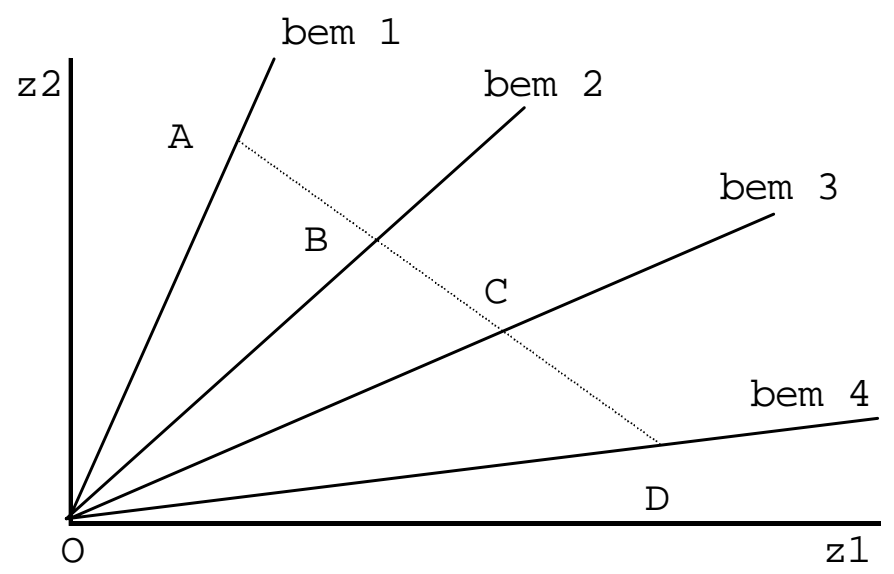

Figura 1: Fronteira de efiiciência para duas características

Fonte: adaptado de Lancaster, 1966a: 139.

Como ressalta Lancaster (1966a: 139), a escolha do consumidor apresenta duas características: (i) objetiva: a escolha da fronteira de eficiência e o conjunto de bens que está associado a essa fronteira; e (ii) uma escolha "privada" (private choice) ou subjetiva: determinar qual ponto, dada a fronteira de características, é a sua preferida (idem, ibidem). Lancaster (1966a: 140) ressalta que a fronteira expande-se ou se contrai linearmente, conforme a renda varia, mas continua tendo a mesma forma para todos os consumidores, pois é uma escolha objetiva.

A questão, pois, passa a ser como essa "fronteira de eficiência" pode ser construída. Para demonstrar isso, Lancaster (1966a) supõe um caso no qual há duas características (atributos) e quatro atividades de consumo. Dada a 
tecnologia de consumo, a "porção" (portion) de atividades-características é assim definida em Lancaster (1966a: 140):

$$
\begin{aligned}
& z_{1}=b_{11} y_{1}+b_{12} y_{2}+b_{13} y_{3}+b_{14} y_{4} \\
& z_{2}=b_{21} y_{1}+b_{22} y_{2}+b_{23} y_{3}+b_{24} y_{4}
\end{aligned}
$$

Para a atividade de consumo 1 , as características serão obtidas pela proporção $b_{11} / b_{21}$ (o raio 1 na Figura 2 abaixo) (Lancaster, 1966a: 140). O mesmo processo aplicado às outras atividades (respectivamente com as proporções $b_{12} / b_{22}, b_{13} / b_{23}$ e $\left.b_{14} / b_{24}\right)$ resultará nos raios seguintes (2, 3 e 4$)$ (idem, ibidem). Dada a restrição orçamentária, $\sum_{i} p_{i} x_{i} \leq k$ e havendo mais bens do que características, o resultado para cada bem $x$ é o seguinte:

$$
x_{i}=a_{i 1} y_{1}+a_{i 2} y_{2}+a_{i 3} y_{3}+a_{i 4} y_{4} ; \quad i=1,2, \ldots, n
$$

Transformando a restrição orçamentária para o Espaço-característica (C-espaço), obtém-se (Lancaster, 1966a: 141):

$$
\left(\sum_{i} p_{i} a_{i 1}\right) y_{1}+\left(\sum_{i} p_{i} a_{i 2}\right) y_{21}+\left(\sum_{i} p_{i} a_{i 3}\right) y_{3}+\left(\sum_{i} p_{i} a_{i 4}\right) y_{4} \leq k
$$

Onde cada um dos "preços compostos" (composite prices) $q_{j}=\sum_{i} p_{i} a_{i j}, j=1 \mathrm{~K} 4$ indica $\circ$ preço de cada atividade de consumo (Lancaster, 1966a: 141). Lancaster (idem, ibidem) enfatiza que o número de bens em relação ao número de atividades de consumo é irrelevante neste ponto da análise. 


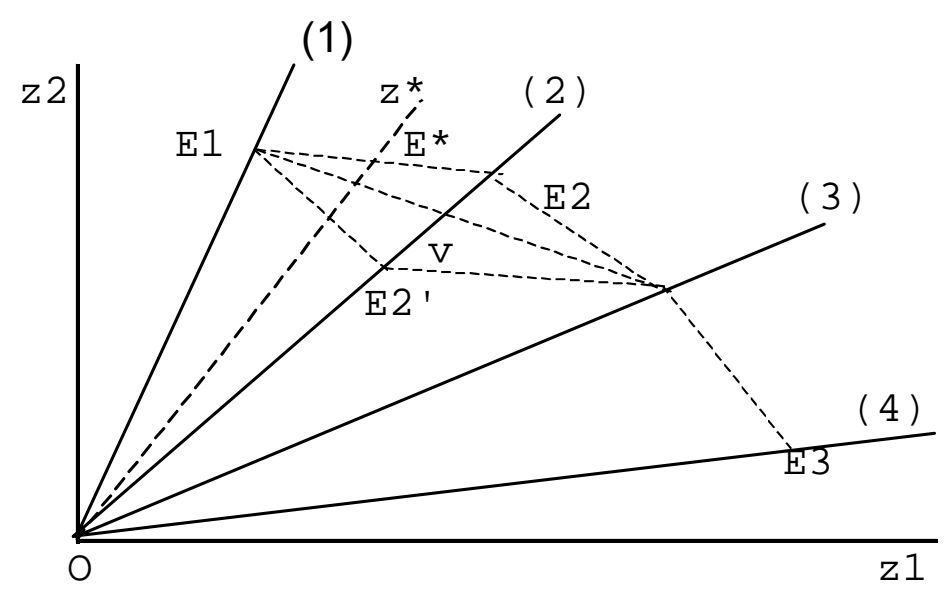

Figura 2: Fronteira de eficiência para dois atributos e quatro atividades de consumo

Fonte: adaptado de Lancaster, 1966a: 141.

A partir desse ponto, Lancaster (1966a: 141-2) apresenta um exemplo.

Dados $\mathrm{q}_{1}, \mathrm{q}_{2}, \mathrm{q}_{3}, \mathrm{q}_{4}$ e $\mathrm{k}$, o máximo nível de cada atividade isoladamente pode ser desenhado em uma figura (os pontos $E_{1}, E_{2}, E_{3}, E_{4}$ na Figura 2 acima). As linhas que unem os pontos representam as combinações eficientes entre os objetos (1 e 2,2 e 3 e 3 e 4), dada a restrição orçamentária (assumindo-se que são as combinações eficientes). Supondo que o consumidor prefira uma dada combinação $z^{*}$, o ponto $E^{*}$ estará na fronteira de eficiência (ver Figura 2 acima) e representará a combinação das características $z_{1}$ e $z_{2}$ do consumidor.

Supondo que aconteça uma modificação nos preços relativos e a atividade de consumo \#2 torne-se mais cara, isto poderia significar uma mudança da fronteira de eficiência do ponto $E_{2}$ para o ponto "v" (Lancaster, 1966a: 141). Se essa mudança for pequena o bastante para não afetar o comportamento do consumidor, a fronteira continuará sendo $E_{2}$ e $O$ consumidor não será afetado. Porém, se a mudança de preço for grande o bastante e significar uma mudança para além do ponto $v$, indo até o ponto $E_{2}^{2}$, então a fronteira de eficiência será deslocada para $E_{1} E_{2} E_{3} E_{4}$ (obviamente, há a suposição de renda constante) (Lancaster, 1966a: 141-2). 
Lancaster (1966a: 142) enfatiza que as mudanças de preços podem acarretar várias situações, entre as duas situações opostas: se forem pequenas o bastante, serão ignoradas. Se forem grandes o bastante, podem causar até a mudança de atividade de consumo (e não a simples troca de bens consumidos).

Para Lancaster (1966a: 142) há duas situações polares: se houver correspondência perfeita entre o número de bens e de atividades de consumo (um bem para cada atividade), mudanças na fronteira de eficiência corresponderão a mudança na atividade de consumo. O caso no outro extremo seria o uso de todos os bens em todas as atividades de consumo: neste caso, a mudança no preço de um bem afetará apenas a quantidade consumida desse bem específico (que, provavelmente, será substituído por outros nas atividades de consumo).

\subsubsection{Uma classificação dos bens com base no modelo de Lancaster}

Uma das aplicações do modelo desenvolvido por Lancaster (1966a) é aperfeiçoar a tradicional classificação dos bens em economia (substitutos versus complementares), tornando-a uma classificação mais precisa.

Supondo, por exemplo, a existência de atividades de consumo que requerem um conjunto específico de bens e que estes bens não sejam usados em nenhuma outra atividade, é possível considerar esses bens como sendo um grupo intrínseco de produtos (intrinsic commodity group). Bens que fizerem parte desse conjunto são substitutos mais próximos do que bens que não façam parte desse conjunto. Lancaster os chama de "intrinsecamente relacionados" (versus “intrinsecamente não relacionados”) (Lancaster (1966a: 144). 
Dentro do grupo intrinsecamente relacionado, é possível imaginar uma escala indo de bens que diferem exclusivamente na proporção de determinados atributos até bens com características similares, porém não idênticas. Lancaster (1966a: 144) chama os primeiros de "substitutos intrínsecos perfeitos" (instrinsec perfect substitutes) e os últimos, de "substitutos próximos" (close substitutes).

Para Lancaster (1966a: 144), também é possível estudar a complementaridade dos bens com base nos atributos (características) e nas atividades de consumo. Assim, se uma atividade de consumo requer mais de um bem para ser realizada, os bens necessários são complementares. Se esses bens forem utilizados somente nessa atividade de consumo, Lancaster (1966a: 145) os chama de "complementos intrínsecos perfeitos" (intrinsic total complements). Porém, pode acontecer de dois bens serem utilizados em mais de uma atividade de consumo e em mais de uma proporção. Neste caso, podem ser complementares e substitutos, em graus variados (idem, ibidem).

Lancaster (1966a) sintetizou em um quadro as principais diferenças entre a sua abordagem e a abordagem da teoria tradicional:

Quadro 1: Comparação de Bens nas Teorias Neoclássica e de Lancaster

\begin{tabular}{l|l}
\hline \multicolumn{1}{c|}{ Teoria Neoclássica } & \multicolumn{1}{c}{ Teoria de Lancaster } \\
\hline $\begin{array}{l}\text { Lenha não poderá ser um substituto } \\
\text { próximo de pão, uma vez que suas } \\
\text { características são diferentes }\end{array}$ & $\begin{array}{l}\text { Não há razão, exceto "gostos" por que } \\
\text { esses bens não possam ser substitutos } \\
\text { próximos (close substitutes) }\end{array}$ \\
\hline $\begin{array}{l}\text { Um Buick vermelho será um substituo } \\
\text { próximo (close substitute) para um Buick } \\
\text { cinza }\end{array}$ & $\begin{array}{l}\text { Não há razão por que esses bens não } \\
\text { possam ser tão próximos quanto lenha e } \\
\text { pão }\end{array}$ \\
\hline $\begin{array}{l}\text { Substituição (por exemplo, manteiga e } \\
\text { margarina) é freqüentemente intrínseca e } \\
\text { objetiva e será observada em muitas } \\
\text { sociedades, sob várias condições de } \\
\text { mercado }\end{array}$ & $\begin{array}{l}\text { Não há razão por que substitutos próximos } \\
\text { em um contexto também o sejam em outro }\end{array}$ \\
$\begin{array}{l}\text { Um bem pode ser retirado do mercado por } \\
\text { novos bens ou mudanças de preços }\end{array}$ & $\begin{array}{l}\text { Nenhuma presunção que bens serão } \\
\text { completamente eliminados }\end{array}$ \\
\hline
\end{tabular}




\begin{tabular}{l|l}
\hline \multicolumn{1}{c|}{ Teoria Neoclássica } & \multicolumn{1}{c}{ Teoria de Lancaster } \\
\hline $\begin{array}{l}\text { A escolha entre trabalho e lazer pode } \\
\text { apresentar um padrão }\end{array}$ & $\begin{array}{l}\text { A escolha entre trabalho e lazer é } \\
\text { determinada apenas pelas preferências } \\
\text { individuais, nenhum padrão além dessas } \\
\text { preferências individuais pode ser estipulado }\end{array}$ \\
\hline $\begin{array}{l}\text { (Lei de Gresham) Um ativo monetário } \\
\text { (moeda) pode deixar de ser uma fronteira } \\
\text { eficiente e irá desaparecer da economia }\end{array}$ & $\begin{array}{l}\text { Não há presunção ex ante que qualquer } \\
\text { bem ou ativo irá desaparecer da economia }\end{array}$ \\
\hline $\begin{array}{l}\text { Um indivíduo é completamente imune a } \\
\text { mudanças de preços que deixam inalterada } \\
\begin{array}{l}\text { a sua fronteira de eficiência sobre os quais } \\
\text { suas escolhas são baseadas }\end{array}\end{array}$ & $\begin{array}{l}\text { Um indivíduo é afetado por mudanças nos } \\
\text { preços }\end{array}$ \\
\hline $\begin{array}{l}\text { Alguns grupos de mercadorias podem ser } \\
\text { intrínsecos e universalmente reconhecidos }\end{array}$ & $\begin{array}{l}\text { Nenhuma presunção que mercadorias } \\
\text { formem um grupo (definido por uma quebra } \\
\text { no espectro de elasticiades-cruzadas) em } \\
\text { um contexto irão formá-lo em outro contexto }\end{array}$ \\
\hline
\end{tabular}

Fonte: adaptado de Lancaster (1966a: 155)

\subsubsection{Principais pontos da análise lancasteriana (e suas implicações para uma análise da demanda de restaurantes)}

Usando serviços como exemplo, é possível imaginar que restaurante e teatro, por exemplo, podem ser complementares ou substitutos, dependendo das características que thes atribuem os consumidores.

Como enfatiza Lancaster (1971: 115), esse modelo do índice de preço hedônico permite estudar uma variedade de mercados de produtos que não são exatamente substitutos, ao contrário de tratar de mercados "agregados" nos quais se assume uma perfeita (ou quase) substitutibilidade entre os bens, como "comida" ou "automóveis".

\footnotetext{
${ }^{36}$ A lei de Gresham diz que a má moeda expulsa a boa de circulação. Por exemplo, no caso de uma hiperinflação, as pessoas podem preferir entesourar uma moeda estrangeira (dólares, por exemplo) e tentar livrar-se da moeda local. Em suma: quando um pagamento é feito em moeda estrangeira em espécie, o troco provavelmente será dado em moeda local. Assim, a moeda "sem valor" tem sua velocidade de circulação levada ao infinito, ao passo que a velocidade da moeda estrangeira que passa a ser usada como referência de valor tende a ser zero.
} 
Restaurantes podem ser "intrinsecamente substitutos" ou "substitutos próximos": o grau de substitutibilidade dependerá do conjunto de atributos (e, neste caso, localização também pode ser um atributo). ${ }^{37}$ Porém, restaurantes também podem ser não-substitutos, dependendo das suas características.

É possível, a partir do estudo dos atributos propostos por Lancaster (1966b, 1971) identificar quais são os atributos que, na percepção dos consumidores, distinguem esses tipos de restaurante e verificar se, na prática, tal classificação faz sentido. Mais do que isso, é possível constatar quais restaurantes são concorrentes entre si e quais não. Como enfatizam Peter e Olson (1999), ao se descobrir quais são os atributos considerados pelos consumidores em um dado mercado, isto possibilita realizar o posicionamento da empresa frente aos seus consumidores.

\subsection{A curva da demanda com formato em "s" de Gary Becker}

O economista Gary Becker, vencedor do prêmio Nobel de Economia em 1992, publicou em 1991 um artigo no qual estuda a influência interpessoal no consumo de restaurantes (Becker, 1991). ${ }^{38}$

\footnotetext{
${ }^{37}$ No caso da localização, a questão pode ser meramente geográfica ou pode referir-se ao custo de transporte. Assim, dois restaurantes podem ser vizinhos (neste caso, o atributo relevante é a geografia) ou o custo de ir até o restaurante é o mesmo, ainda que os restaurantes estejam em lados opostos da cidade (neste caso, o custo de transporte é o atributo mais importante).

${ }^{38}$ Este é apenas um dos trabalhos que Becker escreveu sobre o tema. Aparentemente, um dos mais antigos é Becker (1974).
} 
A pergunta principal que Becker (1991) se propôs é por que os restaurantes não aumentam o preço quando há um aumento de demanda? $\mathrm{O}$ aumento reduziria ou mesmo eliminaria as filas e, simultaneamente, aumentaria os lucros. Graficamente, Becker expõe a questão da seguinte forma:

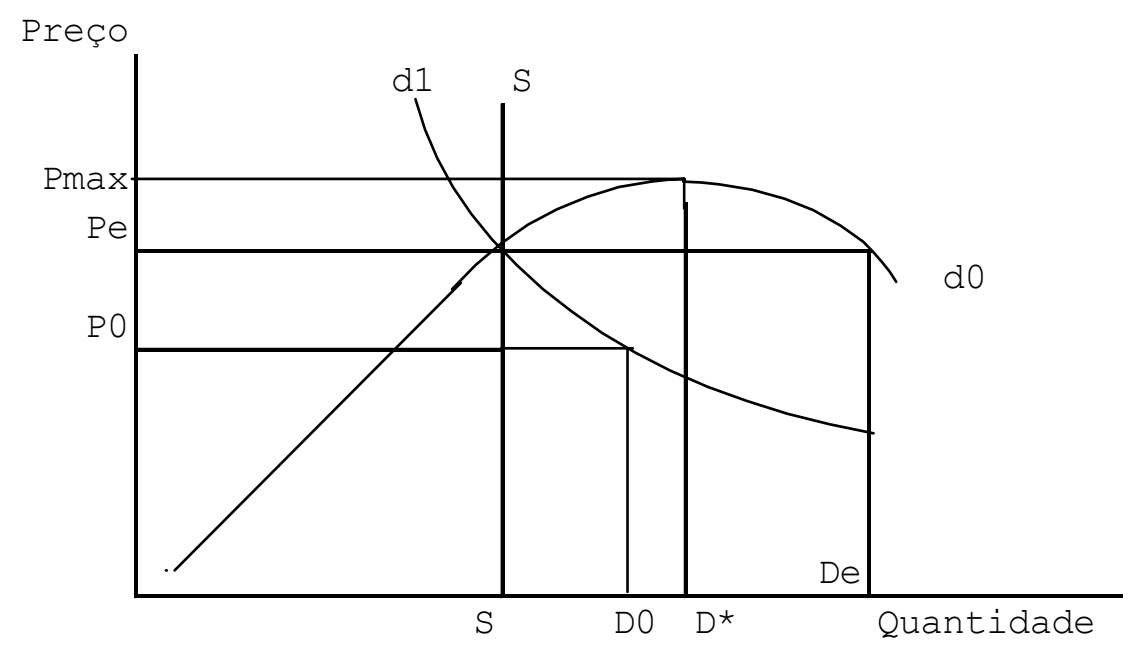

Figura 3: Curvas de Demanda e Oferta de Mesas em Restaurantes

Fonte: Becker (1991: 1111).

Nessa Figura 3, "S" é o número de mesas no restaurante (ou seja: a oferta) e "d${ }_{1}$ " é a demanda com inclinação negativa (Becker, 1991: 1110). Se o preço praticado for $\mathrm{P}_{0}, \mathrm{D}_{0}-\mathrm{S}$ será o excesso demanda nesse preço (Becker, op.cit.). A pergunta feita por Becker (1991) é a seguinte: por que os preços não são elevados até $\mathrm{P}_{\mathrm{e}}$ (o preço de equilíbrio)?

Para responder a essa pergunta, Becker (1991) propõe a seguinte função demanda:

$$
D=\sum d^{i}(p, D)=F(p, D), \quad F_{p}<0, F_{d}>0
$$

Nessa função, a demanda do consumidor i é função do preço (p) e da demanda agregada (D) (Becker, 1991: 1111). Para cada valor de D, há um preço de equilíbrio que resolve $D=F(p, D)$ (idem, ibidem). Assumir que $F_{p}<0$ significa que há um único preço para cada nível de demanda, dado pelo inverso da função 
demanda $p=G(D)$ (idem, ibidem). Já as interações sociais significam que dG/dD pode ser positivo (idem, ibidem), ou seja, $F_{d}>0$.

Becker (1991: 1111) sugere então que se diferencie a equação (3.3.1), obtendo-se assim:

$$
\frac{d p}{d D}=G_{d}=\frac{1-F_{d}}{F_{p}}
$$

Para Becker (1991: 1112), se a influência interpessoal ${ }^{39}$ for grande o bastante para afetar o comportamento de cada consumidor, isto significa que $F_{d}>$ 1. Na Figura 1 acima, se $F_{d}>1$ para toda $D<D^{*}, F_{d}=1$ para $D=D^{*}$ e $F_{d}<1$ para $D>D^{*}$, isto significaria que a demanda aumentaria enquanto $D<D^{*}$, seria máxima em $D=D^{*}$ e passaria a diminuir quando $D>D^{*}$ (idem, ibidem). Para Becker (idem, ibidem) isto explica porque restaurantes populares podem cobrar preços altos e ainda assim a demanda continuar crescendo. Porém, a partir do ponto de máximo de preço (quando o preço será tal que $p=p_{\max }+\epsilon, \epsilon>0$ ), haverá dois preços para a mesma demanda $\left(p_{1}\right.$ e $\left.p_{\max }+€\right){ }^{40}$ Becker (idem, ibidem) chama a demanda existente a partir de pmax de "descontínua" e afirma que nesse momento a demanda tende a cair a zero, não importando quão pequeno seja $€$ (na verdade, aparentemente a partir do ponto pmax, a curva de demanda voltará a ser $\mathrm{d}_{1}$ e a perda de demanda para preços acima de pmax provavelmente será equivalente a " $d_{0}-d_{1}$ ").

Todavia, Becker (1991) reconhece que as curvas de demanda

\footnotetext{
${ }^{39}$ Becker (1991) utiliza a expressão interação social (social interaction) ao invés de influência interpessoal. Provavelmente, para evitar a crítica de que está violando a suposição teórica neoclássica do "individualismo metodológico" (os consumidores não são influenciados por outros consumidores em suas decisões de compra).

${ }^{40}$ Para Becker (1991: 1112) isto é válido para qualquer $€$, não importa quão pequeno seja esse aumento do preço.
} 
desenhadas na Figura 3 acima não são as únicas possíveis (com alguma parte apresentando inclinação positiva). Assim, Becker (1991: 1112) mostra uma outra curva de demanda (a curva com formato de "s"), que primeiro apresenta inclinação negativa, depois a inclinação torna-se positiva e, finalmente volta a ser negativa:

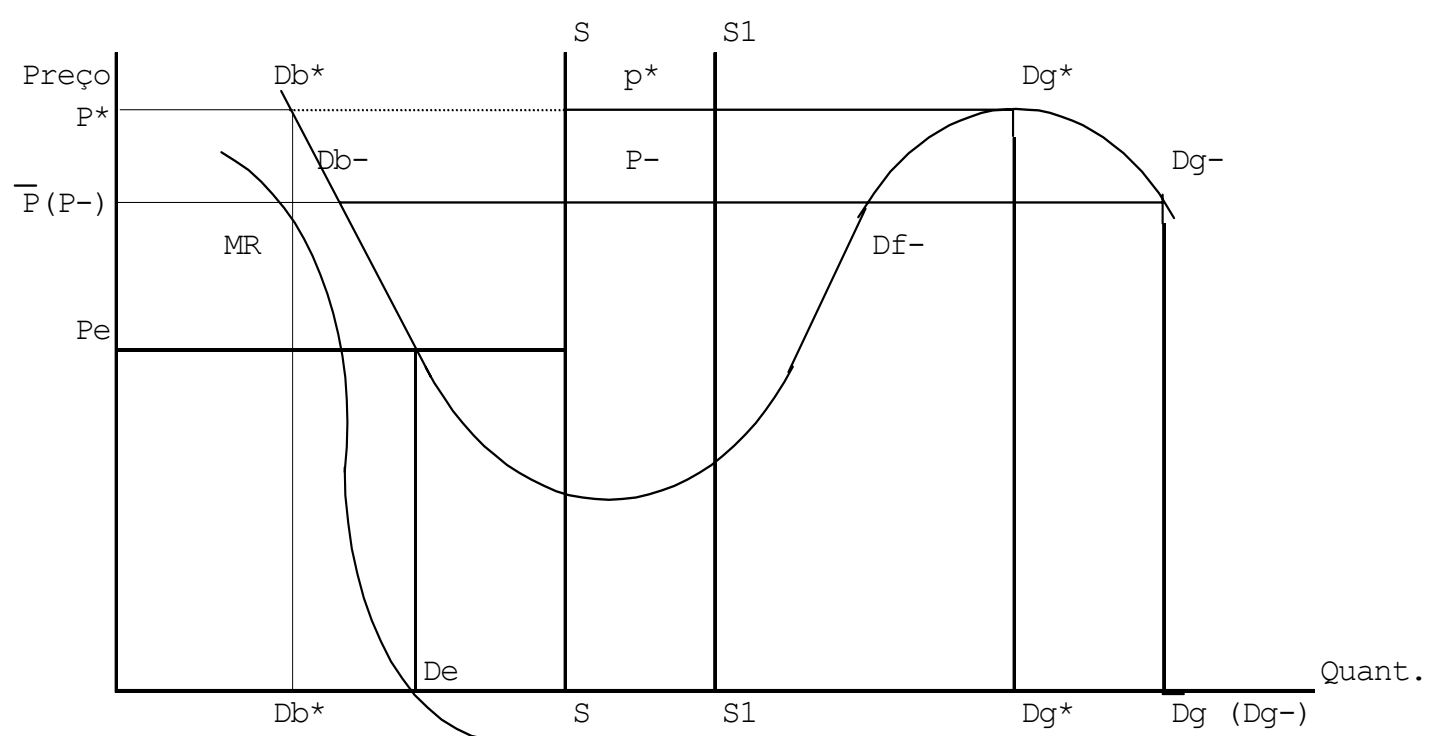

Figura 4: Curva de Demanda em "S" proposta por Becker (1991)

Fonte: Becker (1991: 1113).

Como aponta Becker (1991), a curva de demanda representada na Figura 4 apresenta um problema: se o preço for $\mathrm{p}^{*}$, a demanda tanto poderia ser $D_{b}{ }^{*}$ como ser $D_{g}{ }^{*}$. E, como enfatiza Becker (1991: 1112), a demanda $D b^{*}$ não é atrativa para o restaurante, pois a capacidade ociosa é "substancial" $\left(S-D_{b}{ }^{*}\right)$. Nesse caso, ainda segundo Becker (idem, ibidem), o restaurante fixaria seu nível de preço em $p_{e}$ (versus $\left.p^{*}\right)$, pois a receita marginal nesse ponto seria zero (Becker, idem, ibidem).

Para Becker (1991: 1112), se a curva de demanda de um restaurante for como a mostrada na Figura 4 acima, há dois pontos de equilíbrio possíveis que maximizam o lucro: o primeiro "tem excesso de capacidade e um preço baixo" $\left(S-D_{e}, p_{e}\right)$ e outro, "tem excesso de demanda e um preço alto" $\left(D_{g}{ }^{*}-S, p^{*}\right)-$ 
note-se que na Figura 4 acima a curva "MR" é a curva da Receita Marginal. Segundo Becker (idem, ibidem), a diferença entre um restaurante e outro é que o primeiro lutará com excesso de mesas e o segundo será um desses restaurantes da moda, muito concorrido pelo consumidores. Para Becker (1991: 1113), isto mostra a importância da influência interpessoal e também porque a propaganda funciona como forma de aumentar a demanda de alguns tipos de consumo (Becker aqui refere-se a novos livros): como o aumento de consumo de alguns consumidores (influenciados de alguma forma pela propaganda) leva ao consumo de outros consumidores (que talvez não sejam influenciados pela propaganda e sim pelo consumo alheio). ${ }^{41}$ Assim, para Becker (idem, ibidem), isto significa o reconhecimento de que dois restaurantes que começam suas atividades em épocas semelhantes e apresentam o mesmo padrão de comida e atendimento podem apresentar resultados econômicos distintos: quando um começar a fazer mais sucesso do que o outro, o bem-sucedido chegará no equilíbrio em $\mathrm{Dg}^{*}$, ao passo que o mal-sucedido terá seu equilíbrio em $D_{e}{ }^{42}$

Becker (1991) também discute a estabilidade dos dois possíveis equilíbrios. Para o economista norte-americano, o primeiro $\left(p_{e}, D\right)$ é mais estável do que o segundo $\left(p^{*}, D^{*}\right)$. Assim, para Becker (1991: 1114), é mais fácil um

\footnotetext{
${ }^{41}$ Isto leva a uma questão importante: como calcular o impacto da propaganda na demanda. Se essa influência interpessoal existe, é preciso separar os consumidores em pelo menos dois tipos: "formadores de opinião" e "seguidores" (seguindo o modelo descrito em Corneo \& Jeanne, 1994b). A propaganda então deveria ser voltada para os "formadores de opinião" (o que modificaria a forma como o cálculo da importância da propaganda é apresentada em manuais como, por exemplo, Douglas, 1992, cap.13 e Lambin, 1966, cap.IV). Note-se que este modelo poderia ser ainda mais complexo, pois eventualmente existiriam "formadores de opinião" que não seriam influenciados pela propaganda e ainda, "seguidores" que seriam influenciados pela propaganda destinada aos "formadores de opinião" (neste último caso, um modelo que poderia ser útil em uma primeira aproximação do problema é aquele apresentado em Pantzalis, 1995, cap.4: "um modelo para apreçamento de uma marca exclusiva dada a sua difusão simultânea em dois grupos [de consumidores]").

${ }^{42}$ Becker (1991) também utiliza esse modelo para explicar o sucesso e o fracasso de alguns livros no mercado editorial norte-americano.
} 
restaurante sair de moda (ir do segundo para o primeiro equilíbrio) do que entrar na moda (ir do primeiro equilíbrio para o segundo). Isto também explicaria porque a oferta de mesas não é aumentada quando o restaurante está na moda: dada a volatilidade do comportamento dos consumidores no segundo equilíbrio, expandir a oferta é assumir um risco desproporcional em relação à possibilidade de ganho.

Outra possibilidade aventada por Becker (1991: 1115) é que a demanda agregada varie negativamente em relação ao preço, positivamente em relação à própria demanda agregada e ainda varie positivamente em relação à diferença entre a demanda e a oferta. A equação proposta por Becker (idem, ibidem) neste caso é a seguinte:

$$
D=\sum d^{i}\left(p, D, \frac{D}{S}\right)=F\left(P, D, \frac{D}{S}\right), \frac{\partial F}{\partial d / S}>0
$$

Neste caso, expandir a oferta pode diminuir a diferença entre oferta e demanda e com isso, diminuir a demanda — seguindo Pantzalis (1995) poder-seia dizer que expandir a oferta sugeriria uma diminuição da sensação de exclusividade propiciada pelo excesso de demanda em relação à oferta. Porém, segundo Becker (1991: 1115) esse excesso de demanda não deve ser superenfatizado em relação ao modelo anterior, embora também possa ser relevante, em alguns casos.

Becker (1991) expande a discussão sobre a demanda agregada ser também função da diferença entre a demanda e a oferta sugerindo que pode haver um limite para a influência positiva desse excesso de demanda. A partir de um dado momento, os consumidores considerariam o restaurante como excessivamente lotado. ${ }^{43}$ Esse seria um dos motivos para o equilíbrio $\left(p^{*}, D_{g}{ }^{*}\right)$ ser

\footnotetext{
${ }^{43}$ Becker (1991, p.1115) atribui esse comentário a Ted Bergstrom.
} 
instável em relação ao equilíbrio $\left(p_{e}, D_{e}\right)$. O modelo apresentado por Corneo e Jeanne (1994b) — que será discutido em detalhes na próxima seção deste trabalho - explica essa possibilidade, ao diferenciar o consumidor em dois tipos: "formadores de opinião" e "seguidores" (sendo que os primeiros são em menor número do que os segundos): quando o restaurante passa a ser freqüentado por um número maior de consumidores do tipo "seguidor", os consumidores do tipo "formador de opinião" passam a freqüentar outro lugar.

Uma forma de diminuir a instabilidade do segundo equilíbrio, afirma Becker (1991), é fixar um preço p-, tal que p- < p*. Segundo Becker (1991: 1115), o equilíbrio (p-, D-g) é mais estável em relação a variações na demanda. Neste caso, porém, surge uma outra questão: o preço p- não impede a existência de múltiplos pontos de equilíbrio: ao preço p- é possível obter ainda dois outros equilíbrios: (p-, D-f) e (p-, D-b).

Gary Becker conclui seu trabalho (Becker, 1991) afirmando que muito ainda há para ser feito e que seu modelo é apenas uma das primeiras tentativas de se incorporar a influência interpessoal no estudo da demanda agregada. ${ }^{44}$ Uma outra forma de estudar a influência interpessoal à teoria econômica foi feita por Corneo e Jeanne (1994b), que será discutida na próxima seção deste

\footnotetext{
${ }^{44}$ Gary Becker voltaria ao tema da influência interpessoal no consumo em seu trabalho Becker e Murphy (2000). Porém, Becker continua utilizando a racionalidade do consumidor da teoria econômica como pressuposto indispensável à análise. Becker e Murphy (2000), a pretexto de relaxar esse pressuposto, afirmam que o indivíduo pode ser influenciado pelo grupo social ao qual pertence; todavia pode escolher racionalmente a qual grupo social pertencer. Obviamente, ninguém escolhe em qual família, raça ou sexo pertencer, como aponta Charon (1996: 89), ao iniciar a discussão sobre a inevitabilidade de se pertencer a alguns grupos sociais. Becker e Murphy (2000) realizam ainda discussões que parecem bizantinas: ao estudar como se dá o casamento, afirmam que há um mercado casamenteiro na sociedade e enveredam por uma análise se homens e mulheres são bens complementares ou substitutos (sic). Assim, é difícil perceber qual a validade desse trabalho para uma discussão sobre a influência interpessoal no consumo das pessoas que vivem em um mundo real. São exatamente trabalhos como Becker e Murphy (2000) que dão a má fama de ciência imperialista para a Economia, ao ignorarem a especifidade do tema tratado apenas para utilizar o ferramental teórico da economia neoclássica.
} 
trabalho.

\subsubsection{A importância do público que freqüenta o restaurante}

O artigo de Gary Becker (Becker, 1991) discutido na seção anterior tenta incorporar a influência interpessoal sem abrir mão do arcabouço teórico neoclássico — daí Becker (1991) usar a expressão "interação social" ao invés de "influência interpessoal".

Note-se porém que o debate sobre a influência social sobre o comportamento do consumidor é tema antigo - se não for considerado o enfoque neoclássico como o sendo o único. Via de regra, cita-se Veblen (1899) como o precursor das críticas à teoria neoclássica quanto ao estudo do comportamento do consumidor. Mason (1998) e Pereira (2000) mostraram que há estudos anteriores a Veblen (1899) que já discutiam o problema da influência interpessoal. O ponto importante porém é se é possível criar um modelo formal o bastante para aplicação prática (a ausência de praticidade é uma crítica comum aos trabalhos que seguem em particular a linha vebleniana de estudo do consumo e em geral a escola institucionalista de economia). ${ }^{45}$

Dois autores contemporâneos que tentaram incorporar formalmente a influência são Giacomo Corneo e Olivier Jeanne. Em uma série de artigos, esses autores vêm apresentando modelos que discutem as conseqüências de se abandonar a premissa do "individualismo metodológico" nos estudos de demanda

\footnotetext{
${ }^{45}$ Essas críticas não procedem. Para um conjunto de trabalhos sobre preços de inspiração institucionalista, ver Hamilton (1938). Para um debate do uso do "institucionalismo" como método para trabalhos empíricos, ver, por exemplo, a autobiografia de John R. Commons (Commons, 1934).
} 
ou de estudar demandas "não-convencionais" (demandas que não obedeçam rigorosamente a regra de que quanto maior o preço, menor a quantidade consumida) (Corneo \& Jeanne, 1994a; 1994b; 1997a; 1997b e 1998).

Em especial para o tema aqui estudado, convêm explorar mais detalhadamente Corneo \& Jeanne (1994b). Nesse artigo, os autores pretendem estudar o fenômeno das modas (fashions), assim definido por esses autores: "modas são padrões populares de comportamento adotados por indivíduos durante época e situação particulares" (Corneo \& Jeanne, 1994b: 3).

De acordo com esses autores, há dois pontos importantes no estudo de modas: o primeiro é que modas são "frágeis", ou seja, pequenos choques podem provocar grandes alterações na demanda do bem que está na moda e segundo, modas apresentam "ciclos de vida" (idem, ibidem): usualmente, um ciclo de vida da moda apresenta quatro estágios: introdução, emulação, conformidade (ou massificação) e declínio (idem, ibidem).

Uma das abordagens do problema sugeridas por Corneo e Jeanne (idem, ibidem) é que se o "bem da moda" (fashion good) for usado como símbolo de status a curva de demanda desse bem variará inversamente com a "estimativa do estoque corrente desse bem". Essa forma de ver a questão parece ser idêntica àquela modelada por Becker (1991) na equação (3.3.3) apresentada na seção anterior deste trabalho. Segundo Corneo e Jeanne (1994b) - e em aparente concordância com o modelo formalizado em Becker, 1991, exposto acima - isto gerará oscilações bruscas na demanda desse "bem da moda". ${ }^{46}$

Porém Corneo e Jeanne (1994b) sugerem uma outra abordagem para o estudo do problema do ciclo de vida da moda. Para tanto, esses autores supõe

\footnotetext{
${ }^{46}$ Para uma abordagem alternativa do efeito da limitação na oferta em bens que eventualmente se prestam a utilização como símbolos de status, ver Pantzalis (1995).
} 
a existência de dois tipos de consumidores (dois segmentos) e que a comunicação entre os segmentos não é perfeita, ou seja, há uma defasagem temporal entre o que é de conhecimento de um segmento e de outro ("randômica" é a expressão usada pelos autores - Corneo \& Jeanne, 1994b: 5). Já intrassegmento, a probabilidade de troca de informação entre os indivíduos é maior e menos aleatória (do que a comunicação extrassegmento). O primeiro exemplo que esses autores usam é o do "café típico": turistas "adoram" sentar em Cafés Típicos, mas os nativos preferem freqüentar outros lugares, que não sejam tomados por turistas (Corneo \& Jeanne, 1994b: 5). Se a informação de que os locais preferem outro Café se espalha entre os turistas, estes passam a freqüentar esse novo local e os nativos da cidade deixam de freqüentar o lugar e passam a ir a outro (idem, ibidem). $\mathrm{O}$ ciclo parece ser interminável. ${ }^{47}$

Corneo e Jeanne (1994b) tentaram apresentar um modelo formal desse tipo de ciclo de vida da moda. Para tanto, imaginaram dois tipos de consumidores, o tipo A ou "tipo desejável" (desirable type) e o tipo B ou "tipo indesejável" (undesirable type) — ou "nativos" e "turistas". ${ }^{48}$ A população é normal, com a indivíduos do tipo A e 1-a do tipo B. Ambos os tipos de indivíduos podem escolher entre duas ações: escolher entre dois lugares (restaurantes, por exemplo) para ir. A escolha do lugar depende do número de pessoas de um tipo ou de outro que freqüentam o lugar (Corneo \& Jeanne, 1994b, p.6). A função utilidade do consumidor i é a seguinte (idem, ibidem):

$$
u_{i}=y_{i}+\left(1-I_{i}\right)\left(\frac{\pi_{0}}{i_{\theta}}-C_{0}\right)+I_{i}\left(\frac{\pi_{1}}{i_{\theta}}-C_{1}\right)
$$

\footnotetext{
${ }^{47}$ Um exemplo nacional é velho Bar Pingüim, no centro de Ribeirão Preto, que é freqüentado basicamente por turistas de outras cidades.

${ }^{48}$ Talvez fosse melhor utilizar os termos correntemente usados em marketing: "formadores de opinião" e "seguidores".
} 
Onde $y_{i}$ é a renda do consumidor (expressa em moeda), $p_{j}$ é a proporção de consumidores do tipo A que freqüentam o local (“j” é o tipo de restaurante), $\theta$ é um coeficiente positivo, $c_{j}$ é o custo em moeda de ir para o local $\mathrm{j}$ e $\mathrm{l}_{\mathrm{i}}$ é o lugar escolhido pelo consumidor - uma variável dummy que é 0 se o consumidor vai para o lugar 0 e é 1 se consumidor for para 1 (Corneo \& Jeanne, 1994b: 6$)^{49}$

A partir da equação (3.2.1.1) Corneo e Jeanne (1994b) fazem algumas considerações: nativos geram uma externalidade positiva no restaurante, ao passo que turistas causam uma externalidade negativa. Segundo os autores, esse modelo também serve para explicar a compra de uma casa em um determinado bairro ou a escolha de um determinado clube para se associar. Outro ponto a ser ressaltado é que as preferências descritas na equação (3.2.1.1) são homogêneas intrassegmento e heterogêneas entre os segmentos (Corneo \& Jeanne, 1994b: 6). Ou seja: indivíduos do mesmo tipo apresentam comportamentos semelhantes, o que está de acordo com o conceito de segmentação em marketing. ${ }^{50}$ Os autores propõem ainda a utilidade de se estar sozinho como sendo $\bar{\pi}$ e a a utilidade de estar acompanhado, sendo $\bar{\pi} \leq \alpha$ (idem, p.8).

Nesse modelo, a escolha do lugar depende ainda do conhecimento sobre os lugares, ou seja, de informação. Os "iniciados" (initiates) conhecem os dois locais, 0 e 1, e preferem o local 1. Os "não-iniciados" (non-initiates) freqüentam apenas o local 0, pois são ignoram a existência do local 1 (Corneo \& Jeanne, 1994b: 8). O conhecimento sobre o "novo" local é contínuo ao longo do

\footnotetext{
${ }^{49}$ Corneo e Jeanne (1994b, p.6) ressaltam que o custo de transporte $c_{j}$ pode ser zero.

${ }^{50}$ Sobre segmentação, consultar, por exemplo, Grisi (1986) ou Weinstein (1993).
} 
tempo. Um não-iniciado toma conhecimento do local 1 apenas por meio de um iniciado. Portanto a informação sobre um o novo local 1 é transmitida apenas pelo boca-a-boca (word-of-mouth). ${ }^{51}$

Um ponto importante é que há mais probabilidade de um iniciado informar um seu par sobre a existência do local 1 , do que de informar um nãoiniciado. Corneo \& Jeanne (1994b) enfatizam este ponto, porque isto garante que no modelo a informação não é perfeitamente difundida. Formalmente, a probabilidade de um consumidor do tipo A (iniciado) encontrar outro do tipo A é $\mu$, sendo $\mu<1$. A probabilidade de um consumidor do tipo $A$ encontrar um do tipo $B$ é 1- $\mu$ (Corneo e Jeanne, 1994b: 9). Os autores também assumem que $\mu \geq \alpha$, ou seja a probabilidade de se estar acompanhado é maior do que a de se estar sozinho (idem, ibidem).

Assim, a probabilidade de cada tipo de consumidor se encontrar encontrar com outro consumidor é resumida no Quadro 2 abaixo:

Quadro 2: Probabilidade de consumidores se encontrarem em um bar

\begin{tabular}{|c|c|c|}
\hline & A & B \\
\hline A & $\mu$ & $1-\mu$ \\
B & $\frac{\alpha}{1-\alpha}(1-\mu)$ & $1-\frac{\alpha}{1-\alpha}(1-\mu)$ \\
\hline
\end{tabular}

Fonte: Corneo e Jeanne (1994b: 9)

A partir dessa tabela, Corneo \& Jeanne (1994b) deduzem a dinâmica

${ }^{51}$ Com o quê Corneo e Jeanne (1994b) eliminam a propaganda e outras formas de promoção do modelo. Mas isto é apenas uma simplificação e a forma de propagação do conhecimento do local 1 pode ser modelada de outras formas, que incorporem a propaganda.

Curiosamente, os autores não discutem a questão da propaganda, ao comentar a modelagem da difusão da informação, preferindo discutir se há ou não incentivos para os "iniciados" darem a informação para os "não-iniciados" (Corneo \& Jeanne, 1994b, p.8, nota de rodapé \#5). 
da propagação da informação sobre o novo local 1: supondo $N_{A}$ e $N_{B}$ as frações de pessoas de consumidores do tipo A e do tipo B que conhecem o novo local e supondo que para um período de tempo infinitesimal $[t, t+d t]$ tanto o número de pessoas do tipo A quanto do tipo B que conhecem o novo lugar está aumentando pelo contato com consumidores do tipo A que já conhecem o local 1. Supondo uma "taxa de encontro" (matching rate) igual a r, é possível assumir que (Corneo \& Jeanne, 1994b: 10):

$$
\begin{array}{r}
N_{A}(t+d t)-N_{A}(t)=\rho d t\left(1-N_{A}(t)\right)\left[\mu N_{A}(t)+(1-\mu) N_{B}(t)\right] \\
N_{B}(t+d t)-N_{B}(t)=\rho d t\left(1-N_{B}\right)\left[\frac{\alpha}{1-\alpha}(1-\mu) N_{A}(t)+\left(1-\frac{\alpha}{1-\alpha}(1-\mu)\right) N_{B}(t)\right]
\end{array}
$$

Corneo \& Jeanne (1994b:10) então simplificam essas expressões, tomando como limite $\mathrm{dt}=0$, obtendo as seguintes equações diferenciais:

(S) $\left\{\begin{array}{l}\dot{N}_{A}=\rho\left(1-N_{A}\right)\left[N_{B}+\mu\left(N_{A}-N_{B}\right)\right] \\ \dot{N}_{B}=\rho\left(1-N_{B}\right)\left[N_{B}+\frac{\alpha}{1-\alpha}(1-\mu)\left(N_{A}-N_{B}\right)\right]\end{array}\right.$

Essas equações podem ser analisadas em um espaço $\left(N_{B}, N_{A}\right)$ (Corneo \& Jeanne, 1994b: 10). Os dois pontos estáveis do sistema são $\left(N_{B}, N_{A}\right)=$ $(0,0)$ e $\left(N_{B}, N_{A}\right)=(1,1)$. No primeiro ponto, ninguém conhece o novo local (no caso, o novo restaurante); no segundo, todos conhecem o novo restaurante (idem, ibidem). Segundo os autores, o último ponto é mais estável do que o primeiro, pois "cedo ou tarde" os consumidores se informarão sobre o novo restaurante (idem, ibidem).

A partir dessas equações, Corneo e Jeanne (1994b) passam a estudar 
a dinâmica da interação social entre os dois tipos de consumidores. Para tanto, os autores propõem que, sendo $\eta A$ e $\eta B$ as frações dos tipos de consumidores $A$ e $B$ respectivamente que freqüentam inicialmente o novo local 1 e dados a atratividade e o número total de consumidores do tipo $A, N=\alpha N A+(1-\alpha) N B, o$ número total de consumidores do tipo $A$ que freqüentam esse novo local é $\eta=$ $\alpha \eta A+(1-\alpha) h \eta($ Corneo \& Jeanne, 1994b: 11).

Para mostrar a dinâmica do modelo, Corneo e Jeanne (1994b: 11) supõem que: sendo $\Delta \pi \equiv \pi_{1}-\pi_{0}$ o benefício auferido por se estar no local 1 ao invés de se estar no local 0 e $\Delta c=\Delta c_{1}-\Delta c_{0}$ o custo dessa escolha, a maximização da função utilidade (3.2.1.1) para um consumidor i do tipo A escolher o local 1 será:

$$
i \leq\left\|\frac{\Delta \pi}{\theta \Delta c}\right\|
$$

Onde o operador $\|\bullet\|$ é definido por $\|x\|=\sup (\inf (x, 1), 0)$. Segundo Corneo e Jeanne (1994b: 11), se for usada a lei dos grandes números, as frações das populações de consumidores do tipo $A$ e do tipo $B$ que freqüentam o novo local 1 serão, respectivamente:

$$
\begin{aligned}
& \eta_{A}=\left\|\frac{\Delta \pi}{\theta \Delta C}\right\| N_{A} \\
& \eta_{B}=\left\|\frac{\Delta \pi}{\theta \Delta C}\right\| N_{B}
\end{aligned}
$$

Daí, o número de consumidores que estão no novo local $1(\Delta \pi)$ está relacionado ao número de consumidores do tipo $A$ da forma como se segue (Corneo \& Jeanne, 1994b: 11-12): 


$$
\eta=\left\|\frac{\Delta \pi}{\theta \Delta c}\right\| N
$$

Segundo Corneo e Jeanne (1994: 12), para "fechar o modelo" é preciso fixar o benefício de ir ao local $1(\Delta \pi)$ como uma função da distribuição dos indivíduos nos dois locais. Se $\eta \in(0,1)$, esse benefício será o seguinte (idem, ibidem):

$$
\Delta \pi=\frac{\alpha \eta_{A}}{\eta}-\frac{\alpha\left(1-\eta_{A}\right)}{1-\eta}=\frac{\alpha(1-\alpha)}{\eta(1-\eta)}\left(\eta_{A}-\eta_{B}\right)
$$

Substituindo em (3.2.1.5) $\eta_{A}$ e $\eta_{B}$ pelas equações (3.2.1.6) e (3.2.1.7), é possível obter (Corneo \& Jeanne, 1994b: 12):

$$
\Delta \pi=\frac{\alpha(1-\alpha)}{\eta(1-\eta)}\left\|\frac{\Delta \pi}{\theta \Delta C}\right\|\left(N_{A}-N_{B}\right)
$$

Como afirmam Corneo e Jeanne (1994b: 12), para uma dada "estrutura informacional descrita por $\left(\mathrm{N}_{\mathrm{B}}, \mathrm{N}_{\mathrm{A}}\right)$, um equilíbrio de Nash instantâneo no qual os locais 0 e 1 são freqüentados é um par $(\eta, \Delta \pi)$ que satisfaça $0<\eta<1,-1<\Delta \pi<1$, e as duas equações (3.2.1.8) e (3.2.1.10)". Já se for utilizada a equação (3.2.1.5), o equilíbrio de Nash "no qual apenas o velho local 0 é freqüentado deve simplesmente satisfazer a condição" (Corneo \& Jeanne, 1994b: 12):

$$
i>\left\|\frac{\pi-\alpha}{\theta \Delta c}\right\|
$$

Dada essa dinâmica, Corneo \& Jeanne (1994b) apresentam algumas proposições e conclusões: ${ }^{52}$

\footnotetext{
${ }^{52}$ As demais derivações e provas estão em Corneo e Jeanne (1994b: 12-6 e apêndice). O ponto que interessa a este trabalho é a apresentação do modelo e suas conseqüências. Recomenda-se ao leitor interessado em maiores detalhes que consulte o texto original de Corneo e Jeanne (1994b).
} 
i) se os consumidores do tipo A (os "locais" ou "formadores de opinião") forem relativamente mais bem informados do que os consumidores do tipo B (os "turistas" ou "seguidores"), o novo local 1 será mais freqüentado por alguns indivíduos, mesmo que o custo de ir até esse local seja maior do que o de ir até o antigo local 0 (Corneo \& Jeanne, 1994b:13);

ii) "quanto mais segmentados forem os canais de comunicação, maior será o número total de pessoas que adotará um novo comportamento [em relação à escolha de aonde ir] em cada ponto do tempo" (Corneo \& Jeanne, 1994b: 14);

iii) a forma e a velocidade como a informação passa de um consumidor para outro (e de um segmento para outro) é importante. Se a comunicação for muito rápida (no modelo: $\mu \approx 1$ ), os movimentos serão muito rápidos e tão logo um novo restaurante seja freqüentado pelos consumidores do tipo $A$, também o será pelos consumidores do tipo $B$ e os consumidores do tipo $A$ mudar-se-ão para outro lugar, em um ciclo interminável (Corneo \& Jeanne, 1994b: 15). Porém, se houver "assimetria de encontros dos consumidores de tipos diferentes" (assymetric matching), ou seja, $\mu<\alpha$, será possível obter uma fase de "crescimento" da demanda pelo novo restaurante (como o ciclo de vida do produto em forma de sino dos manuais de marketing).

iv) Corneo \& Jeanne (1994b: 16) mostram que o modelo pode ser visto como uma formalização das teorias propostas por Veblen (1899) e pelo sociólogo alemão Georg Simmel ${ }^{53}$ (chamadas por Corneo \& Jeanne, 1994b, de "teoria da moda de classe alta": upper class theory of fashion), de que o consumo das pessoas da classe social elevada tende a ser copiado pelas de classe mais baixa, e de que quando essa cópia é percebida, os consumidores de classe mais alta

\footnotetext{
${ }^{53}$ Apud Corneo e Jeanne (1994b): Georg Simmel (1904): "Fashion". In International Quarterly 10: 130-155.
} 
mudam seu consumo. Nas palavras de Corneo \& Jeanne (1994b: 16): "nosso modelo sugere que uma estrutura de comunicação fortemente segmentada pode efetivamente induzir o processo de imitação e diferenciação entre classes sociais como as descritas pela 'teoria da classe alta"';

v) a conclusão de Corneo \& Jeanne (1994b: 17-8) é que a estrutura de comunicação em uma sociedade é particularmente importante para a ocorrência de modas entre os vários tipos de consumidores.

Uma limitação importante do modelo, como os próprios Corneo e Jeanne (1994b) destacam é a ausência da propaganda como forma de comunicação. Porém, é possível relevar essa limitação (dentro de certos limites) no caso da demanda por restaurantes em uma dada cidade. Pois, exceto no caso de grandes redes, os restaurantes não costumam ser grandes anunciantes ademais, a mídia utilizada também é segmentada, visando atingir um determinado grupo de consumidores. Destarte, é possível supor, para os fins desta tese, que a propaganda apenas magnifica a propaganda boca-a-boca dentro do segmentoalvo do restaurante.

Um último ponto que convém frisar é a existência de modelos mais modernos sobre o comportamento "volúvel", ou por outra, inconstante, dos consumidores. Ormerod (1998) mostra como é possível derivar uma modelização de modismos a partir da chamada "matemática do caos" ${ }^{44}$ e como pequenas mudanças no comportamento podem gerar grandes variações na demanda agregada (o efeito borboleta).

Contudo, a questão é considerar em conjunto Becker (1991) e Corneo e Jeanne (1994b). A partir desses autores é possível constatar que:

\footnotetext{
${ }^{54}$ Sobre isto, ver Gleick (1987) e Stewart (1989).
} 
i) se a curva de demanda por restaurantes pode não necessariamente seguir apresentar o formato das curvas tradicionais da teoria (com inclinação sempre negativa); e

ii) se os consumidores se influenciam mutuamente e há mais de um tipo de consumidor em um dado mercado, a demanda por um dado produto (no caso, restaurante) pode ser instável e sujeita a modismos.

Então:

iii) é possível modelar teoricamente esse tipo de comportamento supostamente "anômalo".

A questão passa a ser se, à luz dessas constatações, é possível utilizar o teoria lancasteriana dos atributos para modelar uma pesquisa empírica sobre o comportamento dos consumidores de restaurantes - que é um dos temas desta pesquisa. - Note-se que logo na segunda página do seu famoso artigo, Lancaster (1966a: 133) sugere a possibilidade de que uma refeição tem atributos nutricionais e estéticos e ainda seu consumo é afetado pelas circunstâncias sociais (social setting) em que é realizada. Assim, aparentemente, considerar a possibilidade de criar um índice de preço hedônico está de acordo com as idéias elaboradas por Kelvin Lancaster. 


\section{METODOLOGIA DA PESQUISA}

"... pois o objeto de toda ciência é fazer descobertas, e toda descoberta desconcerta mais ou menos as opiniões aceitas."

Émile Durkheim (prefácio de As Regras do Método Sociológico, p.l).

\subsection{Análise Fatorial e o modelo de atributos}

Se é fato que o índice de preço hedônico sugerido por Lancaster (1996a, 1966b, 1971, 1991) é um instrumento útil como ferramenta de marketing, cumpre solucionar a questão: como calculá-lo na prática? Uma possível solução é utilizar uma técnica estatística multivariada chamada "análise fatorial".

A análise de fator é uma técnica que permite estudar variáveis que são interdependentes entre si, considerando todas simultaneamente. Hair Jr., Andersen, Tatham e Black (1998: cap. 3) discorrem sobre o uso exploratório dessa técnica, que permite estabelecer as relações entre as variáveis estudadas. Isto permite descobrir se de fato há interdependência entre as variáveis, qual é 
essa relação de interdependência e quais variáveis são mais importantes. Com isto, é possível depois utilizar outras técnicas para analisar os dados — pois já se sabe a estrutura (de relacionamentos entre as variáveis) do objeto estudado. Ademais, com o uso de "redução dos dados" (data reduction), é possível criar variáveis mais "manuseáveis" para a aplicação de outras técnicas - como a análise conjunta (conjoint analysis), por exemplo.

\subsection{A análise estatística}

\subsubsection{Influência Interpessoal}

A principal questão desta tese é saber se é possível mensurar a influência interpessoal na decisão de consumo. Obviamente, quanto mais próximas socialmente forem as pessoas, maior a probabilidade de haver influência social no consumo pessoal (Engel, Blackwel \& Miniard, 1994; Kotler \& Armstrong, 1991; Solomon, 2002). Daí a opção pela amostra bastante homogênea que foi analisada (ver seção 5.1 A Amostra, abaixo).

A técnica empregada, como já debatido nas seções anteriores (na seção 4.1 Análise Fatorial e o modelo de atributos) foi a análise fatorial. Pretendeu-se resumir todas as variáveis em fatores e verificar se nesses fatores as variáveis ligadas ao público do restaurante eram importantes (apresentavam 
alta carga fatorial).

\subsubsection{Identificação dos Tipos de Consumidores.}

Finalmente, tentou-se verificar as idéais propostas em Corneo e Jeanne (1994b) sobre os dois principais tipos de consumidores: formadores de opinião e seguidores de moda (conforme debatido na seção 3.2.1 "A importância do público que freqüenta o restaurante", acima). Neste caso foi realizada uma análise de conglomerados para tentar identificar e classificar os vários tipos de consumidores.

\subsection{Limitações do método de pesquisa}

\subsubsection{A técnica de análise de conglomerado}

Hair, Anderon, Tatham e Black (1998) apontam que a principal limitação do método estatístico de análise de conglomerado é a ausência de justificativa para os critérios utilizados. Estes devem ser justificados pela literatura específica do assunto pesquisado. $\mathrm{Na}$ ausência dessa literatura, seria a capacidade do pesquisador o juízo último para a seleção dos critérios utilizados. 
Aaker, Kumar e Day (1988: 585-6) afirmam que há ausência de "embasamento teórico estatístico abrangente". Assim, há muita subjetividade envolvida no uso dessa técnica. Finalmente, Aaaker et al. (1988: 595), Cooper e Schindler (2001: 473) e Malhotra (1999: 535-6) indicam que a solução encontrada depende do método de aglomeração utilizado. Métodos distintos geram conglomerados diferentes. Assim, novamente, depende-se da literatura do assunto estudado e da habilidade do pesquisador para se encontrar a solução correta.

\subsubsection{A técnica de análise fatorial}

A análise de fator é uma técnica que permite estudar variáveis que são interdependentes entre $\mathrm{si}$, considerando todas simultaneamente. Os autores discorrem no capítulo sobre o uso exploratório dessa técnica, o que permite estabelecer as relações entre as variáveis estudadas. Isto permite descobrir se de fato há interdependência entre as variáveis, qual é essa relação de interdependência e quais variáveis são mais importantes. Com isto, é possível depois utilizar outras técnicas para analisar os dados - pois já se sabe a estrutura (de relacionamentos entre as variáveis) do objeto estudado (Hair et al., 1998: cap. 3). O ponto a ressaltar neste caso é que se trata de técnica para pesquisa exploratória e seus resultados podem não ser conclusivos. Já Cooper e Schindler (2001: 468) afirmam que a interpretação dos fatores obtidos na análise é "altamente subjetiva". 


\subsection{Quais atributos pesquisar?}

A partir dos trabalhos teóricos discutidos nas seções anteriores, uma questão que se apresenta é a seguinte: ao se criar esse índice de preço hedônico (hedonic price index) para restaurantes, é possível incorporar a influência interpessoal como um dos atributos lancasterianos? E quais deveriam ser os outros atributos pesquisados em relação à demanda por restaurantes?

\subsubsection{Atributos existentes nos guias de restaurantes}

A última pergunta é, a princípio, mais fácil de ser respondida: trata-se de utilizar os critérios apresentados nos vários guias de restaurantes. Quanto aos outros atributos, não diretamente ligados à influência interpessoal entre os consumidores, um primeiro critério foi verificar quais eram os critérios utilizados por críticos de gastronomia em suas colunas publicadas em jornais e, principalmente, nos guias de restaurantes disponíveis para os consumidores. ${ }^{55}$

Por exemplo, tomem-se os critérios utilizados na coluna "Restaurantes", assinada pelo sr. Arnaldo Lorençato no jornal Gazeta Mercantil (ver anexo, ao final do texto, com todos os critérios utilizados pelos guias pesquisados). Para este estudo não se utilizou o critério "avaliação geral”, que aparentemente é uma "média" dos outros critérios utilizados pelo colunista: isto porque o índice de preço hedônico já será a média dos atributos. Não há sentido

55 Os critérios estão listados no anexo 8.3 Os critérios utilizados para a avaliação dos restaurantes nos guias pesquisados (para a cidade de São Paulo). Note-se que Melo (2003) é a versão impressa do sítio na "internet" www.guiajosimar.com.br. 
em usar a própria média no cálculo da média. Como a escala empregada pelo sr. Lorençato é uma escala ordinal, ${ }^{56}$ há sentido estatístico no cálculo do índice hedônico de Lancaster. Pois ao se empregar os conceitos "bom", "regular" etc., é possível transformá-los em números e, destarte, considerar essa escala como sendo uma escala ordinal e calcular-se a média. Note-se porém, que tal escala não é intervalar, pois não há como saber se a distância atribuída entre os conceitos "bom" e "regular" (ou entre "1" e "2") é a mesma para todos os entrevistados. ${ }^{57}$ Raciocínio semelhante serve para os critérios apresentados nos outros guias consultados para a realização desta tese.

Outro critério utilizado pelo crítico sr. Lorençato que pode ser alterado é "tipo de cozinha": neste caso, a questão é saber se a especialização é algo preferível ou não aos olhos do consumidor. Neste caso, o número realmente deve se referir à quantidade: 1 seria a especialização máxima (um único tipo de cozinha) e os vários " $n$ " ( $n>1)$ seriam o grau de ausência de especialização (um restaurante que servisse todos os tipos de comida). ${ }^{58}$ Se o estudo for realizado apenas para um único tipo de restaurante (pizzarias, por exemplo), esse critério não deve ser utilizado, pois perderia o sentido.

Por uma questão de praticidade, foram utilizados como base principalmente os critérios apresentados em Melo (2003). Este guia apresenta um

\footnotetext{
${ }^{56}$ Nas palavras de Malhotra (1999, p.239): "[Escala Ordinal:] Escala de graduação em que se atribuem números a objetos para indicar até que ponto possuem determinada característica. Assim, é possível determinar se um objeto possui essa característica em maior ou menor grau do que outro objeto."

${ }^{57}$ Uma vez mais citando Malhotra (1999, p.240): "[Escala Intervalar:] Escala em que se utilizam números para classificar objetos, de tal modo que distâncias numericamente iguais na escala representam distâncias iguais na característica que está sendo medida."

${ }^{58}$ Obviamente, o máximo número "n" possível é igual ao número de "cozinhas" ou tipos de culinárias existentes. A questão bizantina é se o n máximo seria o número de tipos de culinária disponíveis no município onde seria feita a pesquisa ou se todo o mundo (o planeta) seria considerado como o universo estatístico. No caso específico da cidade de São Paulo, considerando os guias pesquisados, $\mathrm{n}_{\max }=37$ (no guia do crítico Josimar Mello são listados 38 tipos de culinária, mas um dos tipos é uma chamado "variada", ou seja, um restaurante que sirva mais de um tipo de cozinha).
} 
manuseio mais simples, já conta com tabelas para fácil consulta e todos os atributos descritos podem ser transformados em variáveis dicotômicas ou binárias, o que facilita a análise. Houve ainda uma questão pragmática envolvida nessa escolha: uma editora que trabalha no site desse guia dispôs-se a colaborar com o trabalho de de pesquisa e foi possível consultá-la sobre eventuais dúvidas quanto às classificações e análises apresentadas no guia Melo (2003).

A partir disso, foi executado o seguinte procedimento: utilizando-se o modelo de comportamento do consumidor discutido em Engel, Blackwel e Miniard (1994), procedeu-se a uma análise de como um consumidor escolhe um restaurante, quais atributos são percebidos quando se está no restaurante e como - consumidor supostamente avaliaria sua experiência no restaurante. Os trabalhos que serviram de base para identificar as variáveis a serem pesquisadas foram Marvin (1992) e Dorf (1992). O primeiro texto é um manual prático sobre tudo o que um gerente de restaurante deve estar atento para surpreender favoravelmente ou, ao menos, não desagradar seus consumidores. Já Dorf (1992) é um livro que discute a história do conceito de restaurante, apresenta técnicas de gerenciamento e casos de sucesso (sobretudo norte-americanos). O resultado final foi o questionário que está apresentado no anexo 8.1, abaixo nesta tese.

\subsubsection{Atributos usados para constatar a influência interpessoal}

No caso da influência interpessoal, é preciso levar em conta dois pontos: o primeiro, e enfatizado no texto de Becker (1991), é que se essa influência for significativa, a inclinação e mesmo o formato da curva de demanda 
agregada pode ser distinto dos usualmente apresentados nos livros de microeconomia (como, por exemplo, Pindyck \& Rubinfeld, 1991; ou Petersen \& Lewis, 1994). Se a curva de demanda for como a apresentada por Becker (1991), é mister notar que um mesmo preço pode apresentar duas demandas distintas: na primeira, haveria excesso de oferta em relação à demanda, na segunda, aconteceria oposto. Ou seja, pode haver restaurantes quase vazios e restaurantes superlotados (o fenômeno da moda discutido em Corneo \& Jeanne, 1994b). O segundo ponto digno de nota é que uma forma de explicar isso é aceitar como premissa que não há um único consumidor (como o fazem Becker, 1991, em particular e os teóricos neoclássicos em geral). Neste caso, é mister incorporar a diferenciação proposta por Corneo e Jeanne (1994b) de dois tipos de consumidores. Novamente, a questão é como incorporar isto no modelo de atributos proposto por Lancaster (1966a, 1966b, 1969, 1971 e 1991).

Para medir a influência interpessoal foram feitas afirmações do tipo "eu freqüento este restaurante porque...". Os critérios utilizados foram: pessoas que convido para ir comigo, amigos, parentes e cônjuges, pessoas famosas, pessoas importantes para o trabalho, pessoas com status diferenciado, gente da minha idade, filhos e "gente como eu" (para indicar a preferência por pessoas da mesma classe social). Foram acrescidos ainda dois critérios: "muita gente" e "pouca gente", sobre a lotação (movimento) do restaurante e um critério por negação: "eu não me importo com as pessoas que estão no restaurante". Finalmente, foi feita uma pergunta direta sobre a importância de o lugar estar na moda ou não.

Em relação a todos os critérios foram apresentados ao respondente uma escala de cinco pontos: "concordo plenamente/ concordo/ indiferente/ discordo/ discordo plenamente". Resumindo, os atributos avaliados pelos entrevistados foram os seguintes: 
Quadro 3: Atributos pesquisados de um restaurante

\begin{tabular}{ll}
\hline Atributos físicos do restaurante & Atributos referentes ao público que freqüenta o restaurante \\
\hline & V1 são as pessoas que consumidor convidou para acompanhá- \\
& lo; \\
& V2 são as pessoas que acompanham o consumidor ao \\
& restaurante;
\end{tabular}

V3 é o tipo de comida oferecida no restaurante;

V4 é a rapidez no atendimento;

V5 é o preço;

V6 é a localização;

V7 é a proximidade do restaurante em relação à casa do consumidor;

V8 é a proximidade do restaurante em relação ao local de trabalho do

consumidor;

V9 é forma como o consumidor se veste;*

V10 é o horário de funcionamento do restaurante;

V11 é o estacionamento do restaurante;

V12 é a existência de manobrista no estacionamento do restaurante;

V13 é a presença de maitre/hostess no restaurante;

V14 é a existência de sala de espera no restaurante;

V15 é a decoração do restaurante;

V16 é a existência de bar no restaurante;

V17 é o público que freqüenta o restaurante;

V18 é a presença de amigos do consumidor no restaurante;

V19 indica se o restaurante é um lugar da moda (ou não);

V20 é a presenaça de pessoas semelhantes ao consumidor no restaurante ("gente como eu");

V21 é a presenta de pessoas com status social diferenciado no restaurante (na opinião do consumidor)

V22 indica se o consumidor julga o restaurante um lugar propício para levar seus filhos;

V23 é a presença de pessoas no restaurante que estejam na

mesma faixa etária do consumidor;

V24 indica o quanto o consumidor julga agradável a atmosfera do restaurante; V25 indica o quanto o consumidor julga agradável o ambiente físico do restaurante;

V33 indica a exitência de sala privativa no restaurante;

V34 indica a existência de área para fumantes;

V35 indica o quanto o restaurante é limpo;

V36 indica o grau de silêncio no restaurante;

V37 indica a existência de música no restaurante;

V38 signfica que o cardápio do restaurante é compreensível;

V39 significa que o restaurante oferece uma grande variedade de pratos;

V40 significa que o restaurante oferece uma pequena variedade de pratos;

V41 significa que o restaurante tem uma carta de vinhos;

V42 é a apresentação dos pratos;

V43 é a qualidade da comida servida;

V44 indica a aceitação de cartão de crédito como forma de pagamento;

V45 indica a aceitação de cheque como forma de pagamento;

V46 indica a aceitação de ticket como forma de pagamento; e

V47 é a qualidade do serviço;

${ }^{*}$ A forma como o consumidor se veste pode ou não estar relacionada com o público do lugar, daí esta variável estar localizada entre as duas colunas.

V26 é a presença de pessoas conhecidas do consumidor no restaurante;

V27 é a presença de muita gente no restaurante;

V28 é a presença de poucas pessoas no restaurante;

V29 é a presença de pessoas famosas no restaurante

V30 é a presença no restaurante de pessoas importantes para o trabalho do consumidor;

V31 é a presença de clientes no restaurante que reconhecem quem é o consumidor;

V32 indica o quanto é (ou não) a importância das outras pessoas que estão no restaurante para o consumidor; 


\subsubsection{A construção do índice de preços hedônicos}

O índice de preço hedônico foi construído a partir dos resultados das análises fatoriais. Foram sugeridas duas formas de se mensurar os atributos: a partir dos centróides dos conglomerados - construídos a partir dos fatores (técnica que segue a forma de analisar os dados proposta em Malhotra, 1999). A segunda foi utilizar os coeficientes gerados por uma análise discriminante feita para confirmar a análise de conglomerados como ponderadores dos atributos utilizados. 


\subsection{Figura: A síntese da pesquisa}

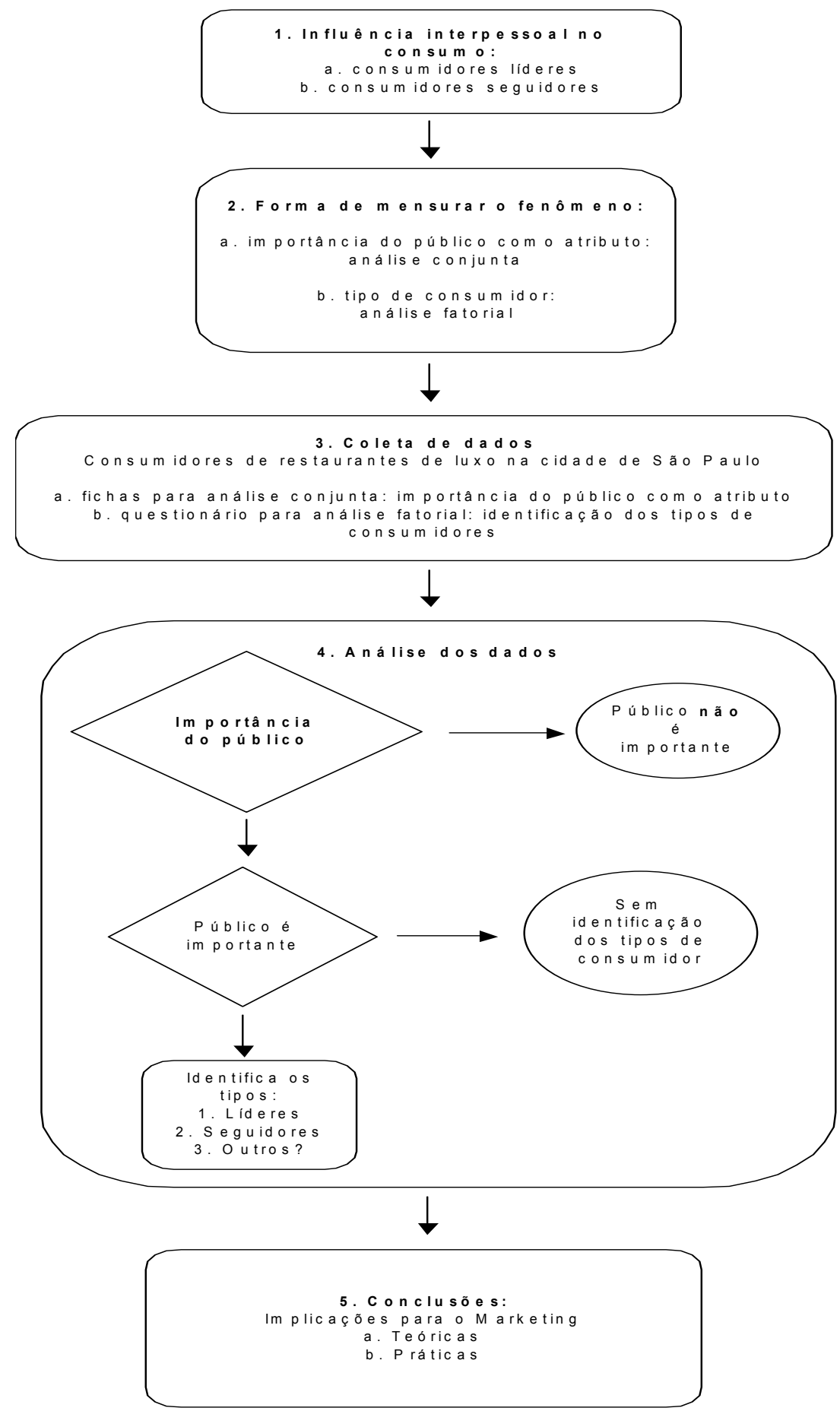




\title{
5. ANÁLISE DOS DADOS: A Construção de um Índice De preços hedônicos para a Cidade de São Paulo
}

\author{
"Quem trabalha com o método analítico nunca pode \\ esquecer que a realidade é bem mais ricas do que \\ as tipologias abstratas, que devem ser \\ continuamente revistas para dar conta dos novos \\ dados ou de novas interpretações dos dados já \\ conhecidos."
}

Norberto Bobbio

\subsection{A Amostra}

A amostra foi tomada da população de estudantes universitários dos principais cursos de Administração e Propaganda da cidade de São Paulo.

O procedimento utilizado para a obtenção dos dados foi contatar professores que ministrassem disciplinas nas escolas USP, FAAP, ESPM e Universidade Mackenzie e pedir que aplicassem o questionário em aula. Foram distribuídos 200 questionários, dos quais 134 foram retornados e 123 utilizados na análise.

A idéia foi entrevistar usuários de restaurantes que supostamente 
oferecessem o mesmo tipo de serviço e produto, tornando-os (no sentido de marketing do termo) comparáveis. Pois a hipótese principal deste trabalho e da tese subseqüente é que os consumidores se influenciam mutuamente.

Embora o universo pesquisado seja limitado, a amostra foi, na medida do possível, aleatória, pois os estudantes não eram conhecidos e tinham a mesma probabilidade de serem entrevistados.

O instrumento de coleta (questionário) está apresentado no Anexo 8.1 Questionário Utilizado Na Pesquisa.

A amostra é composta da seguinte forma: a maioria dos entrevistados (70 pessoas ou $56,9 \%$ ) é composta por mulheres, por pessoas com idade entre 21 e 25 anos (71 pessoas ou $57,7 \%$ ), solteiros (108 pessoas ou $87,8 \%$ ):

Tabela 1: Composição da Amostra por Sexo

\begin{tabular}{l|rrr}
\hline & Homens & Mulheres & Total \\
& 53 & 70 & 123 \\
Freqüência & & & \\
Porcentagem & 43,1 & 56,9 & 100 \\
\hline
\end{tabular}

\section{Gráfico 1:Composição da Amostra por Sexo}

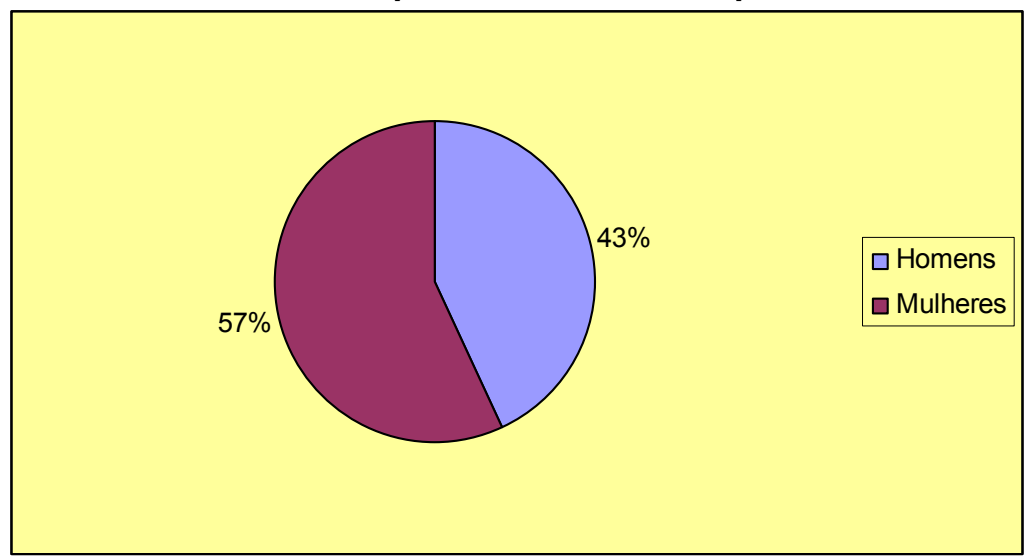

Tabela 2: Composição da Amostra por Faixa Etária

\begin{tabular}{c|cc}
\hline & Freqüência & Porcentagem \\
\hline 18 a 20 anos & 29 & 23,6 \\
\hline
\end{tabular}




\begin{tabular}{c|cc}
\hline 21 a 25 anos & 71 & 57,7 \\
\hline 26 a 30 anos & 7 & 5,7 \\
\hline 31 a 40 anos & 13 & 10,6 \\
\hline 40 a 40 anos & 2 & 1,6 \\
\hline mais de 50 anos & 1 & 0,8 \\
\hline Total & 123 & 100 \\
\hline
\end{tabular}

Gráfico 2:Composição da Amostra por Faixa Etária

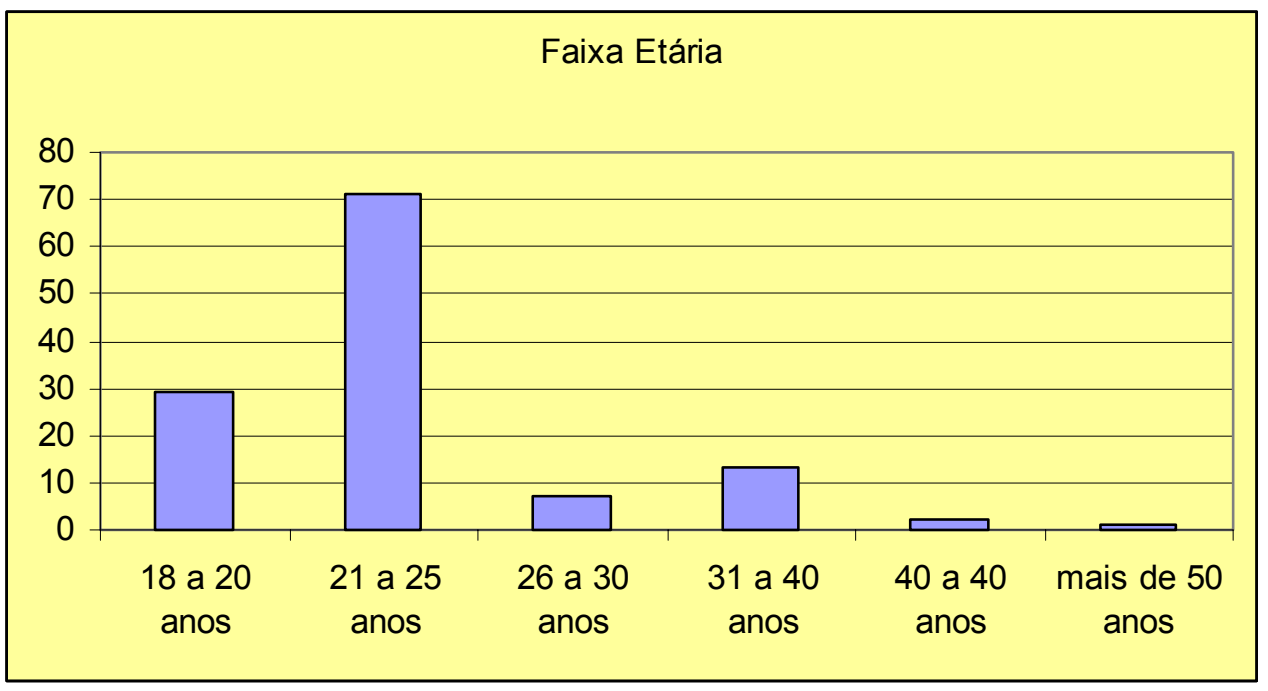

Tabela 3: Composição da Amostra por Estado Civil

\begin{tabular}{c|cc}
\hline & Freqüência & Porcentagem \\
\hline Solteiro(a) & 108 & 87,8 \\
Casado(a) & 13 & 10,6 \\
Separado(a) & 1 & 0,8 \\
Viúvo(a) & 1 & 0,8 \\
\hline Total & 123 & 100 \\
\hline
\end{tabular}


Gráfico 3:Composição da Amostra por Estado Civil

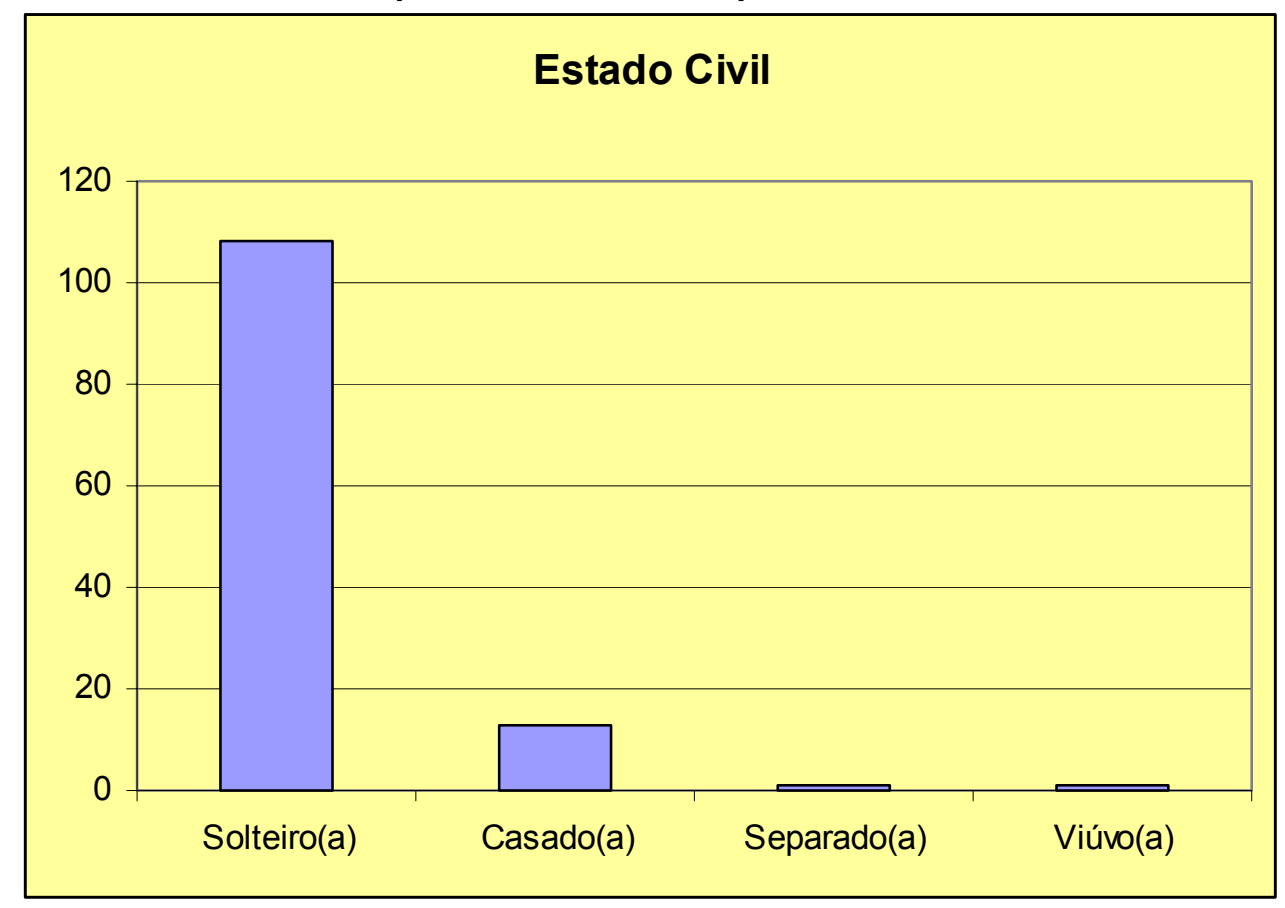

Quanto à classe social, a estimativa foi realizada segundo o chamado "Critério Brasil" da ANEP (Associação Nacional das Empresas de Pesquisa de Mercado). ${ }^{59}$ A maioria dos entrevistados (66 pessoas ou $53,7 \%$ ) pertencem à classe A (A1 e A2). Esta proporção foi intencional, pois seria necessário que essas pessoas conhecessem e freqüentassem restaurantes, para que pudessem avaliar a forma como escolhem um para ir - daí a opção por entrevistar estudantes nas escolas e cursos selecionados.

Tabela 4: Distribuição da Amostra por Classe Social

\begin{tabular}{c|cc}
\hline & Freqüência & Porcentagem \\
\hline A1 & 23 & 18,7 \\
A2 & 43 & 35 \\
B1 & 33 & 26,8 \\
B2 & 18 & 14,6 \\
C & 6 & 4,9 \\
\hline Total & 123 & 100 \\
\hline
\end{tabular}

${ }^{59}$ Os critérios de classificação estão disponíveis no sítio da entidade (ANEP) na internet (www.anep.org.br). 


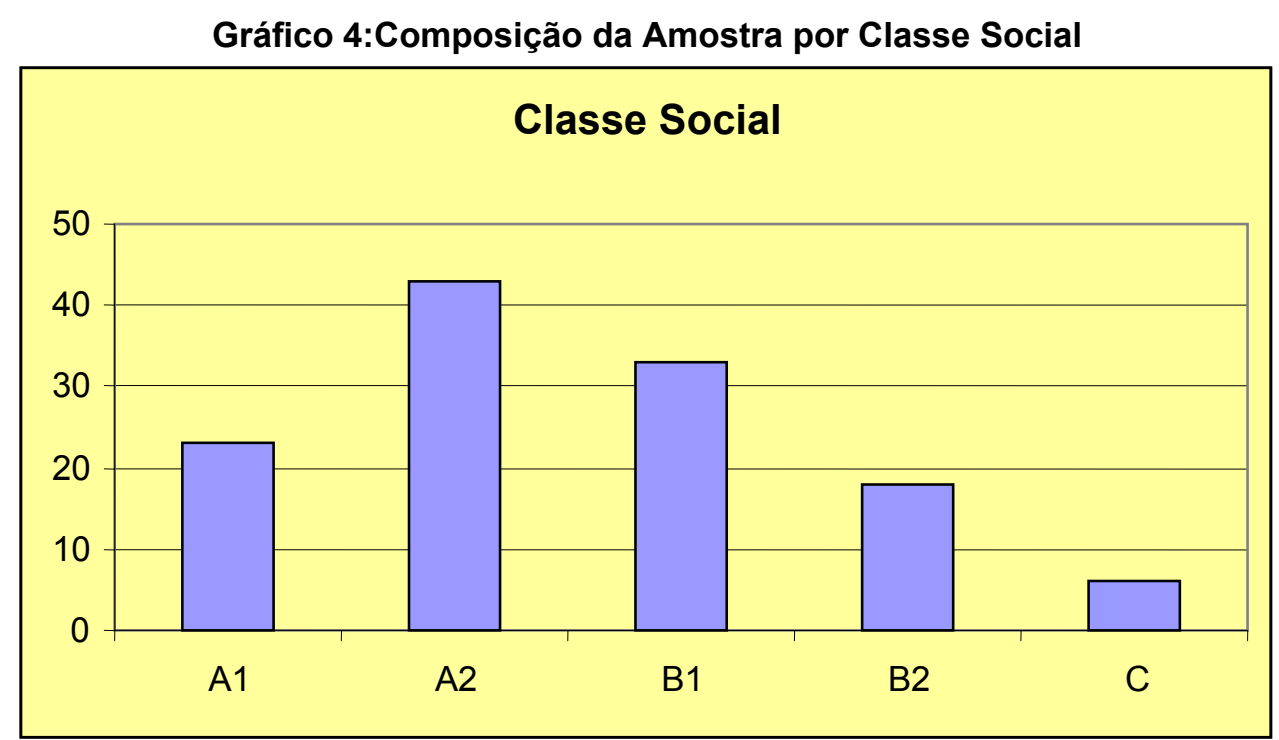

Há uma predominância de mulheres de classe A (A1 e A2) e homens de classe B (B1 e B2) na amostra pesquisada, como é possível observar na tabela abaixo:

Tabela 5: Composição da amostra por Clase Social (Simplificada) e Sexo

\begin{tabular}{l|rrrr}
\hline & \multicolumn{5}{|c}{ Números Absolutos } \\
\hline Homens & A & B & C & \multicolumn{1}{c}{ Total } \\
Mulheres & 22 & 29 & 2 & 53 \\
\hline Total & 44 & 22 & 4 & 70 \\
\hline & 66 & 51 & 6 & 123 \\
\hline & A & B & C & Total \\
Homens & $17,9 \%$ & $23,6 \%$ & $1,6 \%$ & $43,1 \%$ \\
Mulheres & $35,8 \%$ & $17,9 \%$ & $3,3 \%$ & $56,9 \%$ \\
\hline Total & $53,7 \%$ & $41,5 \%$ & $4,9 \%$ & $100 \%$ \\
\hline
\end{tabular}

Quanto às diferenças entre sexo e idades, há um predomínio de pessoas com idade entre 21 a 25 anos $(57,7 \%)$, porém há mais mulheres na faixa entre 18 e 20 anos (17,1\% do total da amostra, versus $6,5 \%$ de homens) e uma predominância de homens na faixa etária acima de 30 anos $(8,9 \%$ do total da amostra, versus $4,1 \%$ de mulheres) (ver Tabela 6 abaixo): 
Tabela 6: Composição da amostra por Faixa Etária e Sexo

\begin{tabular}{|c|c|c|c|c|c|c|c|}
\hline & \multicolumn{3}{|c|}{ Números Absolutos } & & \multicolumn{3}{|c|}{ Porcentagens } \\
\hline & Homens & Mulheres & Total & & Homens & Mulheres & Total \\
\hline 18 a 20 anos & 8 & 21 & 29 & 18 a 20 anos & $6,5 \%$ & $17,1 \%$ & $23,6 \%$ \\
\hline 21 a 25 anos & 32 & 39 & 71 & 21 a 25 anos & $26,0 \%$ & $31,7 \%$ & $57,7 \%$ \\
\hline 26 a 30 anos & 2 & 5 & 7 & 26 a 30 anos & $1,6 \%$ & $4,1 \%$ & $5,7 \%$ \\
\hline 31 a 40 anos & 9 & 4 & 13 & 31 a 40 anos & $7,3 \%$ & $3,3 \%$ & $10,6 \%$ \\
\hline 40 a 40 anos & 1 & 1 & 2 & 40 a 40 anos & $0,8 \%$ & $0,8 \%$ & $1,6 \%$ \\
\hline mais de 50 anos & 1 & & 1 & mais de 50 anos & $0,8 \%$ & $0,0 \%$ & $0,8 \%$ \\
\hline Total & 53 & 70 & 123 & Total & $43,1 \%$ & $56,9 \%$ & $100 \%$ \\
\hline
\end{tabular}

Finalmente, a Tabela 7 abaixo mostra que em relação à distribuição dos entrevistados em relação à classe social (simplificada) e faixa etária, há um predomínio de pessoas entre 21 a 25 anos da classe A (A1 e A2) (33,3\% dos entrevistados), seguido pelo conjunto de pessoas da mesma faixa etária pertencentes à classe B (B1 e B2) (22,8\% dos entrevistados). Note-se que entre as pessoas mais velhas (maiores de 30 anos), a maioria está na classe B (13,8\% da amostra, versus $4,9 \%$ de pessoas da mesma idade que pertencem à classe A) e não há pessoas dessa faixa etária que estão na classe C.

Tabela 7: Composição da amostra por Faixa Etária e Classe Social (Simplificada)

\begin{tabular}{|c|c|c|c|c|c|c|c|c|c|}
\hline & \multicolumn{4}{|c|}{ Número Absolutos } & & \multicolumn{4}{|c|}{ Porcentagens } \\
\hline & A & B & C & Total & & A & B & C & Total \\
\hline $\begin{array}{c}18 \text { a } 20 \\
\text { anos }\end{array}$ & 19 & 6 & 4 & 29 & $\begin{array}{c}18 \text { a } 20 \\
\text { anos }\end{array}$ & $15,4 \%$ & $4,9 \%$ & $3,3 \%$ & $23,6 \%$ \\
\hline $\begin{array}{c}21 \text { a } 25 \\
\text { anos }\end{array}$ & 41 & 28 & 2 & 71 & $\begin{array}{c}21 \text { a } 25 \\
\text { anos }\end{array}$ & $33,3 \%$ & $22,8 \%$ & $1,6 \%$ & $57,7 \%$ \\
\hline $\begin{array}{c}26 \text { a } 30 \\
\text { anos }\end{array}$ & 1 & 6 & 0 & 7 & $\begin{array}{c}26 \text { a } 30 \\
\text { anos }\end{array}$ & $0,8 \%$ & $4,9 \%$ & $0,0 \%$ & $5,7 \%$ \\
\hline $\begin{array}{c}31 \\
\text { anos } \\
\text { ou } \\
\text { mais } \\
\end{array}$ & 5 & 11 & 0 & 16 & $\begin{array}{c}31 \\
\text { anos } \\
\text { ou } \\
\text { mais } \\
\end{array}$ & $4,1 \%$ & $8,9 \%$ & $0,0 \%$ & $13,0 \%$ \\
\hline Total & 66 & 51 & 6 & 123 & Total & $53,7 \%$ & $41,5 \%$ & $4,9 \%$ & $100 \%$ \\
\hline
\end{tabular}




\subsection{Os dados}

Os dados foram obtidos mediante a aplicação de questionários estruturados com estudantes universitários dos cursos de Administração das seguintes faculdades: FEA/USP, Faap, ESPM e Universidade Mackenzie. Foi aplicado um questionário com questões abertas e fechadas ao alunos dessas instituições. De 200 questionários aplicados, foram devolvidos 134. Destes, 123 foram utilizados na análise. Os questionários restantes estavam em branco ou com preenchimento incompleto ou incorreto e não puderam ser aproveitados.

O questionário utilizado está apresentado no Anexo 1 desta tese. Esse instrumento de coleta contém questões abertas e fechadas e foi testado em colegas de Pós-Graduação na FEA/USP.

A amostra é aleatória dentro do Universo pesquisado, portanto, os resultados obtidos não podem ser extrapolados para outros consumidores que não estudantes universitários do curso de Administração nas principais escolas de São Paulo.

\subsection{Análise dos dados}

Nesta seção são apresentadas as análises feitas para se chegar ao índice de preço hedônico. Primeiro, foi realizada uma análise fatorial para resumir as 47 variáveis pesquisadas (os "atributos" de Lancaster, conforme discutido nos 
capítulos anteriores) em um conjunto de fatores. ${ }^{60}$ Depois, utilizando os fatores encontrados, foi executada uma análise de conglomerados, para verificar se seria possível agrupar os consumidores em grupos que fossem distintos uns dos outros - ou seja, verificar a existência de segmentos de consumidores no mercado estudado. Finalmente, a partir desses conglomerados, foi calculado um índice de preços hedônicos para cada um dos segmentos de consumidores - tentando verificar a importância do público que freqüenta o restaurante como um atributo considerado por esses consumidores.

\subsubsection{Análise Fatorial}

A primeira análise dos dados realizada foi a análise fatorial. O principal objetivo desse tipo de análise é agrupar um conjunto de variáveis em uma nova variável ou fator. Outro resultado da aplicação dessa técnica aos dados é descobrir se há uma estrutura subjacente entre as variáveis pesquisadas, ou seja, como estas se relacionam entre si.

Esse agrupamento (fatoração) tem por base as correlações entre as variáveis. As variáveis mais correlacionadas entre si são transformadas em fatores. O resultado obtido com o emprego dessa técnica é discutido a seguir.

Utilizou-se o método dos componentes principais para fazer essa análise. Esse método, segundo Malhotra (1999: 507-8), leva em conta a variância total nos dados. O emprego desse método é recomendado quando o objetivo é "determinar o número mínimo de fatores que respondem pela máxima

\footnotetext{
60 Todas as análises foram feitas utilizando-se o programa de computador ("software") Statistical Package for Social Sciences for Windows versão 10.0.1 (SPSS 10.0.1).
} 
variância nos dados em análises multivariadas subseqüentes"

(Malhotra, 1999: 507)

É este exatamente o objetivo desta análise: reduzir as variáveis a fatores (os componentes principais) e utilizar esses fatores obtidos em uma análise de conglomerado.

O primeiro cálculo realizado na análise fatorial é o da comunalidade das variáveis empregadas. Essa medida mostra o quanto da variância de cada variável é partilhada com as outras (Hair et al., 1998: 88 e 100). Quanto maior for essa medida, mais as variáves estão correlacionadas entre si. As comunalidades obtidas para cada variável estão indicadas na Tabela 8: Comunalidades Obtidas Com A Análise Fatorial apresentada abaixo. O ponto a ser destacado é que todas as comunalidades encontradas foram superiores a $0,5-0$ que indica o quanto as variáveis explicam a variância.

Tabela 8: Comunalidades Obtidas Com A Análise Fatorial

\begin{tabular}{l|ll}
\hline Variáveis & Initial & Extraction \\
\hline pessoas que convido & 1 & 0,652 \\
pessoas que estão comigo & 1 & 0,736 \\
tipo de comida & 1 & 0,732 \\
rapidez no atendimento & 1 & 0,727 \\
Eu escolho o restaurante pelo preço & 1 & 0,835 \\
Localização & 1 & 0,718 \\
minha casa & 1 & 0,649 \\
meu trabalho & 1 & 0,791 \\
forma como me visto normalmente & 1 & 0,661 \\
HORÁRIO & 1 & 0,659 \\
estacionamento & 1 & 0,718 \\
Manobrista & 1 & 0,685 \\
maitre/hostess & 1 & 0,793 \\
\hline
\end{tabular}




\begin{tabular}{|c|c|c|}
\hline Variáveis & Initial & Extraction \\
\hline sala de espera & 1 & 0,753 \\
\hline Decoração & 1 & 0,655 \\
\hline BAR & 1 & 0,708 \\
\hline público que freqüenta o lugar & 1 & 0,577 \\
\hline AMIGOS & 1 & 0,61 \\
\hline MODA & 1 & 0,659 \\
\hline gente como eu & 1 & 0,719 \\
\hline status social diferenciado & 1 & 0,708 \\
\hline meus filhos & 1 & 0,654 \\
\hline gente da minha idade & 1 & 0,643 \\
\hline atmosfera agradável & 1 & 0,773 \\
\hline ambiente ao meu gosto & 1 & 0,793 \\
\hline pessoas me conhecem & 1 & 0,738 \\
\hline muita gente & 1 & 0,777 \\
\hline poucas pessoas & 1 & 0,676 \\
\hline pessoas famosas & 1 & 0,736 \\
\hline Pessoas importantes para o trabalho & 1 & 0,783 \\
\hline outros clientes me reconhece & 1 & 0,771 \\
\hline não me importo com as pessoas & 1 & 0,586 \\
\hline sala privativa & 1 & 0,708 \\
\hline FUMANTES & 1 & 0,602 \\
\hline LIMPEZA & 1 & 0,612 \\
\hline SILÊNCIO & 1 & 0,675 \\
\hline MÚSICA & 1 & 0,695 \\
\hline Cardápio compreensível & 1 & 0,661 \\
\hline grande variedade de pratos & 1 & 0,795 \\
\hline pequena variedade de pratos & 1 & 0,768 \\
\hline carta de vinhos & 1 & 0,591 \\
\hline Apresentação dos pratos & 1 & 0,671 \\
\hline qualidade da comida & 1 & 0,691 \\
\hline cartão de crédito & 1 & 0,683 \\
\hline CHEQUE & 1 & 0,751 \\
\hline
\end{tabular}




\begin{tabular}{l|ll}
\hline Variáveis & Initial & Extraction \\
\hline TICKET & 1 & 0,695 \\
\hline qualidade do serviço & 1 & 0,757 \\
\hline
\end{tabular}

A seguir, foi realizada a extração dos fatores propriamente ditos. 0 critério para a seleção de cada fator para posterior utilização nas outras análises foi o autovalor ("eigenvalue"), que deveria ser no mínimo igual a um (1). Como aponta Malhotra (1999: 508), é possível determinar o número de fatores de seis maneiras: 1) fixar o número de fatores a priori; 2) baseado nos autovalores; 3) com base em na declividade de um gráfico (o gráfico "scree-plot" é obtido representando o autovalor de cada fator nas ordenadas e o fator obtido no eixo das abcissas); 4) fixando uma percentagem da variância ; 5) com base na "confiabilidade meio a meio"; ou 6) com base em testes de significância. Nesta tese optou-se por determinar o número de fatores com base nos autovalores, seguindo Malhotra (1999). Esse autor indica que autovalores menores do que 1,0 "não são melhores do que uma variável isolada" (Malhotra, 1999: 508) e, portanto, a análise fatorial perderia seu sentido de reduzir as variáveis a fatores.

Seguindo essa regra de considerar apenas fatores com autovalor superior a 1,0, foram obtidos quinze (15) fatores, como é possível constatar pela Tabela 9: Total da Variância Explicada apresentada a seguir: 
Tabela 9: Total da Variância Explicada

\begin{tabular}{|c|c|c|c|c|c|c|c|c|c|}
\hline \multirow[b]{2}{*}{ Component } & \multicolumn{3}{|c|}{ Initial Eigenvalues } & \multicolumn{3}{|c|}{$\begin{array}{c}\text { Extraction Sums of Squared } \\
\text { Loadings }\end{array}$} & \multicolumn{3}{|c|}{$\begin{array}{c}\text { Rotation Sums of Squared } \\
\text { Loadings }\end{array}$} \\
\hline & Total & $\begin{array}{c}\% \text { of } \\
\text { Variance }\end{array}$ & $\underset{\%}{\text { Cumulative }}$ & Total & $\begin{array}{c}\% \text { of } \\
\text { Variance }\end{array}$ & $\underset{\%}{\text { Cumulative }}$ & Total & $\begin{array}{c}\% \text { of } \\
\text { Variance }\end{array}$ & $\underset{\%}{\text { Cumulative }}$ \\
\hline 1 & 8,386 & 17,843 & 17,843 & 8,386 & 17,843 & 17,843 & 4,587 & 9,759 & 9,759 \\
\hline 2 & 3,15 & 6,702 & 24,546 & 3,15 & 6,702 & 24,546 & 3,388 & 7,209 & 16,968 \\
\hline 3 & 2,955 & 6,287 & 30,833 & 2,955 & 6,287 & 30,833 & 2,656 & 5,652 & 22,62 \\
\hline 4 & 2,332 & 4,962 & 35,795 & 2,332 & 4,962 & 35,795 & 2,389 & 5,082 & 27,703 \\
\hline 5 & 2,057 & 4,376 & 40,171 & 2,057 & 4,376 & 40,171 & 2,269 & 4,828 & 32,531 \\
\hline 6 & 1,857 & 3,951 & 44,122 & 1,857 & 3,951 & 44,122 & 2,051 & 4,364 & 36,895 \\
\hline 7 & 1,79 & 3,808 & 47,931 & 1,79 & 3,808 & 47,931 & 2,038 & 4,336 & 41,231 \\
\hline 8 & 1,543 & 3,282 & 51,213 & 1,543 & 3,282 & 51,213 & 2,011 & 4,278 & 45,509 \\
\hline 9 & 1,464 & 3,114 & 54,327 & 1,464 & 3,114 & 54,327 & 1,926 & 4,098 & 49,607 \\
\hline 10 & 1,41 & 3 & 57,327 & 1,41 & 3 & 57,327 & 1,905 & 4,053 & 53,659 \\
\hline 11 & 1,357 & 2,888 & 60,215 & 1,357 & 2,888 & 60,215 & 1,822 & 3,877 & 57,537 \\
\hline 12 & 1,292 & 2,748 & 62,963 & 1,292 & 2,748 & 62,963 & 1,711 & 3,64 & 61,176 \\
\hline 13 & 1,199 & 2,552 & 65,515 & 1,199 & 2,552 & 65,515 & 1,532 & 3,259 & 64,435 \\
\hline 14 & 1,166 & 2,48 & 67,995 & 1,166 & 2,48 & 67,995 & 1,379 & 2,935 & 67,37 \\
\hline 15 & 1,073 & 2,283 & 70,278 & 1,073 & 2,283 & 70,278 & 1,367 & 2,908 & 70,278 \\
\hline 16 & 0,999 & 2,126 & 72,404 & & & & & & \\
\hline 17 & 0,965 & 2,054 & 74,457 & & & & & & \\
\hline 18 & 0,902 & 1,919 & 76,377 & & & & & & \\
\hline 19 & 0,87 & 1,852 & 78,228 & & & & & & \\
\hline 20 & 0,808 & 1,72 & 79,948 & & & & & & \\
\hline 21 & 0,735 & 1,563 & 81,511 & & & & & & \\
\hline 22 & 0,642 & 1,365 & 82,876 & & & & & & \\
\hline 23 & 0,602 & 1,281 & 84,157 & & & & & & \\
\hline 24 & 0,588 & 1,251 & 85,408 & & & & & & \\
\hline 25 & 0,555 & 1,18 & 86,588 & & & & & & \\
\hline 26 & 0,533 & 1,134 & 87,721 & & & & & & \\
\hline 27 & 0,524 & 1,115 & 88,836 & & & & & & \\
\hline 28 & 0,497 & 1,057 & 89,893 & & & & & & \\
\hline 29 & 0,449 & 0,956 & 90,849 & & & & & & \\
\hline 30 & 0,407 & 0,866 & 91,715 & & & & & & \\
\hline 31 & 0,39 & 0,83 & 92,545 & & & & & & \\
\hline 32 & 0,368 & 0,784 & 93,329 & & & & & & \\
\hline 33 & 0,348 & 0,74 & 94,069 & & & & & & \\
\hline 34 & 0,341 & 0,725 & 94,794 & & & & & & \\
\hline 35 & 0,306 & 0,651 & 95,445 & & & & & & \\
\hline 36 & 0,289 & 0,615 & 96,06 & & & & & & \\
\hline 37 & 0,238 & 0,506 & 96,565 & & & & & & \\
\hline 38 & 0,232 & 0,494 & 97,059 & & & & & & \\
\hline 39 & 0,226 & 0,48 & 97,54 & & & & & & \\
\hline 40 & 0,198 & 0,42 & 97,96 & & & & & & \\
\hline 41 & 0,172 & 0,366 & 98,326 & & & & & & \\
\hline 42 & 0,169 & 0,359 & 98,685 & & & & & & \\
\hline 43 & 0,152 & 0,324 & 99,009 & & & & & & \\
\hline 44 & 0,144 & 0,305 & 99,314 & & & & & & \\
\hline 45 & 0,125 & 0,265 & 99,579 & & & & & & \\
\hline 46 & 0,108 & 0,23 & 99,809 & & & & & & \\
\hline 47 & $8,97 \mathrm{E}-02$ & 0,191 & 100 & & & & & & \\
\hline
\end{tabular}


Note-se que por essa Tabela 9: Total da Variância Explicada, é possível visualizar o total da variância explicada pelos quinze fatores obtidos é de $70 \%$, aproximadamente.

Essa análise indicou a possibilidade de redução das 46 variáveis originais em quinze (15) fatores. Todos os quinze fatores obtidos na análise fatorial e as respectivas variáveis agrupadas estão na Tabela 10: Matriz Após a Rotação dos Fatores mostrada abaixo. Os critérios para a alocação de cada variável no fator foram dois: 1) apresentar uma carga fatorial maior do de 0,45 ou menor do que -0,45; e 2) quando o critério anterior gerasse mais de uma carga fatorial com escores superiores a [0,45] $(0,45$ em módulo), apresentou-se somente a variável com maior carga fatorial. Isto porque a carga fatorial representa a correlação entre os fatores e as variáveis (Malhotra, 1999: 510) e a intenção da análise é reduzir as variáveis a fatores. Não há sentido em incluir a mesma variável em dois ou mais fatores gerados, pois neste caso não haveria a redução objetivada. Os fatores obtidos foram os seguintes (os números entre parênteses são negativos): 
Tabela 10: Matriz Após a Rotação dos Fatores (Componentes)

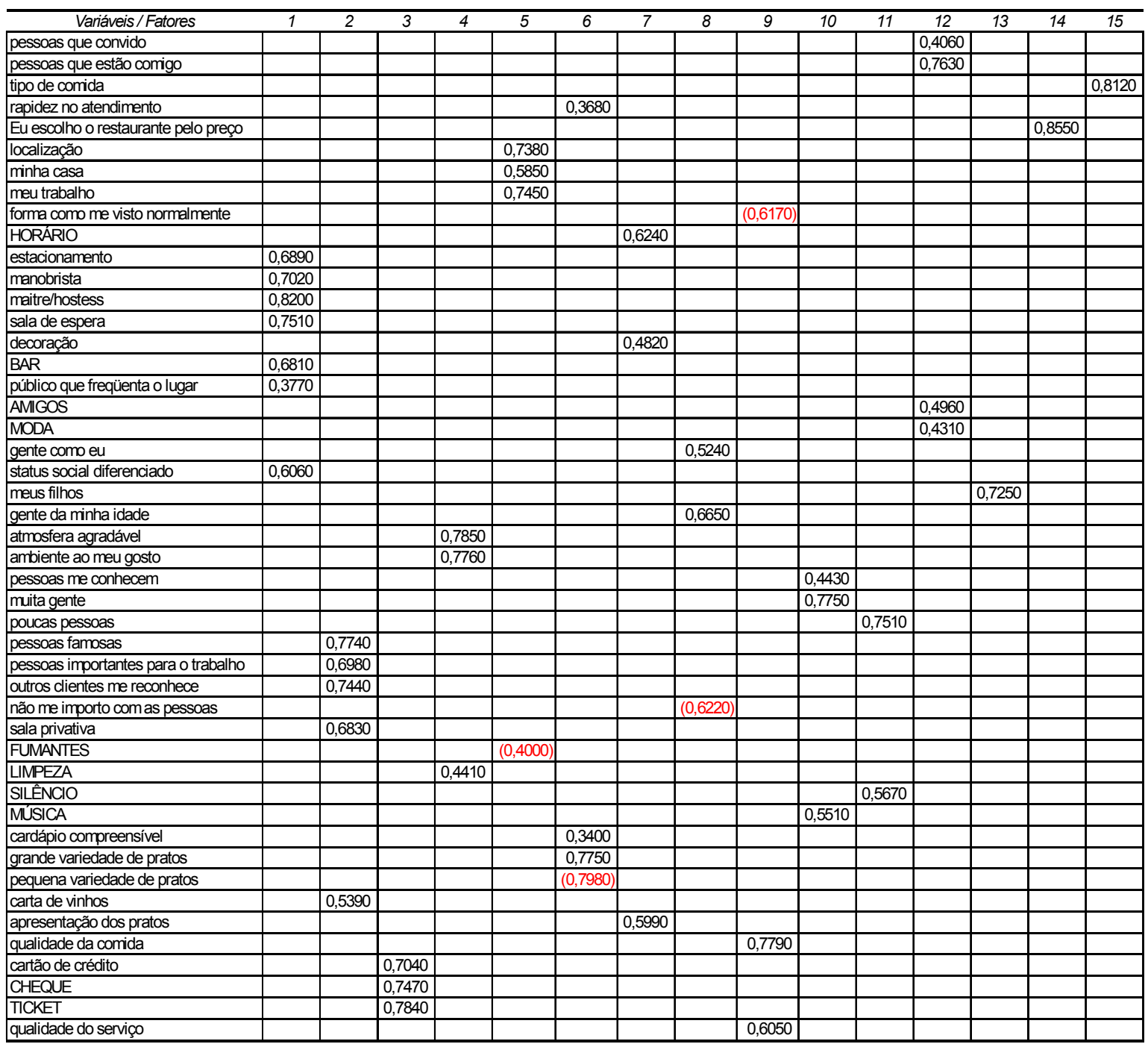

Cumpre destacar algumas exceções ao critério de apresentação das variáveis em relação à Tabela 10: Matriz Após a Rotação dos Fatores apresentada acima. A variável "pessoas que estão comigo" não apresentou carga fatorial superior a $[0,45](0,45$ em módulo) em nenhum dos fatores. Assim, utilizou-se a maior carga fatorial calculada. O mesmo raciocínio, aproveitamento da maior carga fatorial disponível, se aplicou para as variáveis "limpeza" (carga fatorial de 0,4410); "pessoas me conhecem" $(0,4430)$; "moda" $(0,4310)$, "rapidez no atendimento"(0,3680); "público que freqüenta o lugar" $(0,3770)$; "área para fumantes"(-0,4000) e "cardápio compreensível"(0,3400). 
Após a redução das variáveis em fatores, estabeleu-se que os dez (10) primeiros seriam utilizados na análise subseqüente, a saber, a análise de conglomerado (ou análise de "cluster"). Os fatores usados nessa outra análise são os seguintes:

Tabela 11: Descrição dos Fatores

\begin{tabular}{|c|c|c|c|}
\hline \multicolumn{2}{|c|}{ Fator 1: Sofisticação } & \multicolumn{2}{|c|}{ Fator 2: Freqüentadores } \\
\hline Variável & Carga Fatorial & Variável & Carga Fatorial \\
\hline maitre/hostess & 0,8200 & pessoas famosas & 0,7740 \\
\hline sala de espera & 0,7510 & outros clientes me reconhecem & 0,7440 \\
\hline manobrista & 0,7020 & pessoas importantes para o trabalho & 0,6980 \\
\hline estacionamento & 0,6890 & sala privativa & 0,6830 \\
\hline BAR & 0,6810 & carta de vinhos & 0,5390 \\
\hline status social diferenciado & 0,6060 & & \\
\hline público que freqüenta o lugar & 0,3770 & & \\
\hline \multicolumn{2}{|c|}{ Fator 3: Forma de Pagamento } & \multicolumn{2}{|l|}{ Fator 4: Ambiente } \\
\hline \multicolumn{2}{|c|}{ Variável Carga Fatorial } & \multirow{4}{*}{$\begin{array}{r}\text { Variável } \\
\text { atmosfera agradável } \\
\text { ambiente ao meu gosto } \\
\text { LIMPEZA }\end{array}$} & Carga Fatorial \\
\hline TICKET & 0,7840 & & 0,7850 \\
\hline CHEQUE & 0,7470 & & 0,7760 \\
\hline cartão de crédito & 0,7040 & & 0,4410 \\
\hline \multicolumn{2}{|c|}{ Fator 5: Localização } & \multicolumn{2}{|l|}{ Fator 6: Praticidade } \\
\hline Variável & Carga Fatorial & Variável & Carga Fatorial \\
\hline meu trabalho & 0,7450 & pequena variedade de pratos & $(0,7980)$ \\
\hline localização & 0,7380 & grande variedade de pratos & 0,7750 \\
\hline minha casa & 0,5850 & rapidez no atendimento & 0,3680 \\
\hline FUMANTES & $(0,4000)$ & cardápio compreensível & 0,3400 \\
\hline \multicolumn{2}{|c|}{ Fator 7: Imagem do Restaurante } & \multicolumn{2}{|c|}{ Fator 8: Grupo Social } \\
\hline \multicolumn{2}{|c|}{$\begin{array}{ll}\text { Variável } & \text { Carga Fatorial }\end{array}$} & \multirow{4}{*}{$\begin{array}{r}\text { Variável } \\
\text { gente da minha idade } \\
\text { não me importo com as pessoas } \\
\text { gente como eu }\end{array}$} & Carga Fatorial \\
\hline HORÁRIO & 0,6240 & & 0,6650 \\
\hline apresentação dos pratos & 0,5990 & & $(0,6220)$ \\
\hline decoração & 0,4820 & & 0,5240 \\
\hline \multicolumn{2}{|l|}{ Fator 9: Gourmet } & \multicolumn{2}{|l|}{ Fator 10: Animação } \\
\hline Variável & Carga Fatorial & Variável & Carga Fatorial \\
\hline qualidade da comida & 0,7790 & muita gente & 0,7750 \\
\hline forma como me visto normalmente & $(0,6170)$ & MÚSICA & 0,5510 \\
\hline qualidade do serviço & 0,6050 & pessoas me conhecem & 0,4430 \\
\hline
\end{tabular}

O fator 1 foi batizado de sofisticação, pois todas as variáveis agrupadas indicam que não se trata de um restaurante comum, mas sim que possui um conjunto de atributos que não estão comumente presentes em restaurantes mais simples (ou menos sofisticados). A destacar a presença dos atributos "status social diferenciado", que se refere ao tipo de consumidor que usualmente freqüenta esse lugar (na opinião dos entrevistados na amostra pesquisada) e, em 
menor grau, "público que freqüenta o lugar" - pois a importância do público é o objeto de inquérito principal desta tese.

A fama dos freqüentadores parece ser o atributo preponderante no fator 2, daí a forma como este foi batizado. Note-se que pessoas famosas, ser reconhecido pelos outros clientes e encontrar pessoas importantes para o trabalho são os atributos preponderantes nesse fator.

O terceiro fator refere-se exclusivamente às formas de pagamento aceitas no restaurante. Talvez o ponto interessante seja a ausência do atributo "preço" nesse fator (a carga fatorial do atributo preço foi -0,0022 para esse fator).

Ambiente físico é o quarto fator. As questões que representavam os atributos agrupados neste fator eram as seguintes: "eu freqüento esse restaurante porque encontro uma atmosfera agradável para pessoas como eu" e "eu freqüento esse restaurante porque encontro um ambiente ao meu gosto". Somese a isto a importância do atributo Limpeza e poder-se-á supor que este fator refere-se à aparência física do restaurante. Refere-se, pois, ao ambiente físico do restaurante.

O quinto fator é bastante claro: localização, em especial em relação ao trabalho. Um dado importante é a carga negativa do atributo fumantes. As outras variáveis apresentaram cargas fatoriais próximas de zero. Em síntese, isto parece indicar que localização é um fator único e pouco correlacionado com os outros fatores.

A praticidade é a característica principal do fator 6 . Isto é refletido nas cargas fatoriais: grande variedade de pratos, rapidez no atendimento e cardápio compreensível. Se "grande variedade de pratos" apresenta carga positiva, é compreensível que "pequena variedade de pratos" apresente carga negativa - ou 
seja, esses dois atributos estão negativamente correlacionados.

O fator 7 foi chamado de "Imagem do Restaurante", pois as variáveis que estão agrupadas nesse fator refletem a imagem do lugar: horário de funcionamento, apresentação dos pratos e decoração do restaurante. São variáveis que indicam o tipo de lugar antes de se consumir a comida efetivamente servida.

Grupo Social é o fator 8. As variáveis mais importantes indicam o quanto as pessoas que freqüentam o restaurante podem ser tomadas como um atributo do estabelecimento: "gente da minha idade" e "gente como eu". "Eu não me importo com as pessoas que freqüentam esse restaurante" apresentou carga fatorial negativa $(-0,6222)$. Ou seja: as pessoas que freqüentam o restaurante são importantes. É mister notar ainda que esse fator difere-se do fator 2 ("Freqüentadores"), pois trata-se de gente conhecida e/ou pertencente à mesma classe social do consumidor entrevistado - ao contrário do que ocorre com o citado fator 2.

O fator 9 , Gourmet, é talvez o que mais se identifica com a noção do que seja um restaurante, pois as variáveis mais importantes são "qualidade da comida" e "qualidade do serviço". Digno de nota, ainda, é a variável "eu escolho um restaurante adequado à forma como me visto normalmente" apresentar carga fatorial negativa. Isto indica que, para os consumidores que valorizam esse fator, vestir-se especialmente para ir a um restaurante pode ser aceitável ou mesmo necessário, desde que a qualidade da comida e do serviço compensem. Outro ponto interessante é que diversas variáveis apresentaram carga fatorial negativa, ainda que próxima de zero: localização próxima ao trabalho, horário de funcionamento, existência de estacionamento, todas as variáveis referentes aos 
consumidores que freqüentam o lugar (amigos, moda, status, gente como eu, meus filhos). Em síntese, esse fator indica a função básica de um restaurante: prover boa comida.

Finalmente, o fator 10 é chamado de Animação. Este nome decorre de as variáveis mais importantes serem a presença de muita gente e a existência de música ao vivo. A variável representada pela questão "eu freqüento esse restaurante porque aqui as pessoas me conhecem" indica também a importância das pessoas como um atributo do restaurante. Obviamente, a variável "silêncio" obteve carga fatorial negativa. Mais surpreendente é que a "qualidade da comida" também apresentou carga fatorial negativa, ainda que próxima de zero. "Moda" foi uma variável que apresentou carga fatorial negativa, ainda que pequena em relação às mais importantes neste fator. A animação (o "agito") parece ser o componente que define este fator.

\subsubsection{Análise de Conglomerado ("Cluster Analysis")}

A partir dos dez fatores descritos na seção anterior, foi realizada uma análise de conglomerado, na tentativa de descobrir os segmentos que melhor descrevesem os consumidores existentes na amostra pesquisada. Foram realizadas tentativas usando de 8 a 12 fatores, calculando entre 3 e 5 conglomerados ("clusters") para cada conjunto de fatores. Porém, a explicação final para o número de conglomerados deve ser dada pela teoria de marketing (Malhotra, 1999: 534). Acredita-se que os conglomerados encontrados, os segmentos, fazem sentido e ajudam a compreender o fenômeno pesquisado, o público que freqüenta o lugar como atributo do restaurante. 
O resultado encontrado é o que se segue:

Tabela 12: Centróides Finais dos Conglomerados

\begin{tabular}{l|rrr}
\hline & Cluster & & \\
\hline & 1 & 2 & 3 \\
Fator Sofisticação & $(0,2466)$ & $(0,1431)$ & 0,2335 \\
Fator Freqüentadores & 0,5928 & $(0,2421)$ & $(0,3189)$ \\
Fator Forma de Pagamento & 0,3739 & $(0,5908)$ & $(0,0199)$ \\
Fator Ambiente & 0,4359 & $(1,0748)$ & 0,1366 \\
Fator Localização & $(0,3934)$ & $(0,1257)$ & 0,3301 \\
Fator Praticidade & 0,2871 & $(0,3954)$ & $(0,0393)$ \\
Fator Imagem do Restaurante & 0,0393 & $(0,3211)$ & 0,1051 \\
Fator Grupo Social & $(0,1407)$ & 0,0334 & 0,0857 \\
Fator Gourmet & 0,4797 & 0,6643 & $(0,6140)$ \\
Fator Animação & $(0,1122)$ & 0,1812 & 0,0044 \\
\hline
\end{tabular}

Os centróides de cada conglomerado representam os "valores médios dos objetos contidos no conglomerado" de cada um dos fatores utilizados na análise (Malhotra, 1999: 535). Assim, é possível interpretar cada conglomerado com base nesses valores (Malhotra, 1999: 535). Rearranjando a Tabela 12 mostrada acima, é possível verificar os fatores mais importantes em cada conglomerado.

A Tabela 13: Fatores importantes para o Conglomerado 1 apresenta em ordem descrescente o valor para cada centro calculado (os números entre parênteses são negativos. O fator mais importante é "Freqüentadores", que como foi discutido na seção anterior, é formado pelas variáveis "pessoas famosas", "pessoas importantes para o trabalho" e "outros clientes me reconhecem" (entre outras variáveis). Isto indica que para estre grupo de pessoas não apenas o 
público que freqüenta o restaurante é importante, mas ainda que se trata de um grupo específico: pessoas supostamente conhecidas na sociedade, seja pelo trabalho ou por outro motivo. Note-se que a variável "outros clientes me reconhecem" indica a necessidade de ser reconhecido em companhia de celebridades. Frise-se, ainda, que o fator "Grupo Social", que tem entre suas variáveis "gente da minha idade" e "gente como eu" aparece com valor negativo. Ou seja, este conglomerado número 1 aparentemente indica um grupo de pessoas que pretendem freqüentar lugares diferentes daqueles onde normalmente se encontram pessoas da sua classe social. Aspectos do restaurante em si aparecem após o fator Freqüentadores: são os fatores "Gourmet" e "Ambiente". Interessante notar ainda que os fatores "Praticidade" (variedade de pratos, cardápio compreensível) e "Formas de Pagamento" surgem associados a este conglomerado. Portanto, este conglomerado pode ser batizado de "Emuladores Pecuniários", usando-se a terminologia proposta em Veblen (1899). ${ }^{61}$

Tabela 13: Fatores importantes para o Conglomerado 1 (Emuladores Pecuniários)

\begin{tabular}{c|c|cc}
\hline & Cluster 1 (Emuladores Pecuniários) & 2 & 3 \\
\cline { 1 - 3 } Fator Freqüentadores & $\mathbf{0 , 5 9 2 8}$ & $(0,2421)$ & $(0,3189)$ \\
Fator Gourmet & $\mathbf{0 , 4 7 9 7}$ & 0,6643 & $(0,6140)$ \\
Fator Ambiente & $\mathbf{0 , 4 3 5 9}$ & $(1,0748)$ & 0,1366 \\
Fator Forma de Pagamento & $\mathbf{0 , 3 7 3 9}$ & $(0,5908)$ & $(0,0199)$ \\
Fator Praticidade & $\mathbf{0 , 2 8 7 1}$ & $(0,3954)$ & $(0,0393)$ \\
Fator Imagem do Restaurante & $\mathbf{0 , 0 3 9 3}$ & $(0,3211)$ & 0,1051 \\
Fator Animação & $\mathbf{0 , 1 1 2 2 )}$ & 0,1812 & 0,0044 \\
Fator Grupo Social & $\mathbf{( 0 , 1 4 0 7 )}$ & 0,0334 & 0,0857 \\
Fator Sofisticação & $\mathbf{( 0 , 2 4 6 6 )}$ & $(0,1431)$ & 0,2335 \\
Fator Localização & $\mathbf{( 0 , 3 9 3 4 )}$ & $(0,1257)$ & 0,3301 \\
\hline
\end{tabular}

${ }^{61}$ Outros nomes possíveis seriam "Caçadores de Status" ou, mais popularmente, "Ilha de Caras". 
O segundo conglomerado obtido é o das pessoas que desejam apreciar uma boa refeição, independentemente da aparência do lugar, existência de pessoas famosas no restaurante, localização ou preço. Um ponto a ser ressaltado é a importância positiva, ainda que próxima de zero, do fator "Grupo Social", que inclui dentre suas variáveis "gente da minha idade", "gente como eu" e importância das pessoas que freqüentam o restaurante. Isto é mostrado na Tabela 14: Fatores importantes para o Conglomerado 2, apresentada abaixo. Pode-se imaginar a hipótese de que se trata de um segmento de pessoas que gostam de um restaurante pela comida e serviço e, ao mesmo tempo, freqüentados por pessoas conhecidas. São as pessoas que estão em busca de um "lugarzinho" ainda não descoberto por outros grupos sociais. Este conglomerado poderia ser chamado de "Os Bons Gourmets".

Tabela 14: Fatores importantes para o Conglomerado 2 (Os Bons Gourmets)

\begin{tabular}{l|r|c|r}
\hline & 1 & Cluster 2 (Bons Gourmets) & 3 \\
\hline Fator Gourmet & 0,4797 & $\mathbf{0 , 6 6 4 3}$ & $(0,6140)$ \\
Fator Animação & $(0,1122)$ & $\mathbf{0 , 1 8 1 2}$ & 0,0044 \\
Fator Grupo Social & $(0,1407)$ & $\mathbf{0 , 0 3 3 4}$ & 0,0857 \\
Fator Localização & $(0,3934)$ & $\mathbf{( 0 , 1 2 5 7 )}$ & 0,3301 \\
Fator Sofisticação & $(0,2466)$ & $\mathbf{( 0 , 1 4 3 1 )}$ & 0,2335 \\
Fator Freqüentadores & 0,5928 & $\mathbf{( 0 , 2 4 2 1 )}$ & $(0,3189)$ \\
Fator Imagem do Restaurante & 0,0393 & $\mathbf{( 0 , 3 2 1 1 )}$ & 0,1051 \\
Fator Praticidade & 0,2871 & $\mathbf{( 0 , 3 9 5 4 )}$ & $(0,0393)$ \\
Fator Forma de Pagamento & 0,3739 & $\mathbf{( 0 , 5 9 0 8 )}$ & $(0,0199)$ \\
Fator Ambiente & 0,4359 & $(\mathbf{1 , 0 7 4 8 )}$ & 0,1366 \\
\hline
\end{tabular}

Finalmente, o segmento restante é representado pelo conglomerado 3 . Localização e Sofisticação parecem ser os fatores mais importantes para esse 
grupo. Em segundo lugar, os fatores Imagem do Restaurante, Ambiente e, por último, Grupo Social. Note-se que o fator Sofisticação inclui as variáveis "público que freqüenta o lugar" e "status social diferenciado". Curiosamente, o Fator Gourmet aparece com valor negativo, bem como o fator Freqüentadores (pessoas famosas e importantes para o trabalho). Uma explicação baseada em Veblen (1899: 57) é que "o consumo vicário deve não concorrer para o conforto do consumidor vicário". Em outras palavras: consumir alguns produtos (como restaurantes) é obrigação para os membros desse grupo social - fazem parte do papel social dessas pessoas e nada tem a ver com o conforto pessoal ou a satisfação de necessidades fisiológicas (na terminologia de Maslow).

Aparentemente, há por parte dos consumidores desse segmento uma distinção clara entre ser famoso e ter status - o que faz sentido, em termos sociológicos. - Esse grupo de pessoas não compartilha, supostamente, a importância atribuída a pessoas famosas por outros grupos sociais. O ponto importante, neste caso, é a distinção entre ser "conhecido" (o que indica intimidade) e ser "reconhecido" (o que indica fama). Para os entrevistados que estão no conglomerado 1 (Emuladores Pecuniários) o importante é ser percebido pelos outros clientes do lugar, que Ihes são desconhecidos. ${ }^{62}$ Para os membros do conglomerado 3 , que pode ser chamado de "Aristocratas", ${ }^{63}$ o fundamental é encontrar pessoas com quem partilham alguma intimidade e, por conseguinte,

62 Provavelmente, esses consumidores do conglomerado 1 (Emuladores Pecuniários) freqüentam os restaurantes que Peters Filho (2003) chamou de "ver e ser visto".

${ }^{63} \mathrm{Em}$ termos estritamente sociológicos, este nome é incorreto. Aristocracia refere-se a um conjunto de "posições herdadas de privilégios" (Johnson, 1995: 35) em uma sociedade feudal. No capitalismo, trata-se de uma classe alta. Como ressalta Johnson (1995: 35-6), a classe alta distingue-se pela riqueza, mas não somente. Há uma identidade de classe refletida em casamentos, amizades, envio de filhos a escolas selecionadas, ocupação de determinadas posições sociais e mesmo em empresas ou na administração pública. Todavia, feito o registro em nome da precisão teórica utilizou-se o termo "aristocracia" neste conglomerado para facilitar a compreensão de que tipo de pessoas se está tratando. 
provavelmente façam parte da mesma classe social.

Os dados referentes ao Conglomerado 3 ("Aristocratas") são apresentados abaixo:

Tabela 15: Fatores importantes para o Conglomerado 3 ("Aristocratas")

\begin{tabular}{c|cc|c|}
\hline & 1 & 2 & Cluster 3 (Aristocratas) \\
\hline Fator Localização & $(0,3934)$ & $(0,1257)$ & $\mathbf{0 , 3 3 0 1}$ \\
Fator Sofisticação & $(0,2466)$ & $(0,1431)$ & $\mathbf{0 , 2 3 3 5}$ \\
Fator Ambiente & 0,4359 & $(1,0748)$ & $\mathbf{0 , 1 3 6 6}$ \\
Fator Imagem do Restaurante & 0,0393 & $(0,3211)$ & $\mathbf{0 , 1 0 5 1}$ \\
Fator Grupo Social & $(0,1407)$ & 0,0334 & $\mathbf{0 , 0 8 5 7}$ \\
Fator Animação & $(0,1122)$ & 0,1812 & $\mathbf{0 , 0 0 4 4}$ \\
Fator Forma de Pagamento & 0,3739 & $(0,5908)$ & $\mathbf{( 0 , 0 1 9 9 )}$ \\
Fator Praticidade & 0,2871 & $(0,3954)$ & $\mathbf{( 0 , 0 3 9 3 )}$ \\
Fator Freqüentadores & 0,5928 & $(0,2421)$ & $\mathbf{( 0 , 3 1 8 9 )}$ \\
Fator Gourmet & 0,4797 & 0,6643 & $\mathbf{( 0 , 6 1 4 0 )}$ \\
\hline
\end{tabular}

A distribuição dos entrevistados nos conglomerados encontrados está na Tabela 16: Distribuição dos entrevistados pelos conglomerados mostrada abaixo. Dadas as características da amostra (predominância de pessoas da Classe A), seria esperado que houvesse um número expressivo de pessoas no conglomerado Aristocratas. Também seria esperado que por suas características, o conglomerado Bons Gourmets apresentasse o menor número de pessoas entre os conglomerados formados.

Tabela 16: Distribuição dos entrevistados pelos conglomerados

\begin{tabular}{l|ll}
\hline \multirow{2}{*}{ Cluster } & $\mathbf{1}$ (Emuladores Pecuniários) & 41 \\
& 3 (Bons Gourmets) & 24 \\
& & 58 \\
\hline Valid & & 123 \\
\hline
\end{tabular}

A seguir foi realizada uma análise da variância dos fatores encontrados. Note-se que os testes F, neste caso, são "puramente descritivos" 
(Malhotra, 1999: 538). Este teste é utilizado para saber se duas populações têm ou não médias iguais (Malhotra, 1999: 432). Caso a probabilidade de F seja maior do que um valor crítico, para um dado nível de significância, a hipótese nula (médias são iguais) é rejeitada (Malhotra, 1999: 437-8). A questão, neste caso, é saber se os fatores calculados realmente separam os consumidores em conglomerados distintos.

Para os dados ora analisados, todos os $\mathrm{F}$ calculados foram maiores do que os respectivos valores críticos. Todavia, é mister destacar que os fatores “Imagem do Restaurante”, "Animação" e "Grupo Social” apresentaram níveis de significância superiores a 0,05.

Tabela 17: Análise da Variância para os Fatores Utilizados

\begin{tabular}{l|rrrrrr}
\hline & \multicolumn{1}{|c}{ Cluster } & \multicolumn{1}{c}{ Error } & F & Sig. \\
\hline & Mean Square & $d f$ & Mean Square & $d f$ & & \\
Fator Gourmet & 20,944 & 2 & 0,668 & 120 & 31,372 & 0,000 \\
Fator Ambiente & 18,299 & 2 & 0,712 & 120 & 25,711 & 0,000 \\
Fator Freqüentadores & 10,856 & 2 & 0,836 & 120 & 12,989 & 0,000 \\
Fator Forma de Pagamento & 7,065 & 2 & 0,899 & 120 & 7,859 & 0,001 \\
Fator Localização & 6,520 & 2 & 0,908 & 120 & 7,181 & 0,001 \\
Fator Praticidade & 3,611 & 2 & 0,956 & 120 & 3,776 & 0,026 \\
Fator Satisfação & 3,074 & 2 & 0,965 & 120 & 3,184 & 0,045 \\
\hline Fator Imagem do Restaurante & 1,589 & 2 & 0,990 & 120 & 1,605 & 0,205 \\
Fator Animação & 0,653 & 2 & 1,006 & 120 & 0,649 & 0,524 \\
Fator Grupo Social & 0,632 & 2 & 1,006 & 120 & 0,628 & 0,535 \\
\hline
\end{tabular}

A seguir, na Tabela 18: Teste de Igualdade de Médias abaixo é apresentado teste semelhante, mas utilizando as variáveis e não os fatores. A medida Lambda de Wilks, que varia entre 0 e 1 examina a diferença dos grupos (Hair, Anderson, Tatham \& Black, 1998: 351). Quanto mais próximo de zero (0) for o Lambda de Wilks, maior será a diferença das médias dos grupos. Se for 1 , significa que as médias são iguais. Neste sentido, as variáveis que mais se destacaram como separadoras dos grupos são ligadas ao ambiente (ambiente, 
atmosfera e limpeza); qualidade da comida e do serviço e algumas ligadas ao tipo de público (gente como eu, pessoas importantes para o trabalho, pessoas famosas e opúblico que freqüenta o lugar). Isto faz sentido, sobretudo porque as variáveis ligadas à fama dos freqüentadores compõem um fator importante para o conglomerado 1 (Emuladores pecuniários); já as variáveis de qualidade da comida e do serviço são importantes para os membros do conglomerado 3 (Bons Gourmets).

Tabela 18: Teste de Igualdade de Médias

\begin{tabular}{l|ccccc}
\hline & Wilks' Lambda & $\mathrm{F}$ & $\mathrm{df1}$ & Df2 & Sig. \\
\hline ambiente ao meu gosto & 0,655 & 31,653 & 2 & 120 & 0,000 \\
forma como me visto normalmente & 0,773 & 17,591 & 2 & 120 & 0,000 \\
qualidade da comida & 0,797 & 15,273 & 2 & 120 & 0,000 \\
atmosfera agradável & 0,814 & 13,685 & 2 & 120 & 0,000 \\
LIMPEZA & 0,824 & 12,847 & 2 & 120 & 0,000 \\
CHEQUE & 0,831 & 12,217 & 2 & 120 & 0,000 \\
gente como eu & 0,836 & 11,802 & 2 & 120 & 0,000 \\
pessoas importantes para o trabalho & 0,870 & 8,934 & 2 & 120 & 0,000 \\
cartão de crédito & 0,871 & 8,871 & 2 & 120 & 0,000 \\
pessoas famosas & 0,878 & 8,336 & 2 & 120 & 0,000 \\
público que freqüenta o lugar & 0,893 & 7,191 & 2 & 120 & 0,001 \\
Decoração & 0,894 & 7,104 & 2 & 120 & 0,001 \\
TICKET & 0,895 & 7,019 & 2 & 120 & 0,001 \\
qualidade do serviço & 0,897 & 6,924 & 2 & 120 & 0,001 \\
minha casa & 0,905 & 6,311 & 2 & 120 & 0,002 \\
Localização & 0,916 & 5,473 & 2 & 120 & 0,005 \\
SILÊNCIO & 0,921 & 5,152 & 2 & 120 & 0,007 \\
carta de vinhos & 0,938 & 3,981 & 2 & 120 & 0,021 \\
outros clientes me reconhecem & 0,939 & 3,921 & 2 & 120 & 0,022 \\
status social diferenciado & 0,939 & 3,899 & 2 & 120 & 0,023 \\
HORÁRIO & 0,943 & 3,636 & 2 & 120 & 0,029 \\
grande variedade de pratos & 0,945 & 3,514 & 2 & 120 & 0,033 \\
não me importo com as pessoas & 0,948 & 3,266 & 2 & 120 & 0,042 \\
maitre/hostess & 0,949 & 3,249 & 2 & 120 & 0,042 \\
MODA & 0,950 & 3,184 & 2 & 120 & 0,045 \\
pequena variedade de pratos & 0,953 & 2,941 & 2 & 120 & 0,057 \\
Estacionamento & 0,956 & 2,785 & 2 & 120 & 0,066 \\
\hline & & & & \\
\hline
\end{tabular}




\begin{tabular}{l|ccccc}
\hline & Wilks' Lambda & F & df1 & Df2 & Sig. \\
\hline Manobrista & 0,963 & 2,299 & 2 & 120 & 0,105 \\
AMIGOS & 0,963 & 2,275 & 2 & 120 & 0,107 \\
meu trabalho & 0,965 & 2,198 & 2 & 120 & 0,115 \\
FUMANTES & 0,966 & 2,125 & 2 & 120 & 0,124 \\
MÚSICA & 0,967 & 2,063 & 2 & 120 & 0,132 \\
tipo de comida & 0,970 & 1,881 & 2 & 120 & 0,157 \\
cardápio compreensível & 0,976 & 1,476 & 2 & 120 & 0,233 \\
sala privativa & 0,981 & 1,155 & 2 & 120 & 0,319 \\
apresentação dos pratos & 0,982 & 1,088 & 2 & 120 & 0,340 \\
BAR & 0,984 & 0,962 & 2 & 120 & 0,385 \\
pessoas que estão comigo & 0,986 & 0,882 & 2 & 120 & 0,417 \\
poucas pessoas & 0,989 & 0,685 & 2 & 120 & 0,506 \\
meus filhos & 0,990 & 0,628 & 2 & 120 & 0,535 \\
sala de espera & 0,990 & 0,601 & 2 & 120 & 0,550 \\
pessoas me conhecem & 0,995 & 0,317 & 2 & 120 & 0,729 \\
muita gente & 0,995 & 0,282 & 2 & 120 & 0,755 \\
pessoas que convido & 0,998 & 0,125 & 2 & 120 & 0,883 \\
Eu escolho o restaurante pelo preço & 0,998 & 0,116 & 2 & 120 & 0,890 \\
gente da minha idade & 0,999 & 0,089 & 2 & 120 & 0,915 \\
rapidez no atendimento & 0,999 & 0,037 & 2 & 120 & 0,964 \\
\hline
\end{tabular}

\subsubsection{Caracterização dos Conglomerados}

Os conglomerados discutidos acima foram calculados com base em fatores. Estes, por seu turno, foram calculados com base em variáveis que representavam atributos dos restaurantes e que foram classificadas em entrevistas com consumidores. Agora, cumpre discutir se é possível saber quais são as pessoas que estão classificadas em cada conglomerado. Em outros termos, trata-se de descrever o que já foi discriminado, com base nas outras questões apresentadas no instrumento de coleta: sexo, idade, estado civil e classe social.

Em relação à primeira variável, sexo, há proporcionalmente mais mulheres no conglomerado Aristocratas (38 mulheres e 20 homens) e mais 
homens no conglomerado Gourmets (14 homens e 10 mulheres). Embora haja mais mulheres do que homens no grupo dos Emuladores, a diferença de apenas três pessoas não pode ser considerada substancial. Em termos absolutos, também há mais mulheres entre os Aristocratas do que nos dois outros conglomerados somados (38 a 32, respectivamente - ver Gráfico 5 abaixo). 0 mesmo não ocorre em relação aos homens e o conglomerado Gourmet - mas isto pode ser causado por se tratar do menor dos conglomerados.

Tabela 19: Sexo X Conglomerado

\begin{tabular}{c|cccc}
\hline & 1. Emuladores & 2. Gourmets & 3. Aristocratas & Total \\
& & & & \\
\hline Masculino & 19 & 14 & 20 & 53 \\
Feminino & 22 & 10 & 38 & 70 \\
\hline Total & 41 & 24 & 58 & 123 \\
\hline
\end{tabular}

Gráfico 5: Distribuição das Mulheres pelos Conglomerados

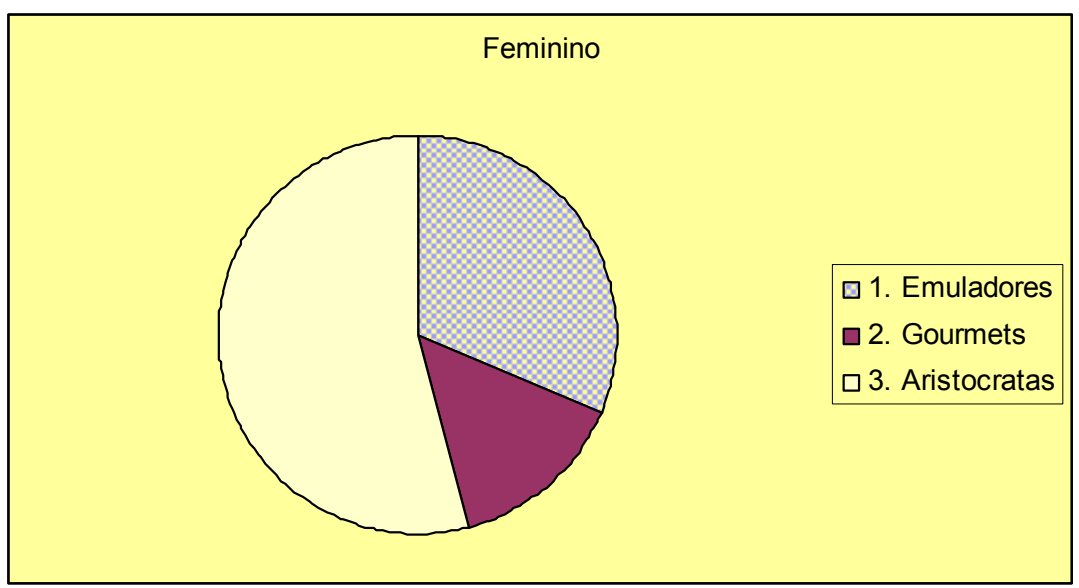

Em relação à idade, dado o pequeno número de respondentes nas faixas superiores a 25 anos, os respondentes foram agrupados sob a rubrica " 26 anos ou mais". Dadas as características da amostra, o grupo de pessoas entre 21 e 25 anos é maioria em todos os conglomerados. Porém, em termos relativos (em cada faixa de idade), os mais jovens estão concentrados entre os Emuladores (14 versus 15 nos outros dois conglomerados) (ver 
Gráfico 6 abaixo). Já os mais velhos estão concentrados entre os aristocratas (12 a 11) (ver Gráfico 7 abaixo). Curiosamente, entre as pessoas de 21 a 25 anos há menos classificadas entre os Gourmets. Contudo, as pessoas dessa idade são maioria absoluta nesse conglomerado (13 a 11 pessoas).

Tabela 20: Idade x Conglomerados

\begin{tabular}{l|cccc}
\multicolumn{5}{c}{ Tabela 20: Idade x Conglomerados } \\
\hline & 1. Emuladores & 2. Gourmets & 3. Aristocratas & Total \\
\hline 18 a 20 anos & 14 & 5 & 10 & 29 \\
21 a 25 anos & 22 & 13 & 36 & 71 \\
26 anos ou mais & 5 & 6 & 12 & 23 \\
\hline Total & 41 & 24 & 58 & 123 \\
\hline
\end{tabular}

Gráfico 6: Distribuição pelos conglomerados das pessoas entre 18 a 20 anos

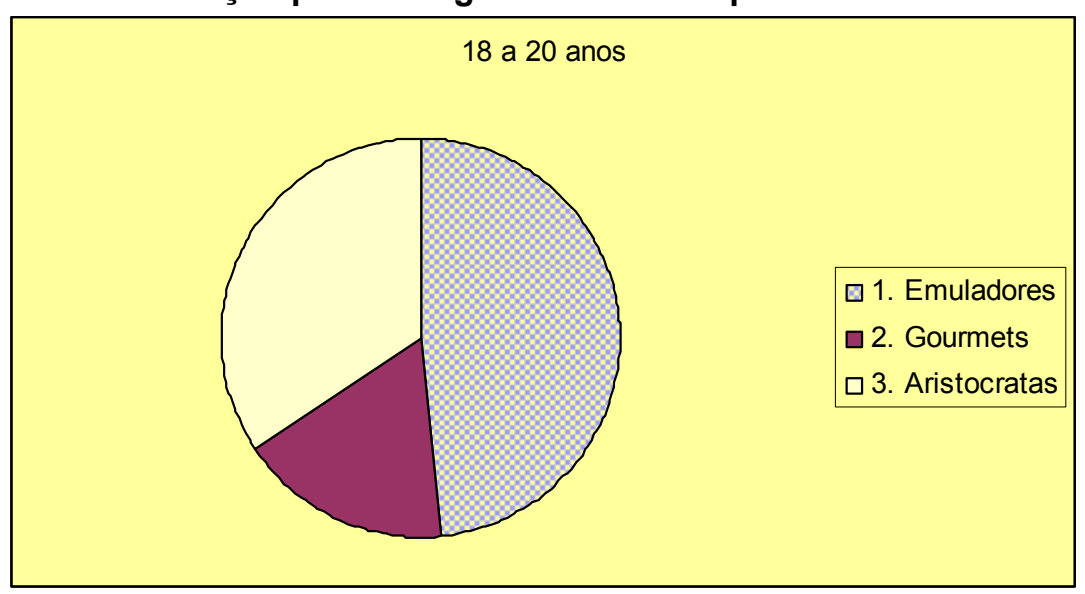

Gráfico 7: Distribuição pelo conglomerados das pessoas com 26 anos ou mais

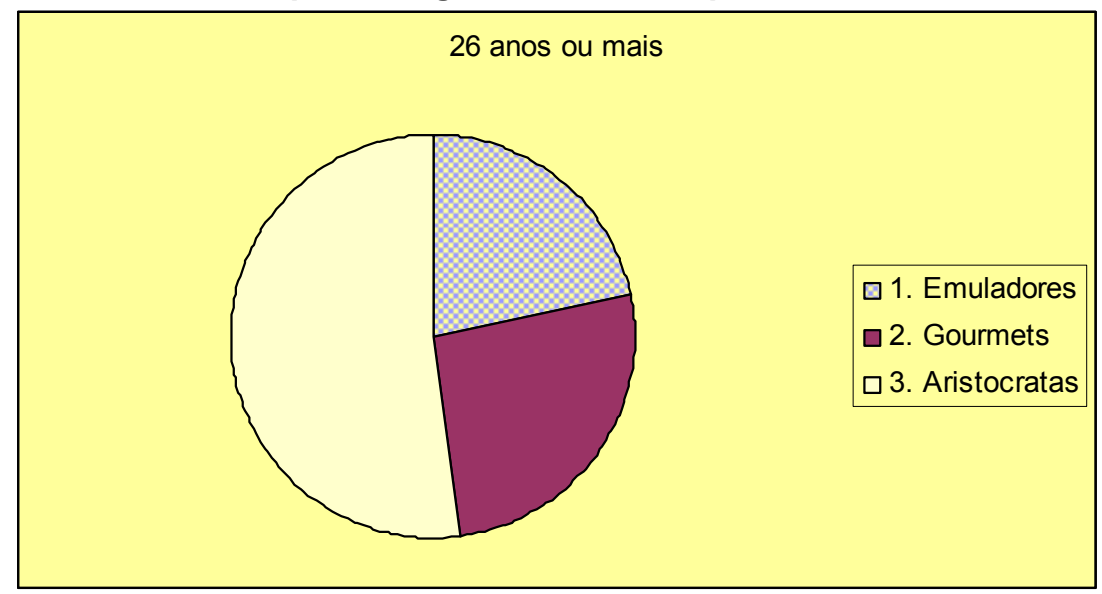

Quanto ao estado civil, dada a amostra utilizada não é possível distinguir nenhum conglomerado. Isto porque dos 123 entrevistados, 108 são 
solteiros, como mostra a Tabela 21:

Tabela 21: Estado Civil x Conglomerado

\begin{tabular}{l|cccc}
\hline & 1. Emuladores & 2. Gourmets & 3. Aristocratas & Total \\
\hline Solteiro & 37 & 21 & 50 & 108 \\
Não-solteiro & 4 & 3 & 8 & 15 \\
\hline Total & 41 & 24 & 58 & 123 \\
\hline
\end{tabular}

Finalmente, quanto à última variável descritiva, classe social, ${ }^{64}$ ocorre o mesmo fenômeno relativo ao estado civil: a amostra é bastante homogênea (além de ser reduzida). Por outro lado, o hábito de freqüentar restaurantes como lazer é provavelmente ligado à renda. Pessoas de baixa renda não costumam ir a restaurantes sofisticados. Logo, talvez seja o pequeno tamanho da amostra que dificulte uma análise com base em classe social. Esse pequeno tamanho da amostra reflete-se na distribuição por classe social e conglomerados apresentado na Tabela 22 abaixo:

Tabela 22: Classe Social x Conglomerados

\begin{tabular}{l|cccc}
\hline & 1. Emuladores & 2. Gourmets & 3. Aristocratas & Total \\
& & & & \\
\hline A1 & 9 & 3 & 11 & 23 \\
A2 & 18 & 7 & 18 & 43 \\
B1 & 6 & 9 & 18 & 33 \\
B2 & 6 & 5 & 7 & 18 \\
C & 2 & & 4 & 6 \\
\hline Total & 41 & 24 & 58 & 123 \\
\hline
\end{tabular}

Ressalvadas as limitações dos dados quanto à classe social dos entrevistados, é possível especular sobre as características dos conglomerados se for simplificada a classificação da ANEP (Critério Brasil). Somando-se as subclasses A1 e A2, bem como as subclasses B1 e B2, obtém-se algumas indicações sobre a composição dos conglomerados (ver Tabela 23, abaixo). A

\footnotetext{
64 A identificação da classe social foi baseada nos critérios da Associação Nacional das Empresas de Pesquisa de Mercado (ANEP) (www.anep.org.br).
} 
maioria absoluta dos Emuladores pertence à classe A (27 pessoas x 14 das classes B e C - ver Gráfico 8 abaixo). O mesmo ocorre com a classe B em relação aos Bons Gourmets (14 x 10 pessoas da classe A). Curiosamente, não há pessoas da classe $\mathrm{C}$ neste conglomerado, mas isto provavelmente se deve ao tamanho e à composição da amostra pesquisada.

Tabela 23: Classe Social (Simplificada) x Conglomerados

\begin{tabular}{l|rlrlr}
\hline & 1. & 2. & \multicolumn{3}{l}{3.} \\
& Emuladores & Gourmets & Aristocratas & Total \\
\hline A & 27 & 10 & 29 & 66 \\
B & 12 & 14 & 25 & 51 \\
$\mathrm{C}$ & 2 & 0 & 4 & 6 \\
\hline Total & 41 & 24 & 58 & 123 \\
\hline
\end{tabular}

Gráfico 8: Distribuição de Classes (Simplificadas) no Conglomerado Emuladores

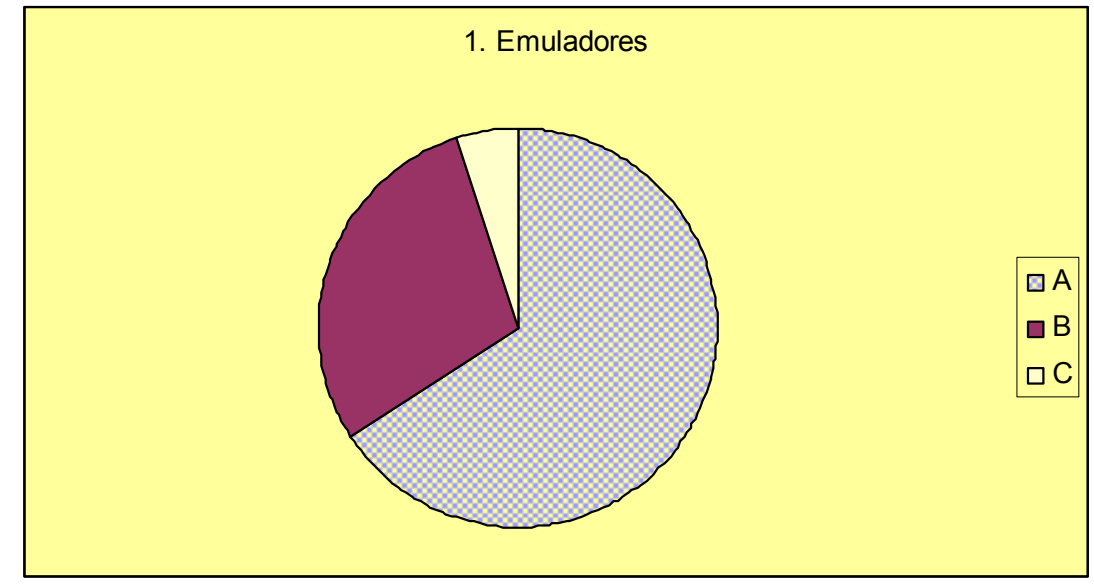

Porém, o que toda essa análise torna óbvio é que dada a homogeneidade da amostra, outras variáveis seriam necessárias para uma descrição precisa das pessoas classificadas nos conglomerados. Isto comprova os avanços em teoria de marketing sobre a importância do conceito de estilo de vida para a prática da segmentação, como demonstrado em Finotti (2004):65 variáveis demográficas não bastam para a descrição dos segmentos de

${ }^{65}$ Finotti (2004) apresenta um levantamento detalhado do conceito de estilo de vida, desde a primeira vez em que esse termo foi usado na sociologia (com Max Weber) até sua apropriação pelos teóricos de marketing, na segunda metade do século XX. 
consumidores de muitos produtos. Como regra de bolso, pode-se afirmar que quanto mais complexo for o consumo do produto, mais complexa deverá ser a caracterização do seu consumidor.

Todavia, é possível sugerir algumas hipóteses sobre as pessoas que estão nos conglomerados: mulheres mais jovens pertencentes à classe A (A1 e A2) têm maior probabilidade de pertencer ao conglomerado Emuladores. Homens da classe B (B1 e B2) apresentam maior probabilidade de estar no grupo dos Bons Gourmets. Finalmente, pessoas mais velhas (acima de 25 anos, no caso desta amostra) aparentemente têm mais chance de integrarem o conglomerado Aristocratas (ver Tabela 24 e Tabela 25 abaixo). Um último ponto curioso, mas que carece de qualquer comprovação dadas as limitações da amostra: todos homens da classe C (2 pessoas) estão no conglomerado Emuladores, ao passo que todas as mulheres dessa classe (4 pessoas) foram classificadas no conglomerado Aristocratas (ver Tabela 25 abaixo).

Tabela 24: Conglomerado x Idade x Sexo

\begin{tabular}{l|lcc|c}
\hline Conglomerado & Faixa Etária & Homens & Mulheres & Total (Conglomerado) \\
\hline \multirow{4}{*}{ 1. Emuladores } & 18 a 20 anos & 3 & 11 & \\
& 21 a 25 anos & 11 & 11 & 41 \\
& 26 anos ou mais & 5 & $\underline{0}$ & \\
\hline \multirow{3}{*}{ 3. Gourmets } & 18 a 20 anos & 3 & 2 & 24 \\
& 21 a 25 anos & $\underline{9}$ & 4 & \\
& 26 anos ou mais & 2 & 4 & 58 \\
\hline & 18 a 20 anos & 2 & 8 & \\
& 21 a 25 anos & 12 & $\underline{24}$ & \\
& 26 anos ou mais & 6 & 6 & 123 \\
\hline
\end{tabular}


Tabela 25: Conglomerado x Classe Social (Simplificada) $x$ Sexo

\begin{tabular}{|c|c|c|c|c|}
\hline Conglomerado & Classe Social & Homens & Mulheres & Total (Conglomerado) \\
\hline \multirow{3}{*}{ 1. Emuladores } & A & 9 & 18 & \multirow{3}{*}{41} \\
\hline & B & 8 & 4 & \\
\hline & C & 2 & 0 & \\
\hline \multirow{3}{*}{ 2. Gourmets } & A & 4 & 6 & \multirow{3}{*}{24} \\
\hline & B & 10 & 4 & \\
\hline & C & 0 & 0 & \\
\hline \multirow{4}{*}{ 3. Aristocratas } & A & 9 & 20 & \multirow{3}{*}{58} \\
\hline & B & 11 & 14 & \\
\hline & C & 0 & 4 & \\
\hline & Total (Sexo) & 53 & 70 & 123 \\
\hline
\end{tabular}

\subsubsection{Análise discrimante dos conglomerados encontrados}

Após a separação dos entrevistados em conglomerados (os segmentos do marketing), feita baseada nos fatores calculados na primeira análise realizada, procedeu-se a uma análise discriminante dos conglomerados obtidos. Como afirma Malhotra (1999: 482), essa é uma das funções dessa técnica:

“Verificar se existem diferenças significativas entre os grupos ,em termos das variáveis prognosticadoras."

Outro objetivo desta análise é, ainda segundo Malhotra (1999: 482), "[a]valiar a precisão da classificação".

Foram calculadas duas funções canônicas para discriminar os grupos (bastam duas funções para discriminar três grupos, ou $n-1$ funções para discriminar $n$ grupos). Houve dois erros de classificação: um membro do conglomerado 2 (Bons Gourmets) foi classificado como pertencente ao conglomerado 1 (Emuladores Pecuniários) e um membro do conglomerado 3 (Aristocratas) foi classificado no conglomerado 2 (Bons Gourmets). Note-se que não houve erros entre os conglomerados 1 e 3 . O resultado obtido está na Tabela 26 abaixo: 
Tabela 26: Resultados das funções canônicas versus conglomerados "reais" Previsão Total

\begin{tabular}{lrrrrr} 
Conglomerado \# & & 1 & 2 & 3 & \\
\hline Contagem Original & 1 & 41 & 0 & 0 & 41 \\
& 2 & 1 & 23 & 0 & 24 \\
& 3 & 0 & 1 & 57 & 58 \\
\hline$\%$ & 1 & 100 & 0 & 0 & 100 \\
& 2 & 4,2 & 95,8 & 0 & 100 \\
& 3 & 0 & 1,7 & 98,3 & 100 \\
\hline $98,4 \%$ dos casos orginais foram corretamente classificados.
\end{tabular}

Graficamente, o resultado é mostrado na figura a seguir:

\section{Canonical Discriminant Functions}

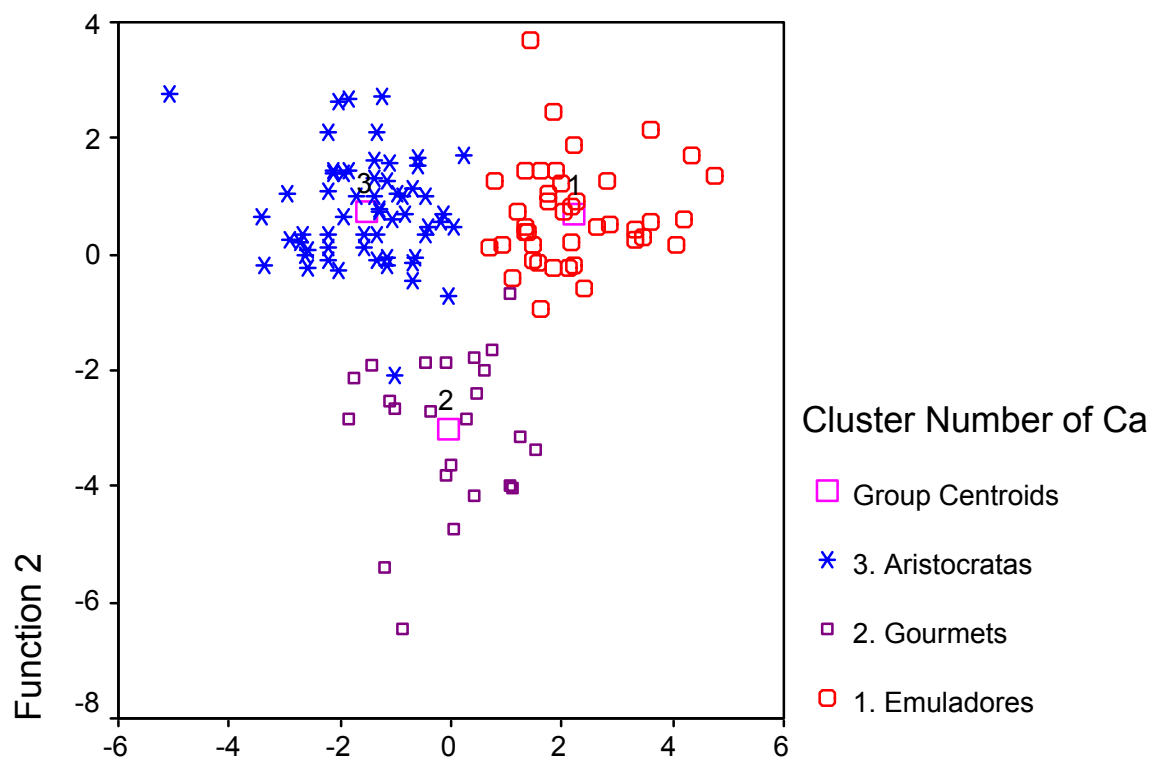

Function 1

Figura 5: Conglomerados baseados em análise discriminante

Um ponto a ser destacado é que os centróides de cada grupo guardam semelhança teórica com o conceito sociológico de "tipo ideal" criado por Max Weber. Esse tipo é uma construção teórica, no qual são atribuídas as principais características sócio-culturais de um determinado grupo social. Se fosse possível determinar quais os desejos e aspirações dos membros de cada conglomerado, seria possível construir teoricamente um tipo ideal para cada tipo de consumidor 
(em termos weberianos: conhecer o sentido da ação de cada consumidor). Assim como o tipo ideal só existe em teoria e é usado como uma ferramenta para analisar a realidade (comparando-se as diferenças entre as pessoas e o tipo ideal), também o centróide é uma abstração que se presta a auxiliar na análise do comportamento dos consumidores.

Depois, para cada grupo foram calculados os coeficientes de uma função linear múltipla. O resultado obtido para cada conglomerado está na Tabela 27 abaixo:

Tabela 27: Coeficientes da Função de Classificação

\begin{tabular}{|c|c|c|c|}
\hline & $\begin{array}{l}1 \text { (Emuladores } \\
\text { Pecuniários) }\end{array}$ & $\begin{array}{c}2 \text { (Bons } \\
\text { Gourmets) }\end{array}$ & $\begin{array}{c}3 \\
\text { (Aristocratas) }\end{array}$ \\
\hline pessoas que convido & 3,856 & 4,567 & 2,854 \\
\hline pessoas que estão comigo & 3,725 & 2,998 & 3,798 \\
\hline tipo de comida & 15,807 & 16,233 & 14,48 \\
\hline rapidez no atendimento & $-0,594$ & $-0,483$ & $-0,79$ \\
\hline Eu escolho o restaurante pelo preço & 9,449 & 8,785 & 9,004 \\
\hline Localização & $-8,087$ & $-7,206$ & $-6,479$ \\
\hline minha casa & 2,504 & 2,396 & 2,991 \\
\hline meu trabalho & $-0,471$ & $-0,414$ & $-0,232$ \\
\hline forma como me visto normalmente & 3,995 & 3,594 & 5,017 \\
\hline HORÁRIO & $-2,804$ & $-2,795$ & $-1,531$ \\
\hline Estacionamento & $-1,108$ & 0,191 & $-0,156$ \\
\hline Manobrista & $-7,293$ & $-4,706$ & $-5,303$ \\
\hline maitre/hostess & $-2,584$ & $-4,094$ & $-2,361$ \\
\hline sala de espera & $-3,149$ & $-1,275$ & $-2,533$ \\
\hline Decoração & $-4,351$ & $-5,514$ & $-4,404$ \\
\hline BAR & $-6,575$ & $-6,538$ & $-6,47$ \\
\hline público que freqüenta o lugar & $-4,002$ & $-3,456$ & $-2,454$ \\
\hline AMIGOS & $-0,0397$ & $-0,255$ & 0,334 \\
\hline MODA & 3,524 & 2,908 & 2,801 \\
\hline gente como eu & 7,325 & 5,9 & 8,438 \\
\hline status social diferenciado & $-2,453$ & $-2,647$ & $-2,566$ \\
\hline meus filhos & 14,798 & 13,876 & 13,85 \\
\hline gente da minha idade & $-1,776$ & $-0,287$ & $-1,793$ \\
\hline atmosfera agradável & 9,114 & 6,1 & 7,316 \\
\hline ambiente ao meu gosto & $-4,7$ & $-6,664$ & $-4,015$ \\
\hline pessoas me conhecem & $-4,92$ & $-3,472$ & $-4,96$ \\
\hline muita gente & 2,131 & 2,179 & 1,957 \\
\hline poucas pessoas & 6,6 & 7,232 & 6,251 \\
\hline pessoas famosas & 11,277 & 7,775 & 9,501 \\
\hline pessoas importantes para o trabalho & 7,014 & 5,564 & 4,091 \\
\hline outros clientes me reconhecem & $-3,777$ & $-2,857$ & $-3,494$ \\
\hline não me importo com as pessoas & 1,697 & 1,64 & 1,088 \\
\hline sala privativa & $-8,824$ & $-8,231$ & $-8,386$ \\
\hline FUMANTES & 1,065 & 1,265 & 0,721 \\
\hline
\end{tabular}




\begin{tabular}{l|ccc}
\hline & $\begin{array}{c}\text { 1 (Emuladores } \\
\text { Pecuniários) }\end{array}$ & $\begin{array}{c}2 \text { (Bons } \\
\text { Gourmets) }\end{array}$ & $\begin{array}{c}3 \\
\text { (Aristocratas) }\end{array}$ \\
\hline LIMPEZA & 17,929 & 13,916 & 15,629 \\
SILÉNCIO & $-0,415$ & $-0,666$ & 0,674 \\
MÚSICA & 6,616 & 5,309 & 6,324 \\
cardápio compreensível & $-13,752$ & $-12,476$ & $-13,45$ \\
grande variedade de pratos & 17,626 & 17,493 & 16,293 \\
pequena variedade de pratos & 4,823 & 6,989 & 6,65 \\
carta de vinhos & 5,497 & 4,371 & 4,693 \\
apresentação dos pratos & 2,467 & 2,156 & 2,075 \\
qualidade da comida & 43,016 & 40,702 & 37,921 \\
cartão de crédito & 4,078 & 4,077 & 4,036 \\
CHEQUE & $-0,75$ & $-1,79$ & $-1,107$ \\
TICKET & 3,444 & 2,789 & 3,386 \\
qualidade do serviço & 23,879 & 23,892 & 20,759 \\
(Constant) & $-335,524$ & $-289,016$ & $-284,096$ \\
\hline
\end{tabular}

Estes coeficientes são utilizados para o cálculo do índice de preços hedônicos, como será discutido na seção 5.4 O índice de preços hedônicos deste trabalho.

\subsubsection{Análise discriminante passo a passo ("stepwise") dos conglomerados encontrados}

A diferença entre a análise discriminante feita pelo método direto e a análise discriminante passo a passo (stepwise) é que nesta última as variáveis são introduzidas uma a uma, com base em sua capacidade de separar os grupos estudados (Malhotra, 1999: 485). Com isso, é possível identificar quais são as variáveis mais importantes na discriminação dos conglomerados. Abaixo são apresentadas as estatísticas para as variáveis incluídas:

Tabela 28: Variáveis Incluídas e Removidas na Análise Discriminante Passo a Passo

\begin{tabular}{|c|c|c|c|c|c|c|c|c|c|}
\hline \multirow{3}{*}{ Passo } & \multirow{3}{*}{ Variáveis Incluídas } & \multicolumn{8}{|c|}{ Wilks' Lambda } \\
\hline & & \multirow{2}{*}{ Statistic } & \multirow{2}{*}{ Df1 } & \multirow{2}{*}{$\mathrm{df2}$} & \multirow{2}{*}{ df3 } & \multicolumn{4}{|c|}{ Exact F } \\
\hline & & & & & & Statistic & df1 & Df2 & Sig. \\
\hline 1 & $\begin{array}{c}\text { ambiente ao meu } \\
\text { gosto }\end{array}$ & 0,655 & 1 & 2 & 120 & 31,653 & 2 & 120 & 0,000 \\
\hline 2 & qualidade da comida & 0,515 & 2 & 2 & 120 & 23,399 & 4 & 238 & 0,000 \\
\hline 3 & $\begin{array}{c}\text { pessoas importantes } \\
\text { para o trabalho }\end{array}$ & 0,444 & 3 & 2 & 120 & 19,674 & 6 & 236 & 0,000 \\
\hline 4 & forma como me visto & 0,378 & 4 & 2 & 120 & 18,33 & 8 & 234 & 0,000 \\
\hline
\end{tabular}




\begin{tabular}{|c|c|c|c|c|c|c|c|c|c|}
\hline \multirow{3}{*}{ Passo } & \multirow{3}{*}{ Variáveis Incluídas } & \multicolumn{8}{|c|}{ Wilks' Lambda } \\
\hline & & \multirow{2}{*}{ Statistic } & \multirow{2}{*}{ Df1 } & \multirow{2}{*}{ df2 } & \multirow{2}{*}{ df3 } & \multicolumn{4}{|c|}{ Exact $\mathrm{F}$} \\
\hline & & & & & & Statistic & df1 & Df2 & Sig. \\
\hline 5 & $\begin{array}{l}\text { normalmente } \\
\text { gente como eu }\end{array}$ & 0,336 & 5 & 2 & 120 & 16,851 & 10 & 232 & 0,000 \\
\hline 6 & $\begin{array}{c}\text { pequena variedade } \\
\text { de pratos }\end{array}$ & 0,304 & 6 & 2 & 120 & 15,623 & 12 & 230 & 0,000 \\
\hline 7 & localização & 0,277 & 7 & 2 & 120 & 14,642 & 14 & 228 & 0,000 \\
\hline 8 & manobrista & 0,258 & 8 & 2 & 120 & 13,667 & 16 & 226 & 0,000 \\
\hline 9 & pessoas famosas & 0,233 & 9 & 2 & 120 & 13,363 & 18 & 224 & 0,000 \\
\hline 10 & LIMPEZA & 0,206 & 10 & 2 & 120 & 13,343 & 20 & 222 & 0,000 \\
\hline 11 & atmosfera agradável & 0,192 & 11 & 2 & 120 & 12,812 & 22 & 220 & 0,000 \\
\hline 12 & qualidade do serviço & 0,179 & 12 & 2 & 120 & 12,416 & 24 & 218 & 0,000 \\
\hline
\end{tabular}

Cumpre realçar na Tabela 28: Variáveis Incluídas e Removidas na Análise Discriminante Passo a Passo que após a variável mais destacada (qualidade da comida), são mostradas três variáveis ligadas de alguma forma ao público que freqüenta o restaurante: "pessoas importantes para o trabalho", a forma de se vestir e "gente como eu". Na Tabela 29 apresentada abaixo é visualizada a ordem de entrada das variáveis na análise: 
Tabela 29: Ordem de Inclusão das Variáveis na Análise Discriminante Passo a Passo

\begin{tabular}{|c|c|c|c|}
\hline Step & Tolerance & $\begin{array}{c}\text { F to } \\
\text { Remove }\end{array}$ & $\begin{array}{c}\text { Wilks' } \\
\text { Lambda }\end{array}$ \\
\hline 1 ambiente ao meu gosto & 1 & 31,653 & \\
\hline ambiente ao meu gosto & 0,986 & 32,566 & 0,797 \\
\hline 2 qualidade da comida & 0,986 & 16,112 & 0,655 \\
\hline ambiente ao meu gosto & 0,985 & 31,502 & $\overline{0,682}$ \\
\hline qualidade da comida & 0,969 & 17,242 & 0,574 \\
\hline 3 pessoas importantes para o trabalho & 0,982 & 9,404 & 0,515 \\
\hline ambiente ao meu gosto & 0,977 & 26,772 & $\overline{0,551}$ \\
\hline qualidade da comida & 0,954 & 10,526 & 0,446 \\
\hline pessoas importantes para o trabalho & 0,919 & 11,756 & 0,454 \\
\hline 4 forma como me visto normalmente & 0,911 & 10,279 & 0,444 \\
\hline ambiente ao meu gosto & 0,942 & 25,007 & 0,48 \\
\hline qualidade da comida & 0,952 & 10,106 & 0,394 \\
\hline pessoas importantes para o trabalho & 0,854 & 15,326 & 0,424 \\
\hline forma como me visto normalmente & 0,904 & 7,478 & 0,379 \\
\hline 5 gente como eu & 0,875 & 7,325 & 0,378 \\
\hline ambiente ao meu gosto & 0,941 & 23,75 & $\overline{0,429}$ \\
\hline qualidade da comida & 0,951 & 9,514 & 0,354 \\
\hline pessoas importantes para o trabalho & 0,729 & 20,468 & 0,412 \\
\hline forma como me visto normalmente & 0,878 & 7,922 & 0,345 \\
\hline gente como eu & 0,874 & 7,177 & 0,341 \\
\hline 6 pequena variedade de pratos & 0,843 & 6,067 & 0,336 \\
\hline ambiente ao meu gosto & 0,941 & 23,347 & $\overline{0,391}$ \\
\hline qualidade da comida & 0,898 & 11,956 & 0,335 \\
\hline pessoas importantes para o trabalho & 0,727 & 19,487 & 0,372 \\
\hline forma como me visto normalmente & 0,875 & 6,693 & 0,31 \\
\hline gente como eu & 0,869 & 5,563 & 0,304 \\
\hline pequena variedade de pratos & 0,839 & 6,231 & 0,308 \\
\hline 7 localização & 0,926 & 5,394 & 0,304 \\
\hline ambiente ao meu gosto & 0,902 & 25,131 & 0,373 \\
\hline qualidade da comida & 0,886 & 12,695 & 0,316 \\
\hline pessoas importantes para o trabalho & 0,677 & 23,053 & 0,364 \\
\hline forma como me visto normalmente & 0,874 & 6,205 & 0,287 \\
\hline gente como eu & 0,868 & 4,944 & 0,281 \\
\hline pequena variedade de pratos & 0,837 & 6,291 & 0,287 \\
\hline localização & 0,926 & 4,98 & 0,281 \\
\hline 8 manobrista & 0,856 & 4,15 & 0,277 \\
\hline ambiente ao meu gosto & 0,9 & 23,969 & 0,332 \\
\hline qualidade da comida & 0,82 & 15,173 & 0,296 \\
\hline pessoas importantes para o trabalho & 0,599 & 9,673 & 0,273 \\
\hline forma como me visto normalmente & 0,874 & 6,081 & 0,258 \\
\hline gente como eu & 0,867 & 4,621 & 0,252 \\
\hline pequena variedade de pratos & 0,837 & 5,897 & 0,257 \\
\hline localização & 0,903 & 6,108 & 0,258 \\
\hline manobrista & 0,741 & 7,619 & 0,264 \\
\hline 9 pessoas famosas & 0,624 & 6,213 & 0,258 \\
\hline ambiente ao meu gosto & 0,855 & 13,903 & 0,258 \\
\hline qualidade da comida & 0,82 & 14,059 & 0,258 \\
\hline pessoas importantes para o trabalho & 0,594 & 10,006 & 0,243 \\
\hline forma como me visto normalmente & 0,872 & 5,897 & 0,228 \\
\hline gente como eu & 0,863 & 4,121 & 0,222 \\
\hline pequena variedade de pratos & 0,836 & 5,217 & 0,226 \\
\hline localização & 0,901 & 6,074 & 0,229 \\
\hline manobrista & 0,638 & 12,251 & 0,252 \\
\hline pessoas famosas & 0,611 & 7,438 & 0,234 \\
\hline 10 LIMPEZA & 0,771 & 7,076 & 0,233 \\
\hline ambiente ao meu gosto & 0,788 & 7,709 & $\overline{0,219}$ \\
\hline qualidade da comida & 0,819 & 14,046 & 0,241 \\
\hline pessoas importantes para o trabalho & 0,593 & 8,993 & 0,224 \\
\hline forma como me visto normalmente & 0,863 & 5,942 & 0,213 \\
\hline gente como eu & 0,755 & 4,394 & 0,208 \\
\hline pequena variedade de pratos & 0,836 & 5,124 & 0,21 \\
\hline localização & 0,899 & 5,429 & 0,211 \\
\hline manobrista & 0,613 & 14,111 & 0,241 \\
\hline pessoas famosas & 0,577 & 9,357 & 0,225 \\
\hline LIMPEZA & 0,769 & 7,155 & 0,217 \\
\hline 11 atm osfera agradável & 0,708 & 4,022 & 0,206 \\
\hline ambiente ao meu gosto & 0,781 & 7,773 & $\overline{0,204}$ \\
\hline qualidade da comida & 0,777 & 8,317 & 0,206 \\
\hline pessoas importantes para o trabalho & 0,593 & 8,296 & 0,206 \\
\hline forma como me visto normalmente & 0,863 & 5,807 & 0,198 \\
\hline gente como eu & 0,744 & 5,064 & 0,195 \\
\hline pequena variedade de pratos & 0,835 & 5,105 & 0,195 \\
\hline localização & 0,838 & 7,421 & 0,203 \\
\hline manobrista & 0,596 & 15,373 & 0,229 \\
\hline pessoas famosas & 0,576 & 9,378 & 0,209 \\
\hline LIMPEZA & 0,742 & 5,65 & 0,197 \\
\hline atmosfera agradável & 0,691 & 4,374 & 0,193 \\
\hline 12 qualıdade do servıço & 0,173 & $4,1 / 1$ & 0,192 \\
\hline
\end{tabular}


A partir dessas variáveis selecionadas na análise discriminante foram geradas duas funções canônicas para classificar todos os entrevistados em conglomerados. O resultado obtido apresentou alguns erros de classificação, a exemplo da análise discriminante realizada na seção anterior. Em relação ao conglomerado 1 (Emuladores), um dos seus membros foi classificado como fazendo parte do conglomerado 2 (Gourmets). O conglomerado 2 (Gourmets) apresentou 2 membros alocados erroneamente no conglomerado 1 (Emuladores) e 3 no conglomerado (Aristocratas). Finalmente, o conglomerado 3 teve 2 membros classificados como pertencentes ao conglomerado 1 (Emuladores) e outros 2 postos no conglomerado 2 (Gourmets). Somente o conglomerado 1 (Emuladores) não teve nenhum membro classificado erroneamente como sendo do conglomerado 3 (Aristocratas). A Tabela 30 abaixo sintetiza esses resultados:

Tabela 30: Resultados das funções canônicas versus conglomerados "reais" (passo a passo)

\begin{tabular}{lrrrrr}
\hline \multirow{2}{*}{ Conglomerado \# } & \multicolumn{3}{c}{ Previsão } & \multicolumn{3}{c}{ Total } \\
\hline Contagem Original & 1 & 40 & 1 & 0 & 41 \\
& 2 & 2 & 19 & 3 & 24 \\
& 3 & 2 & 2 & 54 & 58 \\
\hline$\%$ & 1 & 97,6 & 2,4 & 0 & 0 \\
& 2 & 8,3 & 79,2 & 12,5 & 12,5 \\
& 3 & 3,4 & 3,4 & 93,1 & 93,1 \\
\hline $91,9 \%$ dos casos orginais foram corretamente classificados. \\
\hline
\end{tabular}

Esses resultados também podem ser mostrados graficamente: 


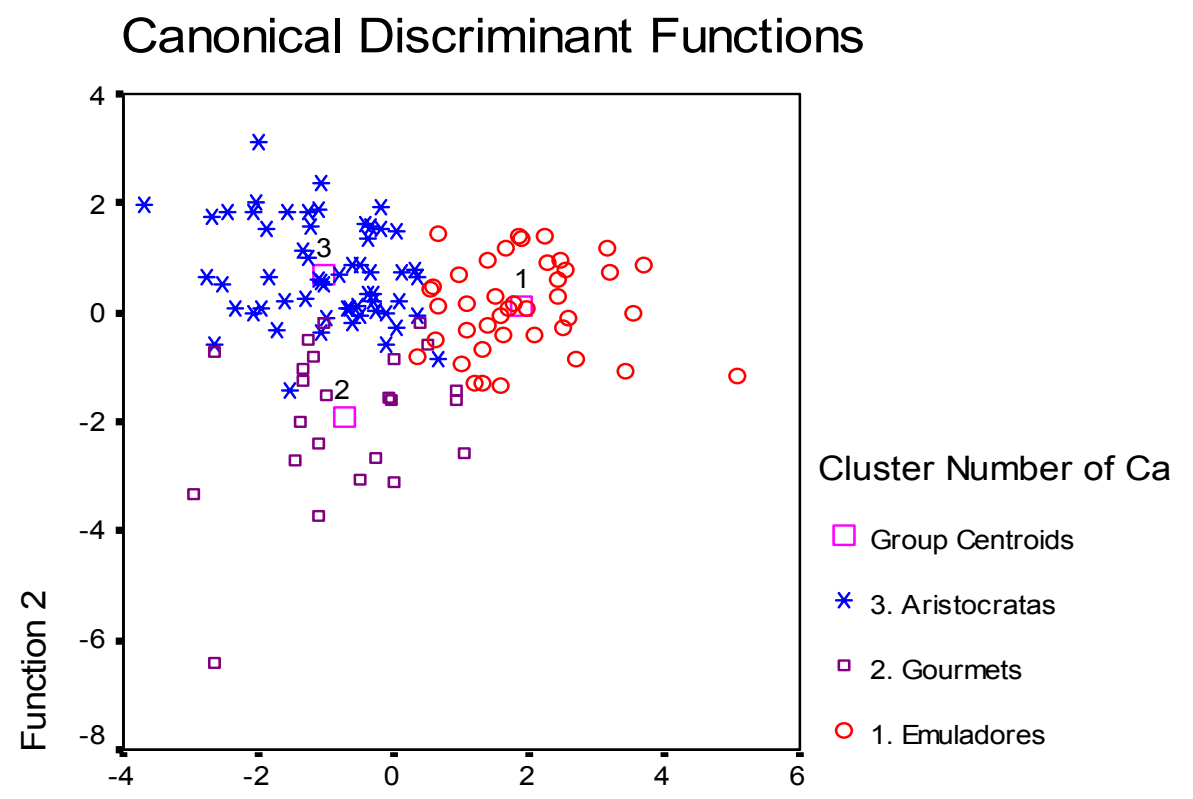

Function 1

Figura 6: Conglomerados baseados em análise discriminante passo a passo

Tabela 31: Coeficientes da Função de Classificação (Análise Passo a Passo)

\begin{tabular}{l|ccc}
\hline \multicolumn{1}{c|}{ Variáveis } & \multicolumn{3}{c}{ Conglomerados } \\
& 1. Emuladores & 2. Gourmets & 3. Aristocratas \\
\hline Localização & $-2,226$ & $-1,296$ & $-0,559$ \\
Forma como me visto normalmente & 4,988 & 4,479 & 5,841 \\
Manobrista & $-8,705$ & $-6,486$ & $-6,595$ \\
gente como eu & $-0,889$ & $-0,286$ & 0,615 \\
atmosfera agradável & 7,608 & 5,761 & 6,371 \\
ambiente ao meu gosto & 4,81 & 2,124 & 4,344 \\
pessoas famosas & 8,913 & 6,793 & 7,145 \\
pessoas importantes para o trabalho & 2,609 & 1,284 & 0,637 \\
LIMPEZA & 11,064 & 8,664 & 9,538 \\
pequena variedade de pratos & 1,666 & 3,191 & 2,952 \\
qualidade da comida & 34,81 & 33,469 & 31,057 \\
qualidade do serviço & 10,438 & 9,86 & 8,312 \\
(Constant) & $-173,09$ & $-141,09$ & $-144,29$ \\
\hline
\end{tabular}




\subsection{O índice de preços hedônicos}

Segundo Lancaster (1966a, 1966b, 1971, 1991), um índice de preços hedônicos é uma somatória dos atributos de um dado bem. Para cada atributo, a quantidade (ou presença) é ponderado pelo seu peso. Há várias formas de se obter essa ponderação. Nesta tese, optou-se por algumas formas de encontrar essa ponderação dos atributos (para o caso estudado: restaurantes). A primeira foi realizar uma análise fatorial e considerar os fatores como atributos. Uma segunda forma, seguindo a ordem das análises realizadas, é utilizar os coeficientes das funções de classificação obtidas na análise discriminate. Ambas as formas são apresentadas a seguir.

Recapitulando, para Lancaster (1966a, 1966b, 1971, 1991), é possível considerar um bem como sendo um conjunto de características (atributos):

$$
B=a_{1}+a_{2}+a_{3}+\ldots+a_{n}
$$

onde,

B é um bem qualquer;

$a_{1}$ é o atributo $1 \ldots$

$a_{n}$ é o atributo $n$.

Assumindo que o bem em questão é um restaurante e que os atributos do restaurante são as 47 variáveis utilizadas na análise discriminate, tem-se que do ponto de vista dos consumidores pesquisados, a oferta de um restaurante pode ser descrita como:

$$
R_{n}=V_{1}+V_{2}+V_{3}+\ldots+V_{45}+V_{46}+V_{47}
$$

onde 
$R_{n}$ é um restaurante $n$ qualquer,

$V_{1}$ são as pessoas que consumidor convidou para acompanhá-lo;

$V_{2}$ são as pessoas que acompanham o consumidor ao restaurante;

$V_{3}$ é o tipo de comida oferecida no restaurante;

$V_{4}$ é a rapidez no atendimento;

$V_{5}$ é o preço;

$V_{6}$ é a localização;

$V_{7}$ é a proximidade do restaurante em relação à casa do consumidor;

$V_{8}$ é a proximidade do restaurante em relação ao local de trabalho do consumidor;

$V_{9}$ é forma como o consumidor se veste;

$V_{10}$ é o horário de funcionamento do restaurante;

$V_{11}$ é o estacionamento do restaurante;

$V_{12}$ é a existência de manobrista no estacionamento do restaurante;

$V_{13}$ é a presença de maitre/hostess no restaurante;

$V_{14}$ é a existência de sala de espera no restaurante;

$V_{15}$ é a decoração do restaurante;

$V_{16}$ é a existência de bar no restaurante;

$V_{17}$ é o público que freqüenta o restaurante;

$V_{18}$ é a presença de amigos do consumidor no restaurante;

$V_{19}$ indica se o restaurante é um lugar da moda (ou não);

$\mathrm{V}_{20}$ é a presenaça de pessoas semelhantes ao consumidor no restaurante ("gente como eu");

$V_{21}$ é a presenta de pessoas com status social diferenciado no restaurante (na opinião do consumidor)

$V_{22}$ indica se o consumidor julga o restaurante um lugar propício para levar seus filhos;

$V_{23}$ é a presença de pessoas no restaurante que estejam na mesma faixa etária do consumidor;

$\mathrm{V}_{24}$ indica o quanto o consumidor julga agradável a atmosfera do restaurante;

$\mathrm{V}_{25}$ indica o quanto o consumidor julga agradável o ambiente físico do restaurante; 
$\mathrm{V}_{26}$ é a presença de pessoas conhecidas do consumidor no restaurante;

$V_{27}$ é a presença de muita gente no restaurante;

$V_{28}$ é a presença de poucas pessoas no restaurante;

$V_{29}$ é a presença de pessoas famosas no restaurante;

$\mathrm{V}_{30}$ é a presença no restaurante de pessoas importantes para 0 trabalho do consumidor;

$\mathrm{V}_{31}$ é a presença de clientes no restaurante que reconhecem quem é o consumidor;

$V_{32}$ indica o quanto é (ou não) a importância das outras pessoas que estão no restaurante para o consumidor;

$\mathrm{V}_{33}$ indica a exitência de sala privativa no restaurante;

$V_{34}$ indica a existência de área para fumantes;

$\mathrm{V}_{35}$ indica o quanto o restaurante é limpo;

$\mathrm{V}_{36}$ indica o grau de silêncio no restaurante;

$\mathrm{V}_{37}$ indica a existência de música no restaurante;

$V_{38}$ signfica que o cardápio do restaurante é compreensível;

$V_{39}$ significa que o restaurante oferece uma grande variedade de pratos;

$\mathrm{V}_{40}$ significa que o restaurante oferece uma pequena variedade de pratos;

$\mathrm{V}_{41}$ significa que o restaurante tem uma carta de vinhos;

$\mathrm{V}_{42}$ é a apresentação dos pratos;

$V_{43}$ é a qualidade da comida servida;

$\mathrm{V}_{44}$ indica a aceitação de cartão de crédito como forma de pagamento;

$\mathrm{V}_{45}$ indica a aceitação de cheque como forma de pagamento;

$\mathrm{V}_{46}$ indica a aceitação de ticket como forma de pagamento; e

$\mathrm{V}_{47}$ é a qualidade do serviço;

Dados esses atributos de um restaurante, seria possível estimar qual seria seu público, ao comparar a função oferta com a função demanda por atributos dos consumidores. Para avaliar os atributos do restaurante, o ideal seria 
realizar uma enquete com seus consumidores, para mensurar como o restaurante é avaliado. Simultaneamente, seria feita uma pesquisa sobre como os consumidores escolhem o restaurante, semelhante à pesquisa realizada nesta tese. Assim, seria possível prever a probabilidade de sucesso para o empreendimento. Este seria uma adaptação do modelo do ponto ideal, descrito na seção 3.1 Os modelos de atributos nos manuais do comportamento do consumidor desta tese.

O ponto importante é que neste caso o público que freqüenta o restaurante estaria sendo utilizado como um atributo, em suas várias formas (como mostram os fatores Freqüentadores, Grupo Social e Animação). Seria possível, então, descobrir se a empresa está conseguindo alcançar o público-alvo ou não. Esta técnica, da forma como aqui apresentada, também permite descobrir porque um restaurante pode tornar-se um sucesso para um público consumidor inesperado. Basta que os atributos do restaurante sejam os mais semelhantes aos atributos ideais desse público. Note-se que o trabalho de Becker (1991) não possibilita essa descoberta. Já os manuais de comportamento do consumidor, conquanto aceitem a influência interpessoal, não apresentam uma forma tão direta de mensurar essa influência.

\subsubsection{O índice hedônico calculado com base no coeficientes das funções discriminantes}

Em caráter exploratório, calculou-se um índice hedônico assumindo-se que os coeficientes das funções discrimintantes calculadas nesta tese podem ser 
considerados equivalentes aos pesos para a ponderação dos atributos nos moldes propostos por Lancaster (1966a).

As vantagens dessa forma de proceder são duas: 1) um aumento da precisão, pois cada variável teria sua própria ponderação; e 2) ganho de tempo, pois com uma pesquisa é possível calcular os índices. Porém, há pelo menos uma desvantagens: há menos fatores do que variáveis (pois um dos objetivos da análise fatorial é mesmo reduzir o número de variáveis a serem manipuladas). Portanto, se fosse utilizada uma análise conjunta para mensurar a importância dos fatores, isto facilitaria a manipulação dos dados, em especial quando há muitas variáveis. Obviamente, qual metodologia utilizar depende, pois, de 1) o número de atributos do produto em si. Quanto maior o número, melhor seria o uso dos fatores; 2) o tempo e o dinherio disponíveis para a pesquisa.

O cálculo dos índices é o seguinte:

Assumindo-se que:

RE seja o restaurante que apresentaria a combinação de atributos ideal para os Emuladores;

RG seja o restaurante ideal para os Gourmets;

RA seja o restaurante ideal para os Aristocratas;

$\mathrm{C}_{\mathrm{rn}}$ uma constante para cada restaurante $\mathrm{n}$.

tem-se que

$$
\begin{aligned}
\mathrm{RE}= & 3,856 \mathrm{~V}_{1}+3,725 \mathrm{~V}_{2}+15,807 \mathrm{~V}_{3}-0,594 \mathrm{~V}_{4}+9,449 \mathrm{~V}_{5}-8,087 \mathrm{~V}_{6}+2,504 \mathrm{~V}_{7} \\
& 0,471 \mathrm{~V}_{8}+3,995 \mathrm{~V}_{9}-2,804 \mathrm{~V}_{10}-1,108 \mathrm{~V}_{11}-7,293 \mathrm{~V}_{12}-2,584 \mathrm{~V}_{13}-3,149 \mathrm{~V}_{14} \\
& -4,351 \mathrm{~V}_{15}-6,575 \mathrm{~V}_{16}-4,002 \mathrm{~V}_{17}-0,0397 \mathrm{~V}_{18}+3,524 \mathrm{~V}_{19}+7,325 \mathrm{~V}_{20}-2,453 \mathrm{~V}_{21} \\
& +14,798 \mathrm{~V}_{22}-1,776 \mathrm{~V}_{23}+9,114 \mathrm{~V}_{24}-4,7 \mathrm{~V}_{25}-4,92 \mathrm{~V}_{26}+2,131 \mathrm{~V}_{27}+6,6 \mathrm{~V}_{28}+ \\
& 11,277 \mathrm{~V}_{29}+7,014 \mathrm{~V}_{30}-3,777 \mathrm{~V}_{31}+1,697 \mathrm{~V}_{32}-8,824 \mathrm{~V}_{33}+1,065 \mathrm{~V}_{34}+17,929 \mathrm{~V}_{35}
\end{aligned}
$$




$$
\begin{aligned}
& -0,415 \mathrm{~V}_{36}+6,616 \mathrm{~V}_{37}-13,752 \mathrm{~V}_{38}+17,626 \mathrm{~V}_{39}+4,823 \mathrm{~V}_{40}+5,497 \mathrm{~V}_{41} \\
& +2,467 \mathrm{~V}_{42}+43,016 \mathrm{~V}_{43}+4,078 \mathrm{~V}_{44}-0,75 \mathrm{~V}_{45}+3,444 \mathrm{~V}_{46}+23,879 \mathrm{~V}_{47} \\
& -335,524 C_{r e} \\
& R G=4,567 V_{1}+2,998 V_{2}+16,233 V_{3}-0,483 V_{4}+8,785 V_{5}-7,206 V_{6}+2,396 V_{7} \\
& -0,414 \mathrm{~V}_{8}+3,594 \mathrm{~V}_{9}-2,795 \mathrm{~V}_{10}+0,191 \mathrm{~V}_{11}-4,706 \mathrm{~V}_{12}-4,094 \mathrm{~V}_{13}-1,275 \mathrm{~V}_{14} \\
& -5,514 V_{15}-6,538 V_{16}-3,456 V_{17}-0,255 V_{18}+2,908 V_{19}+5,9 V_{20}-2,647 V_{21} \\
& +13,876 \mathrm{~V}_{22}-0,287 \mathrm{~V}_{23}+6,1 \mathrm{~V}_{24}-6,664 \mathrm{~V}_{25}-3,472 \mathrm{~V}_{26}+2,179 \mathrm{~V}_{27}+7,232 \mathrm{~V}_{28} \\
& +7,775 \mathrm{~V}_{29}+5,564 \mathrm{~V}_{30}-2,857 \mathrm{~V}_{31}+1,64 \mathrm{~V}_{32}-8,231 \mathrm{~V}_{33}+1,265 \mathrm{~V}_{34}+13,916 \mathrm{~V}_{35}- \\
& 0,666 V_{36}+5,309 V_{37}-12,476 V_{38}+17,493 V_{39}+6,989 V_{40}+4,371 V_{41}+2,156 V_{42} \\
& +40,702 \mathrm{~V}_{43}+4,077 \mathrm{~V}_{44}-1,79 \mathrm{~V}_{45}+2,789 \mathrm{~V}_{46}+23,892 \mathrm{~V}_{47}-289,016 \mathrm{C}_{\mathrm{G}} \\
& R A=2,854 V_{1}+3,798 V_{2}+14,48 V_{3}-0,79 V_{4}+9,004 V_{5}-6,479 V_{6}+2,991 V_{7}-0,232 V_{8} \\
& +5,017 \mathrm{~V}_{9}-1,531 \mathrm{~V}_{10}-0,156 \mathrm{~V}_{11}-5,303 \mathrm{~V}_{12}-2,361 \mathrm{~V}_{13}-2,533 \mathrm{~V}_{14}-4,404 \mathrm{~V}_{15} \\
& -6,47 \mathrm{~V}_{16}-2,454 \mathrm{~V}_{17}+0,334 \mathrm{~V}_{18}+2,801 \mathrm{~V}_{19}+8,438 \mathrm{~V}_{20}-2,566 \mathrm{~V}_{21}+13,85 \mathrm{~V}_{22}- \\
& 1,793 V_{23}+7,316 V_{24}-4,015 V_{25}-4,96 V_{26}+1,957 V_{27}+6,251 V_{28}+9,501 V_{29} \\
& +4,091 \mathrm{~V}_{30}-3,494 \mathrm{~V}_{31}+1,088 \mathrm{~V}_{32}-8,386 \mathrm{~V}_{33}+0,721 \mathrm{~V}_{34}+15,629 \mathrm{~V}_{35}+0,674 \mathrm{~V}_{36} \\
& +6,324 \mathrm{~V}_{37}-13,451 \mathrm{~V}_{38}+6,293 \mathrm{~V}_{39}+6,65 \mathrm{~V}_{40}+4,693 \mathrm{~V}_{41}+2,075 \mathrm{~V}_{42}+37,921 \mathrm{~V}_{43} \\
& +4,036 \mathrm{~V}_{44}-1,107 \mathrm{~V}_{45}+3,386 \mathrm{~V}_{46}+20,759 \mathrm{~V}_{47}-284,096 \mathrm{C}_{\mathrm{A}}
\end{aligned}
$$

Há três formas de simplificar estes cálculos: 1) realizar este cálculo utilizando apenas as variáveis selecionadas pela análise discriminante passoa a passo ("stepwise"); 2) proceder a uma análise discriminante dos conglomerados encontrados usando os fatores ao invés das variáveis; e, finalmente, 3) uma variante desta última forma seria fazer uma análise discriminante passo a passo ("stepwise") com os fatores (o que reduziria ainda mais os termos das equações que representam os índices de preços hedônicos de Lancaster. 


\section{CONCLUSÕES}

"A verdade é raramente pura e nunca simples."

Oscar Wilde

Este capítulo está divido em três seções principais, que estão organizadas pela ordem: conclusões baseadas nas hipóteses de pesquisa, sugestões para novas pesquisas empíricas e sugestões para novas pesquisas práticas.

\subsection{Conclusões feitas a partir das hipóteses utilizadas}

Recapitulando, as duas hipóteses desta tese, apresentadas à seção 2.5, p.18 acima, são as seguintes:

1. É possível mensurar a influência interpessoal entre jovens universitários consumidores de restaurante na cidade de São Paulo.

2. É possível ampliar a explicação teórica em marketing de como se dá a influência interpessoal utilizando a teoria proposta por Kelvin Lancaster. 
Nas próximas duas subseções são discutidas as conclusões referentes a cada hipótese em separado.

\subsubsection{A mensuração da demanda de restaurantes utilizando o público como um atributo}

Para a primeira hipótese de pesquisa, é possível concluir que há formas de mensurar a influência interpessoal entre a amostra pesquisada. Foram utilizadas duas técnicas multivariadas: análise fatorial $e$ análise de conglomerados. A primeira técnica possibilitou a redução das 47 variáveis utilizadas em 15 fatores, dos quais 10 foram utilizados na análise de conglomerados. A aplicação dessa técnica estatística possibilitou o reconhecimento de três conglomerados distintos. Em todos esses segmentos de consumidores, foi detectada a importância de alguma característica do público que freqüenta o restaurante.

Esta conclusão é baseada na composição dos fatores calculados: há três fatores no qual a importância do público é explicitada: 1) "Freqüentadores", no qual estão incluídas as seguintes variáveis: "pessoas famosas", "outros clientes me reconhecem" e "pessoas importantes para o trabalho"; 2) "Grupo Social"; que agrupa as variáveis "gente da minha idade", "não me importo com as pessoas que freqüentam o restaurante" (com correlação negativa, ou seja, as pessoas que estão no lugar importam sim) e "gente como eu"; e 3) "Animação", cuja principal variável incluída é "muita gente". Além desses fatores, há ainda o fator "Sofisticação" no qual a variável "público que freqüenta o lugar" aparece, ainda que marginalmente. 
A partir desses fatores foram calculados os três conglomerados utilizados na análise: "Emuladores Pecuniários", "Bons Gourmets" e "Aristocratas". Em cada um desses segmentos, a importância de cada fator é distinta - ou seja, cada tipo de consumidor avalia de modo distinto o público que freqüenta um restaurante. - Se essa medida parece ser indireta, deve-se à natureza mesma do objeto estudado. Como discute Pereira (2003: 100), quando entrevistadas, as pessoas tendem a responder de acordo com "os valores positivos existentes na sociedade em que vivem". Isto significa que é bastante improvável que alguém vá responder diretamente à questões sobre freqüentar ou não ambientes por causa de outras pessoas (especialmente se a resposta implicar a revelação de algum tipo de preconceito racial, religioso ou sexual).

Essa conclusão de que há diferentes conjuntos de pessoas em uma mesma amostra está de acordo com toda a teoria de segmentação, desde o pioneiro trabalho de Smith (1956) até os dias de hoje, como Toledo (1972), Grisi (1986), Siqueira (1997), Pereira (2000) e Finotti (2004): os consumidores não são homogêneos, tanto nas preferências como na forma de se comportar. Mesmo a racionalidade com que cada consumidor escolhe um produto pode diferir (conclusão que é possível derivar não apenas dos estudos sobre comportamento do consumidor feitos por estudiosos de marketing, mas também por trabalhos de sociologia, desde as distinções feitas por Weber, 1922, sobre os tipos de racionalidade).

Mais importante ainda é a constatação de que os consumidores reconhecem diferenças entre o público que freqüenta um restaurante: para os próprios consumidores, tratam-se de "públicos" e não de um público único. Isto prejudica as conclusões de Becker (1991), que assume as tradicionais homogeneidade dos consumidores e a racionalidade econômica como regra de 
conduta. $^{66}$

Ao mesmo tempo, essa constatação de que há públicos de restaurante e que esses públicos têm consciência das diferenças existentes entre as pessoas corrobora as conclusões de Corneo e Jeanne (1994b e 1999) sobre a dinâmica da variação de consumidores em bares. Há pessoas que preferem encontrar-se com outras que pertençam à mesma classe social e há pessoas que optam por freqüentam lugares onde não encontrarão seus pares (em termos de classe social - ou, hodiernamente, "estilo de vida"). Aparentemente, na amostra pesquisada, as pessoas do conglomerado Emuladores procuram ir a lugares onde estão os consumidores do conglomerado Aristocratas. Mas estes últimos preferem freqüentar lugares onde encontram pessoas que pertençam ao mesmo grupo social. Como há assimetria informacional, isto torna-se um ciclo, como mostrado por Corneo e Jeanne (1994b e 1999). Note-se que as pessoas do último conglomerado ("Bons Gourmets") interessam-se apenas em saber o grau de lotação do restaurante - quanto mais, melhor - mas sem se preocupar excessivamente com o tipo de público (embora dêem preferência a pessoas do mesmo grupo social).

Se tudo isto é verdadeiro, talvez a explicação de Becker (1991) para o formato da curva de demanda de um restaurante seja, no mínimo, incompleta. $\mathrm{O}$ equilíbrio com demanda acima da lotação do restaurante talvez seja mais duradouro do que sugere a análise de Becker (1991). Isto leva à possibilidade de, para um determinado restaurante, haver uma de curva de demanda positivamente

\footnotetext{
${ }^{66}$ Kuttner (1996: cap.2) mostra que as pessoas que tendem a se comportar da maneira mais semelhante possível ao consumidor racional da teoria econômica ortodoxa são exatamente as pessoas treinadas nesse tipo de teoria: economistas e estudantes de Economia. Como diz Pereira (2003: 99): "só vemos aquilo para o qual fomos treinados (socializados) para ver, deixando de lado, geralmente, tudo o que não esteja dentro dos limites de nossos estreitos interesses".
} 
inclinada, como já sugeriram Becker (1991) e Pereira (2000). Mas Becker (1991) sugere que esse fenômeno é passageiro, ao passo que Pereira (2000) indica que talvez o formato da curva de demanda agregada inclua uma seção positivamente inclinada (o chamado Efeito Veblen). O modelo de atributos de Lancaster, acrescido da noção de heterogeneidade da demanda das teorias de marketing (ou seja, há grupos distintos entre si de consumidores), ${ }^{67}$ permite sugerir e complementar as explicações desses autores para as variações e para o formato da curva de demanda. Se o público é parte dos atributos de um restaurante e na verdade há muitos públicos (ou seja, mais de um atributo que represente o público, como parece haver sido confirmado pela análise dos dados), então se um restaurante conseguir atrair um segmento consumidor específico que seja um atributo importante para mais de um segmento de mercado, há a possibilidade de sua demanda tornar-se positivamente inclinada (variação da quantidade é positiva em relação às variações do preços) por um longo período de tempo (e não o fenômeno passageiro preconizado por Becker, 1991).

\subsubsection{A contribuição da abordagem de Lancaster para a teoria de marketing}

Quanto ao aproveitamento da teoria de Lancaster para um aperfeiçoamento da teoria de marketing, que é a segunda hipótese desta tese, é mister concluir que ainda há o que fazer. Lancaster (1966a; 1966b; 1969; 1971 e

\footnotetext{
${ }^{67}$ É mister lembrar que Alderson (1965) propôs um modelo de mercado completamente heterogêneo (em contraposição ao mercado homogêneo de concorrência perfeita da teoria econômica) e sugeriu uma forma de medi-lo. Pereira (2000) aplicou essa medida ao mercado brasileiro de automóveis e constatou que quanto maior for a renda do segmento estudado, maior a heterogeneidade do mercado.
} 
1991) demonstrou não apenas a importância dos atributos, mas também como o uso destes pode ser utilizado para estudar toda a economia. De certa forma, iniciou o que se poderia chamar de "macroeconomia dos atributos".

A ligação do trabalho de Lancaster ao marketing se dá por duas vias: a primeira é histórica, pois o marketing descende da teoria econômica (Grisi et al., 1983, Mazzon, 1978; Pereira, 2000). ${ }^{68}$ Portanto, é natural que modelos desenvolvidos em uma área do conhecimento sejam aplicáveis na outra. Contudo, a Economia também é conhecida como a ciência "imperialista", pois comumente os economistas aplicam seus métodos a problemas não econômicos (a obra de Gary Becker é, talvez, o melhor exemplo disso), ao passo que raramente economistas aceitam que a teoria econômica seja aperfeiçoada com base em teorias não-econômicas. ${ }^{69}$ Assim, o aproveitamento da teoria dos atributos de Lancaster provavelmente gerará mais avanços em marketing do que na teoria econômica.

Se a inclusão do público que consome um bem como um atributo desse bem é possível, e acredita-se que isto foi mostrado nesta tese, o passo seguinte seria tentar entender como se dá o fenômeno dos modismos. Usando o modelo desenvolvido por Lancaster (1966a; 1966b; 1969; 1971 e 1991) de uma matriz de consumo, o ideal seria criar uma matriz análoga à matriz de Leontief (1966), com os vários segmentos de consumidores e os atributos que apreciam nos produtos. Com isto, seria possível estimar a demanda de um produto com base na demanda de outro e ainda prever qual tipo de consumidor se interessaria pelo produto. A diferença dessa abordagem do mero cálculo de correlação

\footnotetext{
${ }^{68}$ Mazzon (1978: 3) chama a Economia de "ciência-mãe" do Marketing.

${ }^{69}$ Os autores que tentam semelhante proeza costumam ser deixados no limbo da História do Pensamento Econômico. O exemplo mais famoso é, provavelmente, a obra de Thorstein Veblen (em especial: Veblen, 1899).
} 
matemática seria a capacidade explicativa da abordagem matricial. A correlação pode indicar uma relação, mas não a explica (no sentido teórico do termo: não fornece nexo causal). Muitas correlações podem ser espúrias. Ademais, a abordagem matricial dos atributos possibilitaria encontrar relações insuspeitas entre os consumidores e seus comportamentos (em outros termos: descobrir a estrutura subjacente do fenômeno, como acontece ao se utilizar a análise fatorial).

Essa abordagem talvez pareça excessivamente economicista para o estudioso do marketing, mas este tipo de formulação é comum em muitos trabalhos de marketing, em especial naqueles publicados no Journal of Macromarketing. Ademais, como já foi discutido na seção 2.1 Introdução: Teoria de Marketing e a Questão do Valor, o marketing lida com trocas econômicas donde o economicismo talvez se torne conseqüência inevitável.

Portanto, em relação à segunda hipótese formulada, de que a abordagem dos atributos apresentada por Kelvin Lancaster auxilia no desenvolvimento da teoria de marketing, a resposta desta tese é inconclusiva. Em termos microeconômicos (ou de micromarketing), a teoria de Lancaster é um avanço - embora já existam modelos que utilizem atributos, estes são posteriores aos principais trabalhos de Lancaster, como foi discutido na seção 3.1 desta tese. - Quanto a uma explicação dos ciclos da moda, a teoria de Lancaster talvez auxilie na elucidação do fenômeno, mas ainda há que ser realizado mais trabalho teórico. 


\subsection{Sugestões para futuras pesquisas empíricas}

Nesta seção discute-se a necessidade de se realizar uma pesquisa empírica que possibilite a análise conjunta (conjoint analysis) dos fatores calculados no capítulo 4 desta tese.

\subsubsection{Análise Conjunta (Conjoint Analysis) e o modelo de atributos}

Se o que foi apresentado ao longo deste trabalho é correto, pode-se concluir que o índice de preço hedônico sugerido por Lancaster (1966a, 1966b, 1971, 1991) é um instrumento útil como ferramenta de marketing. Todavia, a maneira de calculá-lo na prática ainda pode ser matéria de discussão.

Uma resposta a essa questão foi formulada no Capítulo 5 "ANÁLISE DOS DADOS: A Construção de um Índice De preços hedônicos para a Cidade de São Paulo" desta tese. Porém, essa resposta foi dada em caráter exploratório. Um avanço possível seria a utilização dos fatores encontrados naquela análise (ver seção 5.3.1 Análise Fatorial) em uma nova pesquisa de campo, com a utilização da chamada Análise Conjunta ("Conjoint Analysis").

Como ressaltam Hair Jr. et al. (1998), essa técnica permite calcular a utilidade dos vários atributos para cada consumidor e, destarte, estimar qual a utilidade total de um produto para um consumidor. A palavra utilidade não surge por acaso no texto de Hair Jr. et al. (1998): é a palavra utilizada pelos economistas, notadamente os de formação neoclássica, para designar o valor de 
um bem para o consumidor (ver Jevons, 1871, por exemplo). ${ }^{70}$

Desde a chamada "revolução marginalista", em $1871,{ }^{71}$ uma questão crucial da teoria econômica é calcular a utilidade de um bem. Os economistas superaram esse problema propondo que o valor de um bem corresponde, em última instância, ao seu preço (Pereira, 2000 e 2001a). Logo, essa questão foi literalmente contornada. $\mathrm{O}$ trabalho de Lancaster recolocou o problema do cálculo da utilidade, mas sob uma nova ótica. Ainda assim, esse problema seguia como sendo meramente teórico, dada a complexidade do cálculo e da pesquisa empírica exigida para sua resposta.

Como mostraram Hair Jr. et al. (1998), o avanço da capacidade computacional nas últimas décadas do século XX possibilitou a implementação de várias técnicas estatística multivariadas no campo das ciências sociais, possibilitando vários testes empíricos para modelos antes considerados de difícil aplicação prática. Kotler (1988: 145) aborda esse tema de forma indireta, ao apresentar um quadro com uma síntese da evolução do uso das técnicas empregadas na pesquisa de marketing: ${ }^{72}$

Quadro 4: Técnicas desenvolvidas na pesquisa de marketing

\begin{tabular}{l|l}
\hline \multicolumn{1}{c|}{ Década } & \multicolumn{1}{c}{ Técnica } \\
\hline Antes de 1910 & Observação direta (em primeira mão) \\
\hline $1910-1920$ & $\begin{array}{l}\text { Análise de Vendas } \\
\text { Análise de custos operacionais } \\
\text { Elaboração de questionário } \\
\text { Técnicas de levantamento }\end{array}$ \\
\hline $1920-1930$ & $\begin{array}{l}\text { Amostragem por cotas } \\
\text { Análise de correlação simples }\end{array}$ \\
\hline
\end{tabular}

70 Siqueira (1997: 15-6) aborda brevemente essa questão, porém sem destacar a importância do conceito de utilidade como medida de valor, preocupando-se mais em conceituar precisamente utilidade, para realizar a ligação entre o conceito econômico e o estatístico, para demonstrar a validade do uso da técnica estatística de análise conjunta em na mensuração da utilidade de um bem qualquer para um dado consumidor.

71 Sobre a chamada "Revolução Marginalista" em teoria econômica, ver Galbraith (1987), Hunt (1978) e Skousen (2001) e Staley (1989: caps. 12 a 15).

${ }^{72}$ Curiosamente, esse quadro deixou de ser apresentado em edições subseqüentes do livro (Kotler, 1996 e 2000). 


\begin{tabular}{c|l}
\hline \multicolumn{1}{c|}{ Década } & \multicolumn{1}{c}{ Técnica } \\
\hline \multirow{1}{*}{$1940-1950$} & $\begin{array}{l}\text { Análise de distribuição de custos } \\
\text { Técnicas de verificação de estoque }\end{array}$ \\
\hline & $\begin{array}{l}\text { Amostragem por probabilidade } \\
\text { Métodos de regressão } \\
\text { Inferência estatística avançada } \\
\text { Painéis de consumidores e lojas }\end{array}$ \\
\hline Pesquisa de motivação \\
Pesquisas operacionais \\
Regressão múltipla e correlação múltipla \\
Esquema experimental \\
Aparelhos para medir atitudes \\
Análise de variância (ANDEV)
\end{tabular}

A análise conjunta serve para vários tipos de pesquisa: descobrir os fatores relevantes para os consumidores na escolha de um dado produto; prever a demanda para produtos com diferentes combinações de atributos; identificar segmentos de consumidores com base nos gostos em relação a um dado produto (Hair Jr. et al., 1998: 398; Malhotra, 1999: 554). Portanto, é possível utilizar essa técnica estatística para realizar uma pesquisa que teste o modelo lancasteriano

${ }^{73}$ Silveira (1997: 15) cita essa tabela, mas em inglês, pois usa como referência a $6^{a}$ edição norte-americana. Optou-se aqui por citar a edição brasileira de 1992, pois já está traduzida para o português. 
de atributos (o "índice de preço hedônico").

Há duas abordagens básicas de análise conjunta: "abordagem do perfil geral" (trade-off) e "abordagem da substitutibilidade" (full profile) (Aaker \& Day, 1999: 616-7).

A abordagem do perfil geral consiste em apresentar matrizes aos respondentes, cada uma com dois fatores e todos os níveis. Pede-se aos respondentes que classifiquem cada combinação (cada célula da matriz) por ordem de importância. (Hair Jr. et al., 1998: 412). A abordagem da susbtitutibilidade consiste em apresentar aos respondentes cartões com todas as combinações possíveis dos vários fatores (ou seja, com todos os níveis) (idem: 413). Hair et al. (1998) enfatizam, contudo, a necessidade de se evitar as combinações tidas como impossíveis pelos respondentes.

Outro ponto enfatizado por Hair et al. (1998) é a importância de se especificar qual a regra de composição a ser utilizada na análise, ou seja, como os diversos fatores interagem entre si. Há dois tipos de regras: interativa e aditiva. Para Hair et al. (1998: 410), a forma interativa (interactive form) permite uma representação mais acurada das preferências dos consumidores, ao passo que a "forma aditiva" demanda menos avaliações por parte dos respondentes. Se for considerado o modelo de Lancaster (1966b, 1971, 1991), aparentemente a regra de análise conjunta mais próxima da descrita nesse modelo seria a regra de aditiva.

Um último ponto importante é o número de estímulos a serem utilizados na pesquisa. Segundo Hair et al. (1998: 420), o número de estímulos não deve exceder muito o número de parâmetros a serem estimados (as variáveis).

As principais críticas à análise conjunta são duas: 1) a validade da 
segmentação realizada com base nessa técnica (ou seja, a agregação dos agentes econômicos/ indivíduos/ consumidores pode não ser a ideal); e 2) os atributos pesquisados podem não ser os utilizados pelos consumidores na análise dos bens (irrealidade das suposições) (Gibson, 2001 e Hair et al., 1999). Porém Green e Krieger (2002) rebateram as críticas feitas em Gibson (2001) e sustentaram que sim, é possível agregar os consumidores em segmentos fidedignos por meio da análise conjunta.

Finalmente, quanto à análise conjunta, um ponto frisado por Hair et al. (1998) é que essa técnica é usada para analisar dados desagregados (indivíduos). Porém, é possível utilizar essa técnica para descobrir segmentos de consumidores (que apresentem part-worths semelhantes). Outro problema que pode ser estudado com o auxílio dessa técnica é a análise de lucratividade. Ao se descobrir quais atributos de um produto são os mais preferidos pelos consumidores, é possível decidir a inclusão ou aumento (ou não) desse atributo no produto (comparando os custos disso com a rentabilidade esperada). Também é possível realizar análises do tipo ("e se") para estimar quais mudanças em um produto serão mais aceitas pelos consumidores (neste caso, contudo, o modelo deve ser validado - e sua análise refere-se a um grupo de consumidores, não a todo o mercado). Ou seja, essa técnica, combinada com a teoria econômica desenvolvida por Lancaster (1966b; 1971, 1991) permite várias aplicações em marketing.

Aliás, há vários trabalhos utilizando essa técnica estatística no estudo do consumo de alimentos, tais como Ângulo, Gil, Gracia e Sánchez (2000) e Gil e Sánches (1997), que estudaram as preferências dos consumidores de vinho; Monteiro e Lucas (2001), que pesquisaram quais atributos são considerados 
pelos consumidores portugueses ao comprar queijos; Ness e Gerhardy (1994) aplicaram a análise conjunta no estudo da compra de ovos pelos consumidores ingleses. Todavia, ainda são raros os que estudam os atributos dos restaurantes, como Koo, Tao e Yeung (1999), que utilizaram a técnica de análise conjunta para descobrir os principais fatores que levam consumidores de Hong Kong a escolher um retaurante. Conquanto esse trabalho seja relevante para o estudo do comportamento de consumidor de restaurante, novamente há a questão da influência interpessoal, que não é levada em conta.

\subsubsection{A análise conjunta como uma técnica para a aplicação do modelo de Lancaster em restaurantes}

Há vasta literatura ${ }^{74}$ sobre o gerenciamento de restaurantes (Dorf, 1992; Fonseca, 2000; Marvin, 1992; Steadman, 1991), sobre serviços (Bateson \& Hoffman, 2001; Lovelock \& Wright, 2001) e mesmo sobre o marketing aplicado a restaurantes (Smith, 1990). Lovelock e Wright (2001: cap. 13) chegam mesmo a discutir o marketing de serviços usando restaurante como exemplo. Porém, há poucos estudos sobre a aplicação da teoria dos atributos formulada por Lancaster (1966a; 1971; 1991) nesse tipo de serviço.

Koo, Tao e Yeung (1999) aplicaram um modelo de atributos a restaurantes, porém sem citar nenhum trabalho de Lancaster sobre o tema. Nesse estudo, Koo et al. (1999) pesquisaram quais os atributos valorizados em um restaurante por consumidores de restaurantes. Os autores classificaram os

\footnotetext{
${ }^{74}$ A lista ora apresentada não se pretende exaustiva, mas sim servir como indicação de fontes para novas e mais extensas pesquisas bibliográficas.
} 
restaurantes em três tipos, com base no propósito da refeição: para a família, para negócios ou para turistas. Koo et al. (1999) estudaram seis fatores (localização, tipo de comida etc.), com a aplicação de até cinco níveis por fator. Todavia, nenhum dos fatores pesquisados referia-se ao público com parte do produto. Vale dizer, sobre a importância das pessoas que freqüentam aquele restaurante como parte do atributo do serviço.

Note-se que Riley (1994) já havia abordado esse ponto, enfatizando que o consumo é uma atividade social e que o público é parte do atributo de um restaurante (Riley, 1994: 16). Becker (1991) havia tentado incorporar o público como parte do produto restaurante, mas sua modelagem é formal e abstrata, sendo de difícil aplicação em marketing. O mesmo problema ocorre com o modelo apresentado em Corneo e Jeanne (1999): embora esses autores formalizem um modelo com formadores de opinião e seguidores, sua aborgem excessivamente abstrata torna difícil a utilização desse modelo na prática do marketing de restaurantes.

Assim, embora a idéia de um produto ser a soma de um conjunto de atributos seja aceita no marketing (Kotler, 1994; Kotler \& Armstrong, 1991), a teoria de Lancaster permanece pouco explorada nesse campo de estudos. Sobretudo, se for utilizada tendo o comportamento dos outros consumidores como sendo um atributo. A principal dificuldade para a implementação desse estudo era teórica (em estatística) e computacional. Porém, atualmente ambas as dificuldades parecem sanadas: a técnica de análise conjunta parece ser ideal para esse tipo de estudo empírico (Aaker \& Day, 1999; Hair Jr. et al., 1998; Malhotra, 1999) - que teria o mérito de testar esse possível avanço teórico no Marketing. 


\subsection{Indicações para possíveis avanços teóricos: estilo de vida, papel social e atributos de consumidores}

Em sociologia, "papel social" é uma "expectativa socialmente definida seguida pelas pessoas de uma determinada posição social” (Giddens, 2001: 29). Grosso modo (e seguindo Charon, 1996: 88), é possível dizer que um estilo de vida é um conjunto de papéis sociais que uma determinada pessoa assume. Como nota Pereira (1983 e 2003), é possível uma pessoa assumir papéis sociais conflitantes ao longo da vida. O quanto cada papel é importante depende, de alguma forma, da psicologia individual de cada um e das circunstâncias em que se encontra. Daí as dificuldades apresentadas por Finotti (2004) na definição e descrição dos estilos de vida dos consumidores existentes em um um dado mercado. ${ }^{75}$ Esta dificuldade é cada vez maior quanto menos homogênea for a sociedade em questão e a tendência das sociedades capitalistas é tornarem-se mais complexas, com o incremento da população, a proliferação de meios de comunicação e o aumento da divisão do trabalho (Durkheim, 1902, Lukes, 1973). Ao mesmo tempo, à medida em que todas as sociedades mundias são interligadas pelos meios de transporte e comunicação, à medida em que todas as economias nacionais tornam-se, em alguma medida, capitalistas, surgem segmentos mundiais de consumidores (Levitt, 1983). Em outros termos: surgem papéis sociais globais.

Seguindo Charon (1996) e Guidens (2001), o papel social que está sendo executado depende da ação. Guidens (2001: 29) faz ainda a ressalva de

\footnotetext{
${ }^{75}$ No caso de Finotti (2004), trata-se de um estudo sobre os estilos de vida dos consumidores da cidade de São Paulo.
} 
que o papel social não é algo mecânico: pessoas com determinada posição social e em determinada situação nem sempre executam a ação que seria de se esperar (este ponto parece ignorado ou diminuído por Berger, 1963). Ou seja: sempre haverá espaço para a vontade individual (ponto também salientado por Freud, 1921, ao comentar o comportamento do indivíduo em uma turba).

Se o contexto da ação define qual papel social está sendo mais importante para o indivíduo em um dado momento, é de se supor que a noção de estilo de vida, tão cara ao teóricos de marketing, seja uma espécie de "alvo móvel". Como demonstrou o sociólogo alemão Max Weber, para compreender o indivíduo é preciso saber qual o sentido da sua ação (a abordagem weberiana em sociologia é conhecida como "compreensiva" - MacRae, 1974; Pereira, 1983). Weber enfatiza que tanto os papéis sociais quanto os objetivos na vida de uma pessoa podem ser conflitantes entre si. O ser humano não é um animal completamente coerente.

Disto decorre o seguinte ponto: cada ato de consumo provavelmente está ligado a um papel social. Se for possível descobrir e descrever qual é esse papel, será possível realizar uma segmentação mais precisa dos consumidores e oferecer-Ihes um composto de marketing mais ajustado aos seus desejos (em especial, ajustar os atributos do produto ao gosto desse consumidor ideal que executa o papel social). ${ }^{76}$

Em 1956 o sociólogo Siegfried F. Nadel propôs uma análise dos papéis

\footnotetext{
${ }^{76} \mathrm{Em}$ um trabalho de sociologia, Warde e Martens (2000) estudaram os hábitos dos ingleses de comer fora de casa. Realizaram pesquisas qualitativas e quantitativas com mais de 1000 pessoas. Uma das conclusões dessas pesquisas é a multiplicidade de papéis sociais envolvidos no ato de comer fora de casa, seja em casa de parentes, amigos, restaurantes de lazer ou no horário de almoço durante o trabalho.
} 
sociais baseada em atributos. Para Nadel (1956) seria possível identificar os atributos dos papéis sociais da seguinte forma:

$$
\mathrm{P}=\sum p, \mathrm{a}, \mathrm{b} \ldots \mathrm{i} / \mathrm{m} / \mathrm{n}
$$

onde,

P seria o papel social;

$p$ seria os atributos pivotais (necessários) do papel social;

a, b... seriam os atributos relevantes do papel social (substituíveis entre

si); e

$\mathrm{i} / \mathrm{m} / \mathrm{n}$ seriam os atributos periféricos desse papel social (podem estar ausentes).

Supondo que os padrões de consumo são definidos pelos atributos necessários para o exercício do papel social, seria possível calcular uma correlação entre os produtos consumidos e os papéis sociais - o que geraria uma segmentação por papel social. A diferença básica entre esse tipo de segmentação e a realizada por estilo de vida é o reconhecimento tácito de que uma pessoa com o mesmo estilo de vida pode executar múltiplos papéis sociais. Esse tipo de segmentação levaria em conta o contexto da ação de consumo - A partir disso, seria possível fazer uma análise dos atributos dos papéis sociais necessários para o consumo de um determinado bem.

O trabalho realizado nesta tese mostrou que é possível considerar o público que consome um produto como um atributo desse mesmo produto. Mostrou ainda, o que está de acordo com as teorias sociológica e de marketing, que na verdade um produto pode ser consumidor por vários tipos de público (segmentos). Assim, cada segmento consumidor pode ser considerado um atributo do produto. Se o segmento for explicado pelo conceito sociológico de 
papel social, então é possível considerar cada papel social de consumidor como um atributo do produto. Usando o trabalho de Nadel (1956), infere-se que é possível usar os atributos pivotais do papel social em questão como atributos do produto, nos moldes propostos por Lancaster (1966a e 1966b) e discutidos nesta tese. Isto gera a possibilidade de, em trabalhos futuros, construir-se uma teoria de marketing que explique o fenômeno dos modismos em consumo: supondo que bens consumidos como moda estão ligados a papéis sociais que possuem menos atributos pivotais (para usar a terminologia de Nadel, 1956), isto explicaria a velocidade de mudança nas taxas de consumo de bens ligados a modismos, pois esses papéis seriam mais facilmente afetados por mudanças na sociedade. Concluindo, é possível perceber que quanto maior o número de atributos pivotais de um papel social, menor a possibilidade de $\mathrm{o}$ ato de consumir ligado a esse papel ser fenômeno passageiro. Outro ponto interessante dessa abordagem é permitir a associação entre o uso de uma determinada marca de produto e um papel social específico. A perenidade de uma marca seria tanto maior quanto maior seja sua associação a atributos pivotais de papéis sociais.

Se tal teoria é passível de ser construída e testada, é questão em aberto. Mas como diz a frase atribuída a George Bernard Shaw: "a ciência nunca resolve um problema sem criar pelo menos dez outros". 


\section{REFERÊNCIAS BIBLIOGRÁFICAS}

AAKER, David A., V. Kumar \& DAY, George S. (1999): Pesquisa de Marketing. São Paulo: Atlas, 2001.

ABDALLA, Maria Cristina (2002): Bohr - o arquiteto do átomo. São Paulo: Odysseus Editora, 2002 (col. "Imortais da Ciência").

ALDERSON, Wroe (1965): Dynamic Marketing Behavior. Homewood, III: Richard D. Irwin, 1965 (introdução e cap. 1).

AMERICAN PSYCHOLOGICAL ASSOCIATION (1994): Manual de Publicação. Porto Alegre: Artmed, 2001 (trad. de Daniel Bueno).

ANGULO, Ana María; GIL, José Maria; GRACIA, Azucena \& SÁNCHEZ, Mercedes (2000): "Hedonic Prices for Spanish red quality wine". In British Food Journal 102 (10): 481-493. MCB University Press.

ASPROMOURGOS, Tony (1986): "On the origins of the term 'neoclassical'". In Cambridge Journal of Economics 10(3): 265-270, Oxford: Oxford University Press, September 1986.

BACON, Francis (1620): Novum Organum ou Verdadeiras Indicações Acerca da Interpretação da Natureza. São Paulo: Abril Cultural, 1979 [2a. ed.]. (Coleção "Os Pensadores").

BAGOZZI, Richard P. (1975): "Marketing as Exchange". In Ben M. Enis, Keith K. Cox \& Michael P. Mokwa (eds.): Marketing Classics - A Selection of Influential Articles. Saddle River: Prentice Hall, 1995 (pp.33-43). 
BARTELS, Robert (1974): "The Identity Crisis in Marketing". In Journal of Marketing, 38: 73-76. Ann Arbor: American Marketing Association, October 1974.

(1976): The History of Marketing Thought. Columbus, Ohio: Grid, 1976.

BATESON, John E.G. \& HOFFMAN, K. Douglas (2001): Marketing de Serviços. Porto Alegre: Bookman, 2001 (4ª ed.).

BECKER, Gary Stanley (1991): "A Note on Restaurant Pricing and Other Examples of Social Influences on Price". In Journal of Political Economy 99(5): 1109-1116. Chicago: University of Chicago, October 1991.

BECKER, Gary Stanley \& MURPHY, Kevin M. (2000): Social Economics Market Behavior in a Social Environment. Cambridge (MA): Belknap Press/ Harvard Press University, 2000.

BENNETT, Peter D. (ed.) (1995): Dictionary of Marketing Terms. Chicago: American Marketing Association/ NTC Publishin Group, $1995\left(2^{\text {nd }}\right.$. edition).

BERGER, Peter I. (1963): Perspectivas Sociológicas: uma visão humanística. Petrópolis: Vozes, 1972.

BLAUG, Mark (1980): Metodologia da Economia. São Paulo: Edusp, 1993.

BODANIS, David (2000): $E=m c^{2}$ - uma biografia da equação que mudou o mundo e o que ela significa. Rio de Janeiro: Ediouro, 2001.

BOYER, Andre; PALDA, Kristian S. \& RATCHFORD, Brian T. (1984): "The hedonic approach to price-quality relationships and its potential application in marketing". In Jagdish N. Sheth (ed.): Research in Marketing v.7. Greenwich: JAI Press, 1984 (pp. 1-40).

BRENNAN, Richard (1997): Gigantes da Física - Uma História da Física Moderna através de oito biografias. Rio de Janeiro: Jorge Zahar Ed., 1998 (edição revista).

BROWN, Thomas Ford (1997): "Consumer Demand and the Social Construction of Industry". Baltimore: Johns Hopkins University, Sociology Department, 1997 (mímeo).

CHARON, Joel M. (1996): Sociologia. São Paulo: Saraiva, 1999 (trad. da $5^{a}$. Ed.). 
CHURCHILL Jr., Gilbert A. \& PETER, J. Paul (1998): Marketing - Criando valor para os clientes. São Paulo: Saraiva, 2000.

COASE, Ronald H (1937): "The Nature of the Firm". In Oliver E. Williamson e Sydney G. Winter (eds.): The Nature of the Firm: origins, evolution and development. Oxford: Oxford University Press, 1993a (pp. 18-33).

(1987) : "The Nature of the Firm: Origin". In Oliver E. Williamson e Sydney G. Winter (eds.): The Nature of the Firm: origins, evolution and development. Oxford: Oxford University Press, 1993b (pp. 34-47).

COMMONS, John Rogers (1934): Myself. Madison: University of Wisconsin Press, 1964 (paperback edition).

COOPER, Donald R. \& SCHINDLER, Pamela S. (2001): Métodos de Pesquisa em Administração. Porto Alegre: Bookman, 2003.

CORNEO, Giacomo \& JEANNE, Olivier (1994a): "Conspicuous Consumption and the Existence of Upward Sloping Demand Curves". Bonn: University of Bonn, December 1994. Discussion Paper n A-461 (mímeo).

(ftp://ftp.econ2.uni-bonn.de/papers/1994/a/bonnsfa461.pdf)

(1994b): "A Theory of Fashion Based on Segmented Communication". Bonn: University of Bonn, December 1994. Discussion $\begin{array}{llll}\text { Paper } & \mathrm{n}^{\circ} & \mathrm{A}-462 & \text { (mímeo). }\end{array}$ bonn.de/pub/RePEc/bon/bonsfa/bonsfa462.ps; 6/julho/1999, 14h30)

(1997a): "Conspicuous consumption, snobbism and conformism". In Journal of Public Economics 66: 55-71. Amsterdam: Elsevier Science Publishers, october 1997.

(1997b): "Snobs, bandwagons, and the origin of social customs in consumer behavior". In Journal of Economic Behavior \& Organization 32: 333-347. Amsterdam: Elsevier Science Publishers, march 1997.

(1999): "Segmented communication and fashionable behavior." In Journal of Economic Behavior \& Organization 39 (1999): 371-85. Elsevier Science.

de MARCHI, Neil (ed.) (1993): Non-Natural Social Science: Reflecting on the Enterprise of More Heat Than Light. Durham and London: Duke University Press, 1993. (History of Political Economics, Annual supplement to volume 25). 
DeSERPA, Allan \& Roger L. Faith (1996): "Bru-u-u-uce': The Simple Economics of Mob Goods". In Public Choice 89(1-2): 77-91. Dordrecht: Kluwer Academic Publishers, october 1996.

DORF, Martin E. (1992): Restaurants That Work. New York: Whitney Library of Design, 1992.

DORFMAN, Joseph (1947): Thorstein Veblen and his America. New York: Viking Press, 1947 (Chap. II, pp.14-37).

DOUGLAS, Evan J. (1992): Managerial Economics - analysis and strategy. Prentice-Hall International, 1992 ( $4^{\text {th }}$ edition).

DURKHEIM, Émile (1895): As Regras do Método Sociológico. São Paulo: Martins Fontes, 1999.

(1897): O Suicídio. São Paulo: Martins Fontes, 2000.

(1902): Da Divisão do Trabalho Social. Martins Fontes, 1999 (trad. da $2^{a}$. ed. francesa).

ENGEL, James F., BLACKWELL, Roger D. \& MINIARD, Paul W. (1995): Consumer Behaviour. Orlando, Florida: Dreyden Press.

ENIS, Ben M. (1973): "Deepening the Concept of Marketing". In Journal of Marketing 37 (October 1973): 57-62. Ann Arbor: American Marketing Association, October 1973.

FEIJÓ, Ricardo Luis Chaves (1999): A Epistemologia da Escola Austríaca em Menger, Mises e Hayek. Tese de doutoramento apresentada à Faculdade de Administração, Economia e Contabilidade da Universidade de São Paulo, 1999 (mímeo).

FERGUSON, C.E. (1976): Microeconomia. Rio de Janeiro: Forense Universitária, 1984.

FEYNMAN, Richard P. (1965): O que é uma Lei Física? Lisboa: Gradiva, 2002 ( $2^{a}$ edição) (cap. VI: "Probabilidade e incerteza - A visão quântica do mundo", pp. 163-190).

FINOTTI, Marcelo Abib (2004): Estilos de Vida: Uma Contribuição ao Estudo da Segmentação de Mercado. Dissertação de Mestrado apresentada à Faculdade de Economia, Administração e Contabilidade da Universidade de São Paulo, 2004 (mímeo). 
FRENZEN, Jonathan; HIRSCH, Paul M. \& ZERRILLO, Philip C. (1994): "Consumption, Preferences, and Changing Lifestyles". In Neil J. Smelser e Richard Swedberg (eds.): The Handbook of Economic Sociology. Princeton: Princeton University Press, 1994 (pp.403-425).

FREUD, Sigmund (1921): Psicologia de Grupo e a Análise do Ego. In Sigmund Freud (1976): Edição Standard Brasileira das Obras Psicológicas Completas de Sigmund Freud, volume XVIII. Rio de Janeiro: Imago, 1976, pp. 87-179.

FONSECA, Marcelo Traldi (2000): Tecnologias Gerenciais de Restaurantes. São Paulo: Senac, 2000.

GALBRAITH, John Kenneth (1987): O Pensamento Econômico em Perspectiva: uma história crítica. São Paulo: Pioneira/ Novos Umbrais/ Edusp, 1989.

GIBSON, Lawrence (2001): "What's Wrong With Conjoint Analysis?". In Marketing Research (Winter 2001): 16-19.

GIDDENS, Anthony (1978): As idéias de Durkheim. São Paulo: Cultrix, 1981.

(2001): Sociologia. Lisboa: Fundação Calouste Gulbekian, 2003 (tradução da 4a. edição revista e atualizada. 1ª . Ed: 1989) (Cap. 2: "Cultura e Sociedade").

GIL, José M. \& SANCHÉS, Mercedes (1997): "Consumer preferences for wine attributes: a conjoint approach". In British Food Journal 99 (1): 3-11. MCB University Press.

GLEICK, James (1987): Caos: a criação de uma nova ciência. Rio de Janeiro: Campus, 1990 (9a edição).

(1992): Feynman - A natureza do gênio. Lisboa: Gradiva, 1993.

GOULD, Stephen Jay (1981): A Falsa Medida do Homem. São Paulo: Martins Fontes, 1991.

GREEN, Paul E. \& KRIEGER, Abba M. (2002): "What's Right With Conjoint Analysis?". In Marketing Research (Spring 2002): 24-27.

GRILICHES, Zvi (1971): "Introduction: Hedonic Price Indexes Revisited". In Zvi Griliches (ed.): Price Indexes and Quality Change - studies in new methods of measurement. Cambridge, Mass: Harvard Press University, 1971 (pp. 3-15). 
GRISI, Celso Cláudio de Hildebrand e (1986): Contribuições ao Estudo das Técnicas de Segmentação de Mercado - uma análise de dados sobre apostadores da Loteria Federal. Dissertação de Mestrado apresentada à Faculdade de Economia, Administração e Contabilidade da Universidade de São Paulo, 1986 (mímeo).

GRISI, Celso Cláudio de Hildebrand e; GRISI, José Renato Moraes \& SANTOS, Rubens da Costa (1983): "Marketing: As Controvérsias do Marketing Moderno". In Revista de Administração 18(4): 59-65. São Paulo: Instituto de Administração, outubro 1983.

HAIR Jr., Joseph F.; ANDERSON, Rolph E.; TATHAM, Ronald L. \& BLACK, William C. (1998): Multivariate Data Analysis. Upper Saddle River (NJ): Prentice-Hall, 1998 (5th ed.).

HAMILTON, David B. (1989): "Thorstein Veblen As The First Professor of Marketing Science". In Journal of Economic Issues 23(4): 1097-1103. Lincoln: Association For Evolutionary Economics, December 1989.

HAMILTON, Walton (ed.) (1938): Price and Price Policies. New York: McGraw-Hill, 1938 ( $1^{\text {st }}$. Ed.; $2^{\text {nd }}$. Impression).

HARRIS, James Edwin (2002): Social Status and Product Perceptions: A Social Identity Perspective on Information Processing and Product Evaluation. Tese de doutoramento em Administração apresentada à Universidade de Illinoi em Urbana-Champaign, 2002 (mímeo).

HAYEK, Friedrich A. von (1961): "The Non Sequitur of the 'Dependence Effect"'. In Edwin Mansfiel (ed.) (1971): Microeconomics: Select Readings. New York: W.W. Norton \& Co., 1979 (third edition) [pp.7-11].

HEILBRUN, James \& GRAY, Charles M. (1993): The Economics of Art and Culture. Cambridge (USA): Cambridge University Press, 1993 (esp. Part II: "The microeconomics of demand and supply").

HIRSCHMAN, Elizabeth C. (1983): "Aesthetics, Ideologies and the Limits of the Marketing Concept". In Journal of Marketing 47 (Summer 1983): 4555. Ann Arbor: American Marketing Association, Summer 1983.

HODGSKIN, Thomas (1825): A Defesa do Trabalho Contra as Pretensões do Capital - ou A Improdutividade do Capital Demonstrada em Relação às Presentes Associações de Jornaleiros. São Paulo: Abril Cultural, 1983 (Coleção "Os Economistas". Este volume é duplo, consagrado a List e Hodgskin). 
HUNT, E.K. (1978): História do Pensamento Econômico. Rio de Janeiro: Campus, 1989.

HUNT, Shelby D. (1976): "The Nature and Scope of Marketing". In Journal of Marketing 40 (July 1976): 17-28. Ann Arbor: American Marketing Association, July 1976.

(1991): Modern Marketing Theory. Cincinnati: South-Western Publishing Co., 1991.

(1992): "Marketing is..... In Journal of the Academy of Marketing Science 20(4): 301-11. Miami: Sage Periodicals Press, Fall 1992.

IGLESIAS FILHO, Belarmino Fernandez (1990): Marketing de Hospitalidade: Conceitos e Aplicações: um estudo de caso. Dissertação de Mestrado apresentada à Faculdade de Economia, Administração e Contabilidade da Universidade de São Paulo, 1990 (mímeo).

IMBER, Jane \& TOFFLER, Betsy-Ann (2000): Dictionary of Marketing Terms. Hauppage, NY: Barron's Educational, 2000 ( $3^{\text {rd }}$. edition).

IVANOVIC, A. \& COLLIN, P.H. (1996): Dictionary of Marketing. Middlesex: Peter Collin Publishing, 2000 ( $2^{\text {nd }}$. Edition).

JEVONS, William Stanley (1871): A Teoria da Economia Política. São Paulo: Abril Cultural. 1983 (série "Os economistas") (esp. caps. I a III).

JOHNSON, Allan G. (1995): Dicionário de Sociologia. Rio de Janerio: Jorge Zahar Editor, 1997.

KEYNES, John Maynard (1936): A Teoria Geral do Emprego, do Juro e do Dinheiro. São Paulo: Abril Cultural, 1983 (coleção "Os Economistas").

KLAMER, Arjo (1983): Conversas com Economistas. São Paulo: PioneiraNovos Umbrais/ Edusp, 1988.

KOO, L.C.; Fredrick C. Tao \& John H.C. Yeung (1999): "Preferential segmentation of restaurant attributes through conjoint analysis". In International Journal of Contemporary Hospitality Management 11(5): 24250. MCB University Press.

KOTLER, Philip (1965): "Behavioral Models for Analysing Buyers". In Journal of Marketing, 29: 37-45. Ann Arbor: American Marketing Association, October 1965. 
(1972): "A Generic Concept of Marketing". In Journal of Marketing, 36: 46-54. Ann Arbor: American Marketing Association, April 1972.

(1988): Administração de Marketing. São Paulo: Atlas, 1992 (2a edição brasileira; tradução da $6^{\mathrm{a}}$ ed. norte-americana).

(1994): Administração de Marketing. São Paulo: Atlas, 1996 (4 edição brasileira; tradução da $8^{a}$ ed. norte-americana).

(2000): Administração de Marketing. São Paulo: Prentice-Hall, 2000 (tradução da $10^{\mathrm{a}}$ ed. norte-americana, "Edição do Novo Milênio").

KOTLER, Philip \& ARMSTRONG, Gary (1991): Princípios de Marketing. Rio de Janeiro: Prentice-Hall do Brasil, 1993.

KOTLER, Philip \& LEVY, Sidney J. (1969): "Broadening the Concept of Marketing". In Journal of Marketing, 33: 10-15. Ann Arbor: American Marketing Association, January 1969.

KUHN, Thomas S. (1962): A Estrutura das Revoluções Científicas. São Paulo: Ed. Perspectiva, 1975.

KUTTNER, Robert (1996): Tudo à Venda: as virtudes e limites do mercado. São Paulo: Cia. das Letras, 1998.

LANCASTER, Kelvin J. (1966a): "A New Approach to Consumer Theory". In Journal of Poltical Economy 74(2): 132-157. Chicago: University of Chicago, April 1966.

(1966b): "Change and innovation in the technology of consumption". In American Economic Review 56:14-23. Nashville: American Economic Association, 1966.

(1969): Introduction to Modern Microeconomics. Rand McNally \& Co: Chicago, 1969 (caps. 1, 2, 6 e 7).

(1971): Consumer Demand - a new approach. New York: Columbia University Press, 1971.

(1991): "The measurement of changes in quality". In Kelvin Lancaster: Modern Consumer Theory. Aldershot: Edward Elgar, 1991 [Cap. 6: pp.81-99].

LEONTIEF, Wassily (1966): A Economia do Insumo-Produto. São Paulo: Abril Cultural, 1983 (coleção "Os Economistas"). 
LEVITT, Theodore (1983): "The Globalization of Markets". In Ben M. Enis; Keith K. Cox \& Michael P. Mokwa: Marketing Classics: A Selection of Influential Articles $-25^{\text {th }}$ Aniversary Edition. Upper Saddle River (NJ): Prentice Hall, 1991 ( ${ }^{\text {th }}$ Ed.) (pp.53-65).

LEWIS, Barbara R. \& LITTLER, Dale (eds.) (1999): Dicionário Enciclopédico de Marketing. São Paulo: Atlas, 2001

LORINO, Phillipe (1989): O Economista e O Administrador. São Paulo: Nobel, 1992.

LOURENÇATO, Arnaldo (2001): Coluna "Restaurantes". In Gazeta Mercantil (cad. "Fim de Semana" - publicado às sextas-feiras), vários números.

LOVELOCK, Christopher \& WRIGHT, Lauren (2001): Marketing de Serviços. São Paulo: Saraiva, 2001.

LUCK, David J. (1969): "Broadening the Concept of Marketing - Too Far". In Journal of Marketing 33 (July 1969). Ann Arbor: American Marketing Association, July 1969.

LUKES, Steven (1973): Emile Durkheim: His Life and Work - A Historical and Critical Study. Stanford: Stanford University Press, 1985.

LUNN, J. A. (1974): "Consumer Decision-Process Models". In Jagdish Sheth (ed.): Models of Buyer Behavior. New York: Harper \& Row, 1974, pp.3469.

MaCRAE, Donald G. (1974): As idéias de Weber. São Paulo: Cultrix, 1975.

MAGEE, Bryan (1973): As Idéias de Popper. São Paulo: Cultrix, 1973.

MALHOTRA, Naresh K. (1999): Pesquisa de Marketing. Porto Alegre (RS): 2001 (trad. da $3^{\mathrm{a}}$ edição em inglês).

MARVIN, Bill (1992): Restaurant Basics. New York: John Wiley \& Sons, 1992.

MARX, Karl (1852): O 18 Brumário e Cartas a Kugelman. Rio de Janeiro: Paz e Terra, 2002 (7 $7^{\mathrm{a}}$ edição).

(1857): Para a Crítica de Economia Política. São Paulo: Abril Cultural, 1982 (série Os Economistas).

(1867): O Capital, v.1. São Paulo: Abril Cultural, 1983 (série Os Economistas). 
(1875): Gotha - Comentários à margem do Programa do Partido Operário Alemão. In Karl Marx e Friedrich Engels (1848): Manifesto do Partido Comunista (1848) seguido de Gotha -- comentários à margem do Programa do Partido Operário Alemão (1875) por Karl Marx. Porto Alegre: L\&PM, 2002 (coleção L\&PM Pocket, volume 227).

MASON, Roger S. (1984): "Conspicuous Consumption: A Literature Review". In European Journal of Marketing 18(3):26-39, Bradford: MCB University Press, 1984.

(1995): "Interpersonal Effects on Consumer Demand in Economic Theory and Marketing Thought, 1890-1950". In Journal of Economic Issues 29(3): 871-881. Lincoln: Association For Evolutionary Economics, September 1995.

(1998): The Economics of Conspicuous Consumption (Theory and thought since 1700). Cheltenham: Edward Elgar.

(1999): "Breakfast in Detroit: Economics, Marketing, and Consumer Theory, 1930 to 1950". In Journal of Macromarketing 18(2): 145-152. Fort Lauderdale: Sage Publications, Fall 1999.

MAYNARD, Harold H.; WEIDLER, Walter C. \& BECKMAN, Theodore N. (1932): Principles of Marketing. New York: The Ronald Press (Esta é a segunda edição revista. A primeira é de 1927).

MAZZON, José Afonso (1978): Formulação De Um Modelo De Avaliação E Comparação De Modelos Em Marketing. Dissertação de Mestrado apresentada à Faculdade de Economia, Administração e Contabilidade da Universidade de São Paulo, 1978 (mímeo)

McDANIEL, Carl \& GATES, Roger (2003): Pesquisa de Marketing. São Paulo: Pioneira Thomson Learning, 2003.

MELO, Josimar (2003): Guia Josimar Melo 2003. São Paulo: DBA, 2003.

MENGER, Carl (1871): Princípios de Economia Política. São Paulo: Abril Cultural. 1983 (série "Os economistas").

MONTEIRO, Diogo Monjardino de Souza \& LUCAS, Maria Raquel Ventura (2001): "Conjoint measurement of preferences for tradicional cheeses in Lisbon". British Food Journal 103 (6): 414-424. MCB University Press. 
MOREIRA, Júlio César Tavares; PASQUALE, Perrotti Pietrangelo \& DUBNER, Alan Gilbert (1999): Dicionário de Termos de Marketing. São Paulo: Atlas, 1999 ( $3^{a}$. edição).

MUTH, Richard F. (1966): "Household Production and Consumer Demand Functions”. In Econometrica 34(3): 699-708. July, 1966.

NESS, Mitchell R. \& GERHARDY, Hubert (1994): "Consumer Preferences for Quality and Freshness Attributes of Eggs". British Food Journal 96 (3): 2634. MCB University Press.

ORMEROD, Paul (1998): Butterfly Economics. England: Faber and Faber, 1999.

PANTZALIS, Ioannis (1995): Exclusivity Strategies in Pricing and Brand Extension. Tese de doutorado em Administração (Business Administration) apresentada à Universidade do Arizona (EUA), 1995 (mímeo).

PEREIRA, Carlos de Brito (2000): As faces de Jano: sobre a a possibilidade de mensuração do Efeito Veblen. Dissertação de Mestrado apresentada à Faculdade de Economia, Administração e Contabilidade da Universidade de São Paulo, 2000 (mímeo).

(2001a): "Notas para uma crítica institucionalista da Nova Economia Institucional". Working Paper $n^{\circ}$ 01/009. São Paulo: FEA/USP (www.ead.fea.usp/wpapers).

(2001b): "Algo de novo no front". Working Paper n 01/013. São Paulo: FEA/USP (www.ead.fea.usp/wpapers).

(2001c): "Notas para uma conceitualização do termo marketing". Working Paper $\mathrm{n}^{\circ}$ 01/014. São Paulo: FEA/USP (www.ead.fea.usp/wpapers).

PEREIRA, Carlos de Brito \& GRISI, Celso Cláudio de Hildebrand (2000): "Globalization as a Step of Capitalism". BALAS, 2000.

PEREIRA, José Carlos de Medeiros (1983): A Explicação Sociológica na Medicina Social. Tese de Livre-Docência apresentada à Faculdade de Medicina da Universidade de São Paulo. Ribeirão Preto, 1983 (mímeo).

(2003): Medicina, Saúde e Sociedade. Ribeirão Preto: Complexo Gráfico Villimpress, 2003. 
PESCUMA, Derna \& CASTILHO, Antonio Paulo F. (2001): Referências Bibliográficas. São Paulo: Olho D’Água, 2003.

PETER, J. Paul \& OLSON, Jerry C. (1999): Consumer Behavior and Marketing Strategy. Boston: Irwin/McGraw-Hill(5th ed.).

PETERS FILHO, Theodoro Agostinho (2003): Mensuração da Influência de Qualidade, Valor, Satisfação e Envolvimento do Consumidor Sobre Intenções Comportamentais em Restaurantes Finos da Cidade de São Paulo. Tese de Doutoramento apresentada à Fundação Getúlio Vargas. São Paulo, 2003 (mímeo).

PETERSEN, H. Craig \& LEWIS, W. Cris (1994): Managerial Economics. New York: MacMillan [Third Edition. First Edition: 1986].

PINDYCK, Robert S. \& RUBINFELD, Daniel L. (1991): Microeconomia. São Paulo: Makron Books, 1994.

POPPER, Karl (1959): A Lógica da Descoberta Científica. São Paulo: Edusp/ Itatiaia, 1975 (cap. I: "Colocação de Alguns Problemas Fundamentais"). 156). (1974): Autobiografia Intelectual. São Paulo: Cultrix, 1986 (pp. 11-

PRIGOGINE, llya (1993): As leis do caos. São Paulo: Ed. Unesp, 2000.

QUESTER, Pascale G. \& SMART, Justin (1998): "The influence of consumption situation and product involvement over consumers' use of product attribute". In Journal of Consumer Marketing 15(3): 220-38. MCB University Press.

RADA, Vidal Diaz de (1998): "A single consumer or different types of consumer: na analysis of social types according to their consumer habits". In British Food Journal 100(7): 326-36. MCB University Press.

RICARDO, David (1823): Princípios de Economia Política e Tributação. São Paulo: Abril Cultural, 1982 (Coleção "Os Economistas").

RILEY, Michael (1994): "Marketing Eating out: The Influence of Social Culture and Innovation". In British Food Journal 96 (10): 15-18. MCB University Press.

ROSENFELD, Rogério (2003): Feynman \& Gell-Mann - luz, quarks, ação. São Paulo: Odysseus, 2003. 
SANDRONI, Paulo (1983): "Apresentação". In Thomas Hodgskin (1825): A Defesa do Trabalho Contra as Pretensões do Capital - ou A Improdutividade do Capital Demonstrada em Relação às Presentes Associações de Jornaleiros. São Paulo: Abril Cultural, 1983, pp.291-300 (Coleção "Os Economistas". Este volume é duplo, consagrado a List e Hodgskin).

SARTORIS NETO, Alexandre (1996): Estimação de modelos de precos hedônicos:um estudo para residências na cidade de São Paulo. Dissertação de Mestrado apresentada à Faculdade de Economia, Administração e Contabilidade da Universidade de São Paulo, 2000 (mímeo).

SCHIFFFMAN, Leon G. \& KANUK, Leslie Lazar (1994): Consumer Behavior. Englewood Cliffs (NJ): Prentice-Hall (5th ed.).

SCHUMPETER, Joseph Alois (1911): Teoria do Desenvolvimento Econômico. São Paulo: Abril Cultural, 1982.

(1954): History of Economic Analysis. London: Allen \& Unwin, 1982.

SKOUSEN, Mark (2001): The making of modern economics. Armonk (NY): M.E. Sharpe, 2001.

SHETH, Jagdish N. (ed.) (1974): Models of Buyer Behavior. New York: Harper \& Row.

(1979): "The Surpluses and Shortages in Consumer Behavior Theory and Research". In Melanie Wallendorf \& Gerald Zaltman (eds.) (1979): Readings in Consumer Behavior. John Wiley \& Sons: New York, 1979 (pp. 5-11).

SIQUEIRA, Antonio Carlos Barroso de (1997): Contribuições ao Estudo de Segmentação de Mercado Industrial: Caso da Indústria Brasileira de Elevadores. Tese de doutoramento apresentada à Faculdade de Administração, Economia e Contabilidade da Universidade de São Paulo, 1997 (mímeo).

SIQUEIRA, José de Oliveira (1995): Mensuração da estrutura de preferência do consumidor: uma aplicação do conjoint analysis em marketing. Dissertação de Mestrado apresentada à Faculdade de Administração, Economia e Contabilidade da Universidade de São Paulo, 1995 (mímeo). 
SMITH, Adam (1776): A Riqueza das Nações - Investigação Sobre sua Natureza e suas Causas (volumes I e II). São Paulo: Abril Cultural, 1983 (coleção "Os Economistas").

SMITH, Wendell R. (1956): "Produtc Differentiaton and Market Segmentation as Alternative Marketing Strategies". In Journal of Marketing 20(July): 3-8

SMITH, William O. (1990): Restaurant Marketing. New York: Glencoe, 1992 (2nd ed.).

SOLOMON, Michael R. (2002): O Comportamento do Consumidor comprando, possuindo e sendo. Porto Alegre: Bookman, 2002 (trad. da $5^{\text {a }}$ ed. norte-americana).

STALEY, Charles E. (1989): A History of Economic Thought: From Aristotle to Arrow. Cambridge (USA): Basil Blackwell Inc., 1989.

STEADMAN, Dave (1991): Restaurant Biz is ShowBiz!. New York: Whittier Green, 1991.

STEWART, lan (1989): Será que Deus Joga Dados?. Rio de Janeiro: Jorge Zahar Editor, 1991.

TOLEDO, Geraldo Luciano (1972): Segmentação de mercado e estrategia de marketing. Tese de doutoramento apresentada à Faculdade de Administração, Economia e Contabilidade da Universidade de São Paulo, 1972 (mímeo).

UNIVERSIDADE FEDERAL DO PARANÁ (2002): Normas para Apresentação de Documentos Científicos. Curitiba: Editora UFPR, 2002 (coleção em 10 volumes).

VEBLEN, Thorstein B. (1899): A Teoria da Classe Ociosa. São Paulo: Abril Cultural, 1984 (série "Os economistas").

WALTERS, C. Glenn (1980): "Consumer Behavior: An Appraisal". In Journal of the Academy of Marketing Science 7(4): 273-284. Miami: Sage Periodicals Press, Fall, 1980.

WARDE, Alan \& MARTENS, Lydia (2000): Eating Out - Social Differentiation, Consumption and Pleasure. Cambridge: Cambridge University Press, 2000.

WEBER, Max (1922): Economia e Sociedade, v.1. Brasília: Editora da Universidade de Brasília, 1998 [tradução da edição de 1972]. 
WEINSTEIN, Art (1993): Segmentação de Mercado. São Paulo: Atlas, 1995.

WILLIAMSON, Oliver E. (1985): Las Instituciones Económicas del Capitalismo. México D.F: Fondo de Cultura Económica, 1989 (prólogo e caps. 1-4).

(1993): "Introduction". In Oliver E. Williamson e Sydney G. Winter (eds.): The Nature of the Firm: origins, evolution and development. Oxford: Oxford University Press, 1993 (pp. 3-17).

(1998): "Human Actors and Economic Organization". Berkeley: University of California (mímeo).

WRIGHT MILLS, C. (1959): La imaginación sociológica. México D.F: Fondo de Cultura Económica, 1961 [caps. I a III].

\subsection{Sítios na internet}

http://netec.mcc.ac.uk/WoPEc.html

[Sítio de rascunhos (working papers) e artigos de teoria econômica, a maioria disponíveis para serem copiados na íntegra.]

$\underline{\text { http://guiadosabor.terra.com.br }}$

http://www.guiajosimar.com.br

http://www.panelinha.com.br 


\section{Anexos}

\subsection{Questionário Utilizado Na Pesquisa}

Esta pesquisa é parte de tese de doutorado realizada na Faculdade de Economia, Administração e Contabilidade da Universidade de São Paulo (FEA/USP) pelo economista Carlos de Brito Pereira, sob a orientação do Prof. Dr. Celso Cláudio de Hildebrand e Grisi, que muito agradecem a sua colaboração.

Todos as respostas serão mantidas em sigilo. Nenhuma análise será feita de um questionário individual. Não há identificação do respondente.

Se o senhor(a) tiver qualquer dúvida ou sugestão, por favor entre em contato conosco pelos e-mails carlosbp@usp.brecchgfea1@usp.br.

1. $\mathrm{O}(\mathrm{A})$ senhor(a) freqüenta restaurantes com alguma regularidade?

$\operatorname{sim} \square \quad$ não

(se não, encerre o questionário - obrigado pela colaboração).

2. Dentre os restaurantes que o(a) senhor(a) habitualmente freqüenta, quais são os seus preferidos? Por favor, responda em ordem de preferência, do mais preferido para o menos preferido.

1.

2.

3. 
4. Abaixo é apresentado um conjunto de frases relacionado à razão de escolha de um restaurante. Por favor, informe o grau de concordância ou discordância que o(a) senhor tenha em relação a cada frase:

Eu escolho o restaurante de acordo com a(s) pessoa(s) que convido para ir comigo. Eu escolho o restaurante principalmente para atender os gostos das pessoas que estão comigo.

Eu escolho o restaurante pelo tipo de comida que é servida.

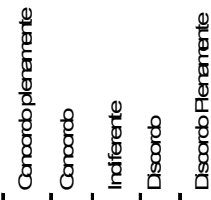

Eu escolho um restaurante pela rapidez no atendimento.

Eu escolho o restaurante pelo preço.

Eu escolho o restaurante pela sua localização.

Eu escolho o restaurante pela proximidade em relação à minha casa.

Eu escolho o restaurante pela proximidade em relação ao meu trabalho.

Eu escolho um restaurante adequado à forma como me visto normalmente.

Eu escolho o restaurante pelo horário.

Eu escolho o restaurante que tenha estacionamento.

Eu escolho o restaurante que tenha manobrista.

Eu escolho o restaurante que tenha maitre/hostess.

Eu escolho o restaurante que tenha sala de espera.

Eu escolho o restaurante pela sua decoração.

Eu escolho o restaurante que tenha também um bar.

Eu escolho o restaurante pelo público que freqüenta o lugar.

Eu escolho o restaurante que meus amigos costumam freqüentar.

Eu escolho o restaurante que está na moda.

Eu escolho o restaurante que é freqüentado por gente como eu.

Eu escolho o restaurante que é freqüentado por gente com status social diferenciado.

Eu escolho o restaurante onde posso levar meus filhos.

Eu escolho o restaurante onde há gente da minha idade.

Eu freqüento esse restaurante porque encontro uma atmosfera agradável para pessoas como eu.

Eu freqüento esse restaurante porque aqui encontro um ambiente ao meu gosto.

Eu freqüento esse restaurante porque aqui as pessoas me conhecem.

Eu freqüento esse restaurante porque está sempre com muita gente.

Eu freqüento esse restaurante porque esta sempre com poucas pessoas.

Eu freqüento esse restaurante porque aqui encontro pessoas famosas.

Eu freqüento esse restaurante porque aqui encontro pessoas importantes para

o meu trabalho.

Eu freqüento esse restaurante porque aqui a maioria dos outros clientes

me reconhece.

Eu não me importo com as pessoas que freqüentam este restaurante.

Eu escolho o restaurante que possua sala privativa.

Eu escolho o restaurante que tenha área para fumantes.

Eu escolho o restaurante pela limpeza do lugar.

Eu escolho o restaurante pelo silêncio do lugar, para poder conversar calmamente.

Eu escolho o restaurante que apresenta música ao vivo.

Eu escolho o restaurante que tenha um cardápio compreensível.

Eu escolho o restaurante que apresente grande variedade de pratos.

Eu escolho o restaurante que tenha pequena variedade de pratos.

Eu escolho o restaurante que tenha carta de vinhos.

Eu escolho o restaurante pela apresentação dos pratos.

Eu escolho o restaurante pela qualidade da comida.

Eu escolho o restaurante que aceita cartão de crédito.

Eu escolho o restaurante que aceita cheque.

Eu escolho o restaurante que aceita ticket.

Eu escolho o restaurante pela qualidade do serviço.

\begin{tabular}{l|l|l|l|}
\hline & $\perp$ & $\perp$ & $\perp$
\end{tabular}

$+\mid \begin{array}{llll}\mid & \perp & \perp\end{array}$

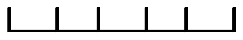

\begin{tabular}{|l|l|l|l|}
\hline & $\mid$ & $\mid$ & $\mid$
\end{tabular}

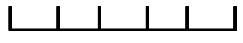

$+\mid \begin{array}{lllll} & \perp & \perp & \mid\end{array}$

$\begin{array}{llllll}\mid & \mid & \mid & \mid & \mid\end{array}$

$\begin{array}{lllll} & \perp & \perp & \perp\end{array}$

$+\mid \begin{array}{llll}\mid & \perp & \mid & \mid\end{array}$

$\begin{array}{lllll} & \perp & \perp & \perp\end{array}$

\begin{tabular}{llllll}
\hline & 1 & 1 & 1 & $\perp$
\end{tabular}

$\begin{array}{lllll} & 1 & 1 & 1 & 1\end{array}$

$\begin{array}{lllll} & 1 & 1 & 1 & 1\end{array}$

\begin{tabular}{lllll}
\hline & $\perp$ & $\perp$ & $\perp$
\end{tabular}

$\begin{array}{llllll} & \perp & \perp & \perp & \perp\end{array}$

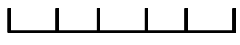

$\begin{array}{lllll} & \perp & \perp & \perp & \perp\end{array}$

$\begin{array}{llllll} & 1 & 1 & \mid & \perp\end{array}$

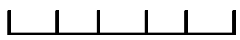

$\begin{array}{lllll} & 1 & 1 & \perp\end{array}$

$\begin{array}{lllll} & \perp & \perp & \perp & \perp\end{array}$

\begin{tabular}{llllll}
\hline & $\perp$ & $\perp$ & $\perp$
\end{tabular}

$\begin{array}{lllll} & 1 & 1 & \perp\end{array}$

$\begin{array}{lllll} & 1 & 1 & 1\end{array}$

$\begin{array}{llllll} & 1 & 1 & 1 & \perp\end{array}$

\begin{tabular}{llllll}
\hline & $\mid$ & $\mid$ & $\mid$ & $\mid$
\end{tabular}

\begin{tabular}{|l|l|l|l|}
\hline & 1 & $\perp$ &
\end{tabular}

$\begin{array}{llllll} & \perp & 1 & \perp & \perp\end{array}$

L $1 / 1 / 1 / 1$

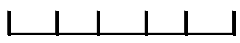

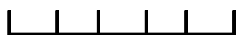

$\begin{array}{lllll} & 1 & 1 & 1 & \end{array}$

$\begin{array}{llllll} & 1 & 1 & 1 & \mid\end{array}$

$\begin{array}{lllll} & 1 & 1 & \perp & \end{array}$

\begin{tabular}{llllll}
\hline & 1 & 1 & $\mid$ &
\end{tabular}

L

$\begin{array}{lllll} & 1 & 1 & \mid & \end{array}$

$\begin{array}{lllll} & 1 & 1 & 1 & 1\end{array}$

$\begin{array}{llllll} & 1 & 1 & 1 & \perp\end{array}$

\begin{tabular}{ll|l|l}
\hline & $\perp$ & $\perp$ &
\end{tabular}

\begin{tabular}{llllll}
\hline & & 1 & 1 & &
\end{tabular}

لـ

$\begin{array}{lllll} & \perp & \perp & \perp\end{array}$

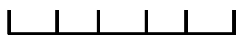

$\begin{array}{llllll} & 1 & 1 & 1 & \perp\end{array}$

工

$\begin{array}{lllll} & \perp & \perp & \perp\end{array}$

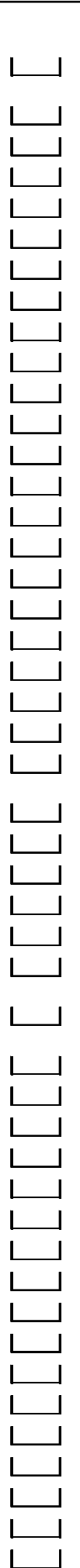

5. Por favor, agora indique as três frases mais importantes na sua escolha de um restaurante para lazer. Use

" 1 " para a frase mais preferida, " 2 " para a segunda e " 3 " para a terceira. 
6. Se o(a) senhor(a) fosse construir um restaurante que fosse do seu gosto, como seria esse restaurante? (Por favor, pense no tipo de comida, na localização, no preço aproximado, na decoração e no tipo de gente e como estariam vestidas as pessoas que freqüentariam o lugar)

7. Por favor, descreva as pessoas que freqüentariam esse restaurante que o(a) senhor(a) imaginou? Pense em termos de classe sócio-econômica, evidência (na mídia) e prestígio em sua área de atuação.

8. Sexo Masculino $\square \quad$ Feminino $\square$

9. Idade menor de 18 anos $\square$ 18 a 20 anos $\square$ 21 a $25 \square$ 26 a 30 口 31 a 40 口 40 a 50 口 mais de 50 anos $\square$

10. Estado civil
solteiro(a) $\square$
casado(a) $\square$
separado(a) $\square$
viúvo(a) $\square$

11. Posse de bens.

\begin{tabular}{|c|c|c|c|c|c|}
\hline \multirow{2}{*}{ Posse de Itens } & \multirow{2}{*}{ Não Tem } & \multicolumn{4}{|c|}{ Tem } \\
\hline & & 1 & 2 & 3 & 4 ou mais \\
\hline \multicolumn{6}{|l|}{ Televisão em cores } \\
\hline \multicolumn{6}{|l|}{ Rádio } \\
\hline \multicolumn{6}{|l|}{ Banheiro } \\
\hline \multicolumn{6}{|l|}{ Automóvel } \\
\hline \multicolumn{6}{|l|}{ Empregada Mensalista } \\
\hline \multicolumn{6}{|l|}{ Aspirador de pó } \\
\hline \multicolumn{6}{|l|}{ Máquina de lavar } \\
\hline \multicolumn{6}{|l|}{ Videocassete e/ou DVD } \\
\hline \multicolumn{6}{|l|}{ Geladeira } \\
\hline $\begin{array}{l}\text { Freezer (independente } \\
\text { ou parte de geladeira }\end{array}$ & & & & & \\
\hline
\end{tabular}

12. Grau de instrução do chefe da família

\begin{tabular}{|l|l|}
\hline Analfabeto/Primário incompleto & \\
\hline Primário completo/ Ginasial incompleto & \\
\hline Ginasial completo/ Colegial incompleto & \\
\hline Colegial completo/ Superior incompleto & \\
\hline Superior Completo & \\
\hline
\end{tabular}




\subsection{Referências Bibliográficas para o Estudo do Conceito de Externalidade na Teoria Econômica}

Em teoria econômica há o reconhecimento de que o mercado é incapaz de prover todos os bens que a sociedade necessita ou demanda. Neste caso, acontece o que se convencionou chamar de "externalidade". O caso mais comum de "externalidade" é o chamado "bem público". Uma discussão conexa à definição de externaldidade é o conceito de "falha de mercado" - que ocorre quando o mercado não consegue prover o bem desejado.

Contudo, parece que os economistas ainda não chegaram a um consenso sobre o que seria precisamente "externalidade", "bem público" e "falha de mercado". Esse tema foi pesquisado para esta tese, por sugestão de um dos Professores Doutores que participaram da banca do Exame de Qualificação. Para esse Professor, que é economista, o fenômeno da moda e o problema da transformação do público consumidor de um produto em atributo desse produto seriam externalidades e, portanto, perfeitamente explicados pela teoria econômica tradicional. A teoria de marketing nada teria a acrescentar à essa questão.

Respondendo aos pontos observados pelo Professor, fez-se então um levantamento bibliográfico sobre o tema (que ora se inclui neste anexo). O estudo desses autores levou à conclusão de que o conceito de externalidade ainda não está plenamente desenvolvido e que, por conseguinte, moda e consumidores como atributos de produtos não são externalidades (seja qual for a maneira como os economistas definem isso).

Destarte, optou-se por não incluir uma discussão do conceito de externalidade no bojo do trabalho. Afinal, esta é uma tese de Marketing e não de 
Economia., ainda que tributária da teoria econômica.

Portanto, esta bibliografia recomendada sobre o tema é o resultado da pesquisa feita sobre o conceito de externalidade e aqui é incluída como anexo para o leitor que desejar aprofundar-se no assunto.

Dois trabalhos são fundamentais para o estudioso do conceito de externalidade:

PAPANDREOU, Andreas A. (1994): Externality and Institutions. Oxford: Oxford University Press, 1998 [Col. "Clarendon Paperbacks"]. Este livro é talvez o mais detalhado levantamento sobre o conceito de extarnalidade, tanto em termos históricos como teóricos. É a tese de doutorado de Papandreou, que foi orientado pelo Prof. Amartya Sen, vencedor do Prêmio Nobel de Economia.

NUSDEO, Fábio (1972): Contribuições ao Estudo das Deseconomias Externas. Tese de doutoramento apresentada à Faculdade de Administração, Economia e Contabilidade da Universidade de São Paulo, 1972 (mímeo).

O Prof. Nusdeo fez um excelente levantamento dos textos existentes sobre o conceito de externalidade. Além de tentar explicitar o conceito, fez várias conexões com outras áreas de conhecimento, notadamente, com o uso de "externalidade" em Direito, algo que aparentemente escapou a Papandreou (1994).

Kelvin Lancaster também apresentou seu conceito de externalidade, em seu trabalho de 1973. Como Nusdeo (1972), Lancaster (1973) fez alusão ao uso do conceito em Tribunais de Justiça (nos EUA). É mister notar que Lancater (1973) não fez nenhuma conexão entre sua teoria dos atributos e o conceito de externalidade. :

LANCASTER, Kelvin (1973): A Economia Moderna - Teoria e Aplicações. Rio de Janeiro: Zahar, 1977.

A seguir, é apresentada uma lista de autores, organizada por ordem alfabética. Todos esses trabalhos discutem os conceitos de externalidade e bem público. Inexiste coincidência perfeita entre as definições apresentadas. 
ANDRADE, Eduardo \& MADALOZZO, Regina (2003): Microeconomia. São Paulo: Publifolha, 2003 (Coleção "Biblioteca Valor").

BRONFENBRENNER, Martin; SICHEL, Werner \& GARDNER, Wayland (1990): Economics. Boston: Houghton Mifflin Co., 1990 (3rd. Ed.) (Caps. 2, 33 e 38$)$.

BYRNS, Ralph T. \& STONE, Gerald W. (1987): Economics. Glenview (III.): Scott, Foresman \& Co., 1987 (3rd. Ed.) (Caps. 31 e 33).

HARVEY, Jack (1994): Mastering Economics. London: MacMillan Press Ltd., 1994 (1st. Ed. 1984) (Caps. 1 e 7).

MANSFIELD, Edwin (1974): Economics - Principles, Problems, Decisions. New York: W.W. Norton Inc., 1974 (1st. Ed.) (Cap. 5).

MILGROM, Paul \& ROBERTS, John (1992): Economics, Organization and Management. Englewood Cliffs (NJ): Prentice-Hall, 1992 (Cap. 3).

PASHIGIAN, B. Peter (1995): Price Theory and Applications. McGraw-Hill: New York, 1995 (cap. 19).

RIDDELL, Tom; SHACKELFORD, Jean; \& STAMOS, Steve (1990): Economics - A tool for understanding Society. Reading (MS): AddisonWesley Publishingj Co., 1991 (4th. Ed.) (Cap. 15).

SAMUELSON, Paul \& NORDHAUS, William D. (1992): Economia. Lisboa: McGraw-Hill, 1993 (trad. da 14ª Ed. norte-americana) (Caps. 3, 18 e 31).

SINGER, Neil m. (1976): Public Microeconomics - an introduction to government finance. Boston: Little, Brown \& Co (2nd. Ed. 1st. Ed: 1972) (Caps. 5 e 6 ).

STIGLER, George J. (1996): The Theory of Price. New York: MacMillan Press, 1996 (4th Ed. 1st Ed: 1942) (Caps. 7 e 20).

STIGLITZ, Joseph E. (1993): Economics. New York: W.W. Norton \& Co., 1993.

(2000): Economics of the Public Sector. New York: W.W. Norton Co. (3rd Ed. 1st Ed: 1986) (Cap. 4).

STIGLITZ, Joseph E. \& WALSH, Carl E. (2002): Introdução à Microeconomia. Rio de Janeiro: Campus, 2003 (trad. da 3a. Ed. norte-americana. 1a. Ed: 1993). 


\subsection{Os critérios utilizados para a avaliação dos restaurantes nos guias pesquisados (para a cidade de São Paulo)}

Observações:

1) Em todos os critérios de preço: por pessoa, inclui entrada, prato e sobremesa.

2) Os sítios foram pesquisados entre $9 \mathrm{~h} 00$ e $10 \mathrm{~h} 00$ do dia 23 de maio de 2001.

\subsubsection{Jornal Gazeta Mercantil (coluna "Restaurantes")}

Critérios:

1. tipo de cozinha (o tipo, ou os tipos, de comida servida);

2. carta de vinhos;

3. ambiente;

4. nível sonoro;

5. serviço;

6. aceitação de cartões de crédito;

7. existência de acesso para deficientes físicos;

8. existência de estacionamento (e se emprega manobristas);

9. "avaliação geral" e

10. o gasto médio por pessoa (incluindo couvert, prato, sobremesa, água e serviço). 


\subsection{2. http://guiadosabor.terra.com.br}

Critérios:

1. Tipo de cozinha (20 listadas)

2. horário de funcionamento

3. número de lugares

4. média do tempo de espera (citar Pashigian sobre a questão do custo do tempo para jovens e velhos)

5. aceita reservas

6. couvert grátis

7. cartões de crédito

8. área para fumantes

9. ar condicionado

10. estacionamento

11. estacionamento (manobrista)

12. entrega em domicílio

13. "rolha": "serviço de rolha: o restaurante autoriza o cliente a levar o próprio vinho e cobrar uma taxa para servi-lo."

14. Oferece charutos (na verdade, vende)

15. Preço (por pessoa): 4 faixas de preço: até $R \$ 25,00 ; R \$ 26,00$ a $R \$ 40,00 ; R \$ 41,00$ a $R \$ 60,00$; acima de $R \$ 60,00$.

16. Possui bar

\subsection{3. http://www.guiajosimar.com.br}

Critérios:

1. Tipo de cozinha (38 listadas)

2. Bons vinhos

3. Locais de tradição

4. Vale pelo cenário

5. Para ir a dois

6. Almoço de negócios

7. Sala privativa 
8. Com mesas ao ar livre

9. Também para crianças

10. Onde o bar já é um programa

11. Para comer depois da meia-noite

12. Ar condicionado

13. Delivery

14. Delivery (arredores)

15. Música ao vivo

16. Bar

17. Consumação mínima

18. Fumantes

19. Deficientes físicos

20. Estacionamento (pago $x$ grátis)

21. Manobrista (pago $x$ grátis)

22. Preço (por pessoa): 4 faixas de preço: até $R \$ 20,00 ; R \$ 21,00$ a $R \$ 40,00 ; R \$ 41,00$ a $R \$ 60,00$ e acima de $R \$ 60,00$.

23. Avaliação geral (4 avaliações apresentadas: regular, bom, muito bom e excelente)

\subsection{4. http://www.panelinha.com.br}

Critérios:

1. Tipo de cozinha (30 listadas)

2. Preço (por pessoa): 4 faixas de preço: até $R \$ 20,00 ; R \$ 21,00$ a $\mathrm{R} \$ 35,00 ; \mathrm{R} \$ 36,00$ a $\mathrm{R} \$ 60,00$; acima de $\mathrm{R} \$ 60,00$.

3. Categorias (ambiente):
a.Bar-restaurante,
b.crianças,
c.lanches na madrugada,
d.negócios,
e.novidades,
f.romântico,
g.toda a família,
h.tradicional/antigo,
i.ver e ser visto,
j.moderninho

4. Estacionamento (pago $x$ grátis) 
5. Manobrista (pago $\times$ grátis)

6. Cartão de crédito

7. Capacidade: número de pessoas

8. Tickets

9. "outros serviços":

a.acesso a deficientes,

b.área para fumantes,

c.música ao vivo.

\subsection{Breve Histórico sobre o início da técnica de Análise Fatorial}

O primeiro autor a desenvolver essa técnica e aplicá-la em um problema de ciência humana foi Charles Spearman, psicólogo e estatístico (Gould, 1981: 270). A questão enfrentada por Spearman era descobrir uma medida de inteligência "geral" para seres humanos que fosse mais confiável do que os vários testes existentes à época. Para tanto, Spearman desenvolveu a técnica de análise fatorial, apresentada em um artigo publicado em 1904 (Gould, 1981: cap.6). ${ }^{77}$ O processo empregado por Spearman foi calcular todas as correlações entre vários testes de inteligência e isolar o fator principal, o fator $\mathrm{g}$ ou medida de inteligência geral (Gould, 1981). Embora Gould (1981) deixe claro que essa é uma falsa medida de inteligência e que Spearman incorreu no erro metodológico da reificação, ou seja, tomar como real uma construção teórica abstrata, a técnica da análise fatorial permaneceu como uma ferramenta estatística empregada em vários problemas de Ciências Sociais e, especificamente, na disciplina de Marketing.

${ }^{77}$ Segundo Gould (1981), o artigo é o seguinte: "General Intelligence objectively determined and measured". In American Journal of Psychology 15: 201-293. 


\subsection{Referências Bibliográficas sobre restaurantes}

Neste anexo é apresentada uma relação de livros que foram totalmente lidos ou, ao menos, consultados para a realização desta tese. Nem todos estão citados no corpo da tese. Esta lista foi incluída para ajudar o leitor que se interessar pelo tema específico de administração de restaurante. Os livros sobre marketing de hospitalidade listados contém capítulos sobre restaurantes. Obviamente, não é uma lista exaustiva, dado que o tema não é o principal desta tese.

BOURDAIN, Anthony (2000): Cozinha Confidencial. São Paulo: Cia. das Letras, 2001.

Este livro na verdade são memórias de um chefe de cozinha famoso. O livro descreve com bastante acuidade como é a operação de uma cozinha de um restaurante de luxo.

BRILLAT-SAVARIN, Jean-Baptiste (1826): A fisiologia do gosto. São Paulo: Cia. das Letras, 1995. (A data original não consta da edição brasileira. Foi obtida em Spang, 2000).

CHON, Kye-Sung \& SPARROWE, Raymond T. (2000): Hospitalidade: Conceito e Aplicações. São Paulo: Pioneira-Thompson, 2003.

CASTELLI, Geraldo (2001): Administração Hoteleira. Caxias do Sul: EDUCS, 2001 (9a. Ed. Revisada).

DORF, Martin E. (1992): Restaurants That Work. New York: Whitney Library of Design, 1992.

FONSECA, Marcelo Traldi (2000): Tecnologias Gerenciais de Restaurantes. São Paulo: Ed. Senac de São Paulo, 2000 (col. "Apontamentos Hotelaria" v.57).

HSU, Cathy H.C. \& POWERS, Tom (2002): Marketing Hospitality. New York: John Wiley \& Sons, $2002\left(3^{\text {rd }}\right.$. Ed.). 
JANEIRO, Joaquim António (1997): Manual de Cafetaria. Portugal: Edições CETOP, 1997 (col. Hotelaria \& Turismo, v.10).

KRIPPENDORF, Jost (2001): Sociologia do Turismo. São Paulo: Aleph, 2003 (trad. da $3^{\mathrm{a}}$. edição alemã revisada; $1^{\mathrm{a}}$. ed: 1984) (série “Turismo").

LAURIER, Eric; WHYTE, Angus \& BUCKNER, Kathy (s.d.): "An Ethnography of a café: the socio-spatial organisation of furniture and background noise. http://www.geog.gla.ac.uk/ elaurier/texts/cafe_ethno.pdf (acessado em 27 de setembro de 2002, 01h34 AM).

Trabalho de antropólogos em um café, usando a técnica de observação.

MARICATO, Percival (2001): Como montar e administrar bares e restaurantes. São Paulo: Ed. Senac São Paulo, 2001 (3ª. ed.).

MARVIN, Bill (1992): Restaurant Basics. New York: John Wiley \& Sons, 1992.

Uma espécie de "check-list" do que deve ser observado para o bom funcionamento de um restaurante (chega ao requinte de alertar para o problema de poças d'água em estacionamentos mal-asfaltados, que podem sujar o cliente em um dia de chuva, antes mesmo que este chegue ao salão do restaurante).

MELO, Josimar (2003): Guia Josimar Melo 2003. São Paulo: DBA, 2003. (2004): Guia Josimar Melo 2004. São Paulo: DBA, 2004.

MIELE, Alberto \& MIOLO, Adriano (2003): O Sabor do Vinho. Bento Gonçalves: Miolo/ Embrapa, 2003.

MILL, Robert Christie (2001): Restaurant Management: Customers, Operations and Employees. Upper Saddle River (NJ): Prentice Hall, 2001 $\left(2^{\text {nd }}\right.$. ed.; $1^{\text {st }}$ ed: 1998$)$.

Este livro é um dos poucos manuais a apresentar um capítulo exclusivo sobre o comportamento do consumidor.

PACHECO, Arisitides de Oliveira (2004): Manual de Serviço do Garçom. São Paulo: Ed. Senac São Paulo, 2004 (5ª ed.).

POWERS, TOM \& BARROWS, Clayton W. (2003): Administração no Setor de Hospitalidade: turismo, hotelaria, restaurante. São Paulo: Atlas, 2004.

SCANLON, Nancy (1993): Restaurant Management. New York: John Wiley \& Sons, 1993. 
SCHLOSSER, Eric (2001): País do Fast Food: o lado nocivo da comida norteamericana. São Paulo: Ática, 2001.

Este livro é uma crítica à forma como é organizada a cadeia produtiva das empresas de fast-food. Talvez o autor seja um neoludista.

SMITH, William O. (1990): Restaurant Marketing. New York: Glencoe, 1992 (2nd ed.).

Apesar do "marketing" no título, o livro é basicamente um compêndio de como montar um restaurante. Há pouco de marketing no sentido de compreender o consumidor de restaurante.

SPANG, Rebecca L. (2000): A Invenção do Restaurante: Paris e a moderna cultura gastronômica. Rio de Janeiro: Record, 2003.

Conta a história do restaurante moderno, desde sua invenção em Paris, antes da Revolução Francesa. Restaurante originalmente era uma sopa de carne, servida como remédio. Os lugares que serviam tal sopa (prescrita por médicos) tornaram-se conhecidos como "restaurantes".

STEADMAN, Dave (1991): Restaurant Biz is ShowBiz!. New York: Whittier Green, 1991.

STEINGARTEN, Jeffrey (1997): O homem que comeu de tudo: feitos gastronômicos do crítico da Vogue. São Paulo: Cia. das Letras, 2000.

Este livro é para os interessados em saber como é a vida de um crítico gastronômico.

TEICHMANN, Ione (2000a): Tecnologia Culinária. Caxias do Sul: EDUCS, 2000 (col. "Hotelaria").

Um manual completo sobre a atividade técnica (mas não gerencial) de cozinha em restaurantes e hotéis.

TEICHMANN, Ione (2000b): Cardápios: técnicas e criatividade. Caxias do Sul: EDUCS, 2000 (5a. ed.) (col. "Hotelaria")

VALLEN, Gary K. \& VALLEN, Jerome J. (2000): Check-in, Check-out: Gestão e Prestação de Serviços em Hotelaria. Porto Alegre: Bookman, 2003 (trad. da $6^{\mathrm{a}}$. ed. em inglês).

VEJA São Paulo (2002): Guia Comer \& Beber. São Paulo: Abril, 2002. 
WALKER, John R. \& LUNDBERG, Donald (2001): The Restaurant: from Concept to Operation. New York: John Wiley \& Sons, 2001 ( $3^{\text {rd }}$ ed.).

Há uma tradução brasileira publicada pela Ed. Bookman. Sugere-se ao leitor interessado que prefira a ed. norteamericana, que é fisicamente maior e melhor para a leitura. A ed. brasileira tem 52 páginas a menos (sic), para se ter uma idéia da "compressão" das letras.

WARDE, Alan (1997): Consumption, Food \& Taste. London: Sage, 1997.

WARDE, Alan \& MARTENS, Lydia (2000): Eating Out - Social Differentiation, Consumption and Pleasure. Cambridge: Cambridge University Press, 2000.

O melhor livro consultado para esta tese sobre o comportamento do consumidor de restaurante. Feito por dois sociólogos ingleses, apresenta os resultados de centenas de entrevistas feitas com consumidores ingleses em três cidades da Inglaterra. A abordagem é sociológica, mas o especialista de Marketing aproveitará a leitura.

WRIGHT, Jonathan L. (2002): The Picky Palate: A Content Analysis of Restaruant Reviews in Large-Circulation U.S. Daily Newspapers. Dissertação de Mestrado apresentada à University of Nevada, Reno. Reno: May 2002 (mímeo)

Esta dissertação de mestrado é uma engenhosa análise das colunas de gastronomia publicadas nos jornais norteamericandos. O autor descobriu que os críticos das regiões litorâneas, tanto a Leste como a Oeste, são mais rigorosos nas avaliações do que os críticos do interior do país.

ZANELLA, Luiz C. \& CÂNDIDO, Índio (2002): Restaurante: técnicas e processos de administração e operação. Caxias do Sul: EDUCS, 2002 (col. "Hotelaria"). 